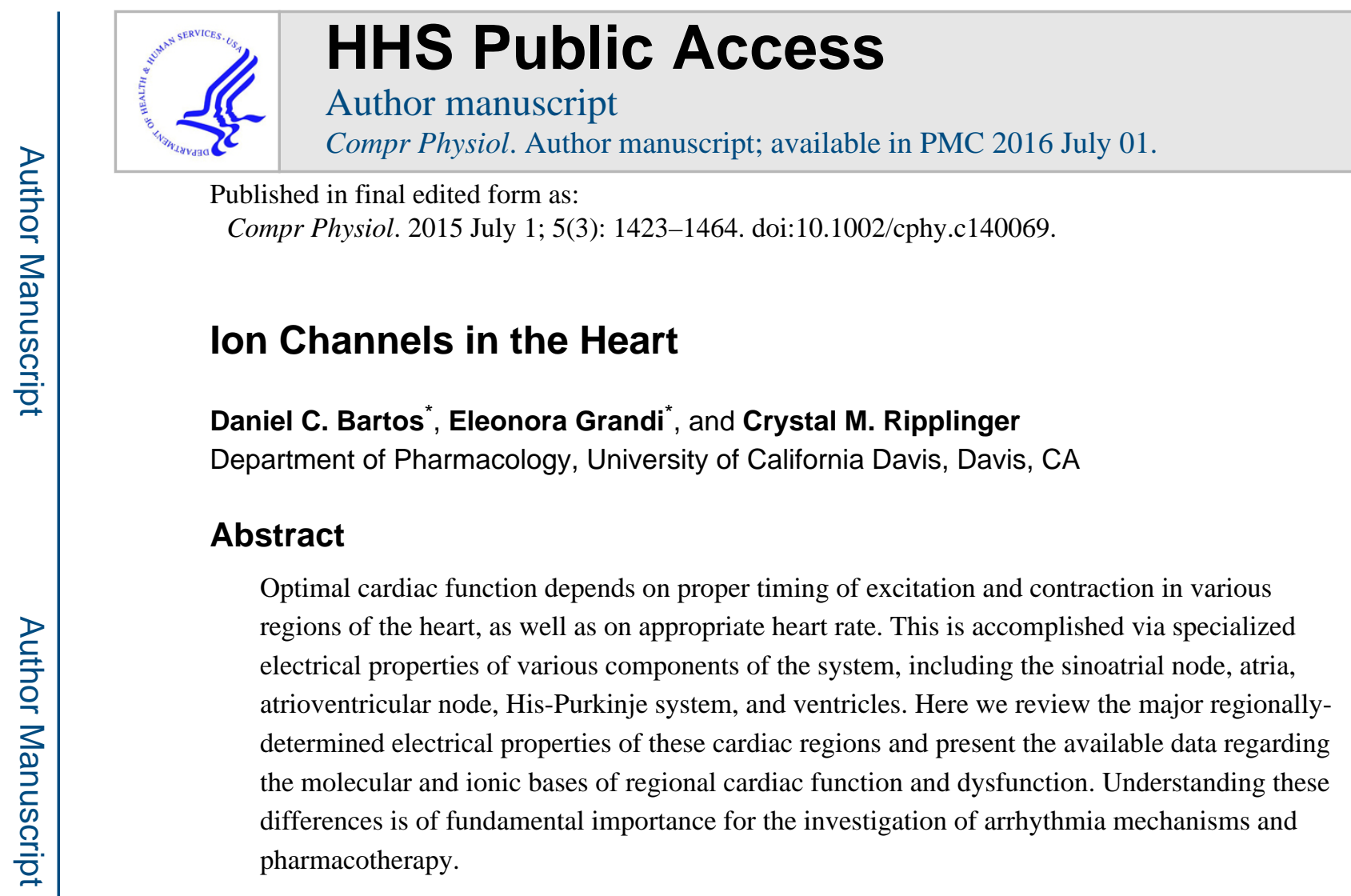

\title{
Introduction
}

The normal cardiac impulse originates in the sinoatrial node (SAN) and propagates through the atria to reach the atrioventricular node (AVN). From the AVN, electrical activity passes rapidly through the cable-like His-Purkinje system to reach the ventricles, triggering coordinated cardiac pumping action. The various cardiac regions are characterized by specific action potential (AP) morphology and duration, which result from regionally distinct collections of ionic currents. The molecular and ionic bases of regionally defined electrophysiology are reviewed here, along with region-specific heart disease-induced remodeling and its functional consequences.

In this review, the molecular and ionic bases of regionally defined electrophysiology are summarized, along with region-specific heart disease-induced remodeling and its functional consequences. The review is organized functionally following the propagation of the AP (SAN, atrium, AVN, His-Purkinje system, ventricles). For each major region of the heart, function, ionic mechanisms, and molecular bases are first discussed (Figure 1C).

Heterogeneity within each region is then highlighted, with particular emphasis on species differences and atrioventricular differences discussed in the ventricular section. Finally, a discussion of both inherited and acquired cardiac disease is covered, including what is currently known about pathology-induced remodeling of ion channels. Both experimental and computational findings are discussed throughout this review. For a more detailed discussion of methodologies pertaining to these findings, the reader is referred to the following excellent methodological reviews (453).

Correspondence: Crystal M. Ripplinger, Ph.D., Department of Pharmacology, University of California Davis, 451 Heath Sciences Drive, 2219A Tupper Hall, Davis, CA 95616, Tel: (530) 752-1569, Fax: (530) 752-7710, cripplinger@ ucdavis.edu.

These authors contributed equally to the work. 


\section{Sinoatrial Node}

Function

The SAN is the primary pacemaker in the normally functioning heart and is an electrophysiologically and anatomically heterogeneous and complex structure. The human SAN is a crescent-shaped, intramural structure with its head located subepicardially at the junction of the right atrium and the superior vena cava and its tail extending 10 to $20 \mathrm{~mm}$ along the crista terminalis (Figure 1A and Figure 2A). Although once thought to be a relatively compact and discrete structure, recent evidence has revealed a more diffuse elaborate structure, with an extensive 'paranodal area' identified in humans located within the crista terminalis and comprised of loosely packed nodal and atrial myocytes (101).

Source-sink relationships are critical to proper functioning of the SAN and exactly how the depolarizing 'source' current generated by the SAN drives depolarization and activation of the surrounding atrial tissue (current 'sink') remains unclear. It has been proposed that the SAN is not functionally continuous with the atrial myocardium, but rather areas of functional or anatomical conduction block exist, creating discrete sites at which SAN activation can exit the node to excite the atrial myocardium (435). Electrical and optical mapping studies in rabbit, canine, and human SAN have confirmed the presence of areas of functional conduction block and discrete exit pathways $(62,167,168)$. Such an arrangement would allow for electrical insulation of the SAN from the surrounding atrial myocardium and hence a reduction in the source-sink mismatch. Despite the convincing functional data, detailed histological studies in the human heart have failed to demonstrate evidence for an insulating or fibrous sheath surrounding the SAN $(323,419)$, suggesting that this may be a functional rather than anatomical phenomenon. Indeed, as discussed below, differential expression of ion channels and gap junctions plays an important role in the emergent function of the SAN.

SAN APs are markedly different from those of the working atrial myocardium, with diastolic Phase 4 depolarization (also called the 'pacemaker potential') (77) as the hallmark (Figure 2C). When diastolic depolarization reaches a threshold potential, an AP is triggered. The rate of diastolic depolarization determines how quickly the threshold potential is reached, hence providing heart rate modulation. Other key features of the SAN AP are a relatively depolarized (less negative) diastolic membrane potential, $\mathrm{E}_{\mathrm{m}},(-60$ to $-70 \mathrm{mV}$ ) and a slow upstroke $(<10 \mathrm{~V} / \mathrm{s})$, mainly driven by L-type $\mathrm{Ca}^{2+}$ current $\left(\mathrm{I}_{\mathrm{CaL}}\right)$.

\section{Ionic Mechanisms and Molecular Bases}

Since the discovery of the SAN by Keith and Flack over a century ago (258), the underlying mechanisms of the pacemaker potential and diastolic depolarization have remained an area of intense investigation. Currently, two main hypotheses have emerged, the first positing that the 'voltage clock', predominantly comprised of the 'funny current' $\left(\mathrm{I}_{\mathrm{f}}\right)$, is a major contributor to the pacemaker potential (141), whereas the second proposes the importance of the ' $\mathrm{Ca}^{2+}$ clock' in diastolic depolarization $(276,317)$. Although a plethora of experimental studies have demonstrated the existence and physiological relevance of each clock system, there is currently no consensus as to the importance or predominance of either clock. Here, 
we will not review the detailed evidence for or against either hypothesis (see Point/ Counterpoint by Lakatta and DiFrancesco (275)), but rather will provide an overview of each system and the mechanisms by which each clock system, both alone and in combination, contribute to the pacemaker potential. Indeed, the current paradigm suggests the 2 clocks function in concert in a 'coupled clock' system (411).

Voltage Clock-The best-known SAN ionic current is $\mathrm{I}_{\mathrm{f}}$, the 'funny current', which is an inward current carried by $\mathrm{Na}^{+}$and $\mathrm{K}^{+}$and is activated at hyperpolarized $\mathrm{E}_{\mathrm{m}}(139,140)$. The hyperpolarization-activated cyclic-nucleotide gated $(\mathrm{HCN})$ channel is responsible for $\mathrm{I}_{\mathrm{f}}$, with HCN1 and HCN4 the predominant human isoforms (101). $\mathrm{I}_{\mathrm{f}}$ is activated during Phase 4 of the $\mathrm{AP}$ and a reduction in $\mathrm{I}_{\mathrm{f}}$ with either $\mathrm{CsCl}$ or ivabradine leads to a reduction in heart rate due to a decrease in the slope of the pacemaker potential (Figure 2D) $(65,85,357)$. Conversely, $\beta$-adrenergic receptor stimulation leads to an increase in $\mathrm{I}_{\mathrm{f}}$ and heart rate due to cAMP (produced in response to $\beta$-adrenergic receptor stimulation) binding to the $\mathrm{HCN}$ channel via a cytoplasmic cyclic nucleotide binding domain (530). On the other hand, it has been shown that transgenic mice lacking HCN4 have preserved response to $\beta$-adrenergic stimulation (36).

Although $\mathrm{I}_{\mathrm{f}}$ provides an inward depolarizing current that contributes to diastolic depolarization, working in concert with $\mathrm{I}_{\mathrm{f}}$ in the $\mathrm{SAN}$ is a reduction in outward $\mathrm{K}^{+}$currents. The SAN has no Kir2.1 channels (101), resulting in a lack of inward rectifier $\mathrm{K}^{+}$current $\left(\mathrm{I}_{\mathrm{K} 1}\right)$, which acts to stabilize the resting $\mathrm{E}_{\mathrm{m}}$ in the normal working atrial and ventricular myocardium. In fact, knocking out Kir2.1 in the ventricles results in pacemaking activity (328). Additionally, the delayed rectifier $\mathrm{K}^{+}$currents $\left(\mathrm{I}_{\mathrm{Kr}}\right.$ and $\left.\mathrm{I}_{\mathrm{Ks}}\right)$, which are responsible for repolarization of the SAN AP, decay following repolarization, allowing $\mathrm{I}_{\mathrm{f}}$ and other inward currents to depolarize the cell. Indeed, this decay in $\mathrm{K}^{+}$currents was once thought to be the major mechanism responsible for the pacemaker potential (487).

SAN myocytes express both L-type and T-type $\mathrm{Ca}^{2+}$ channels. The T-type $\mathrm{Ca}^{2+}$ channels Cav3.1-Cav3.3 are significantly more abundant in the SAN than in the working myocardium (101) and the T-type $\mathrm{Ca}^{2+}$ current $\left(\mathrm{I}_{\mathrm{CaT}}\right)$ contributes to the final phase of diastolic depolarization (208). $\mathrm{I}_{\mathrm{CaL}}$ in the $\mathrm{SAN}$ is the predominant current responsible for the $\mathrm{SAN}$ AP upstroke (in central nodal cells (265), see below) and is dependent upon Cav1.3 (and perhaps to a lesser extent Cav1.2), while in the working myocardium $\mathrm{I}_{\mathrm{CaL}}$ is exclusively carried by Cav1.2 (477). Cav1.3 has a more negative threshold potential compared to Cav1.2, thus it activates earlier during diastolic depolarization which may be advantageous in pacemaker cells which rely upon $\mathrm{I}_{\mathrm{CaL}}$ for the AP upstroke (318).

The fast inward $\mathrm{Na}^{+}$current $\left(\mathrm{I}_{\mathrm{Na}}\right.$, carried by Nav1.5), normally responsible for the AP upstroke in the working atrial and ventricular myocardium, is present in the periphery of the SAN but is absent from central SAN cells (Figure 2C) $(101,477)$. This explains the slow $\mathrm{I}_{\mathrm{CaL}}$-dependent upstrokes of the central SAN cells (265). $\mathrm{I}_{\mathrm{Na}}$ in the SAN periphery contributes to a faster AP upstroke in these regions and is discussed in more detail below.

$\mathbf{C a}^{2+}$ Clock-In addition to the membrane currents discussed, intracellular $\mathrm{Ca}^{2+}$ handling also contributes to pacemaking in the SAN. Lakatta and colleagues have shown that $\mathrm{Ca}^{2+}$ is 
spontaneously released from the sarcoplasmic reticulum (SR) late during the pacemaker potential $(64,276)$, and is not triggered by $\mathrm{I}_{\mathrm{CaT}}$ as previously proposed $(593) . \mathrm{Ca}^{2+}$ released from the SR (via the ryanodine receptor [RyR]) instantaneously triggers $\mathrm{Ca}^{2+}$ extrusion from the cytosol by the $\mathrm{Na}^{+}-\mathrm{Ca}^{2+}$ exchanger (NCX). NCX exchanges $3 \mathrm{Na}^{+}$ions for each $\mathrm{Ca}^{2+}$ ion, thus generating a net inward current $\left(\mathrm{I}_{\mathrm{NCX}}\right)$ that is thought to contribute to the final phase of diastolic depolarization (63). In agreement with this interpretation, slowing of diastolic depolarization and heart rate by block of $\mathrm{SR} \mathrm{Ca}^{2+}$ release with ryanodine have been reported (Figure 2E) (64). The mechanism that permits SAN, but not ventricular myocytes to generate rhythmic diastolic $\mathrm{Ca}^{2+}$ releases under basal conditions has not been fully resolved, but may owe to higher cAMP and basal cAMP-mediated, PKA-dependent phosphorylation of phospholamban (PLB) in these cells compared with other cardiac cell types (519). Basal PKA phosphorylation is required for maintaining pacemaker activity, and stimulation of the $\beta$-adrenergic receptors with isoproterenol increases the frequency of diastolic SR $\mathrm{Ca}^{2+}$ releases (519). Furthermore, isoproterenol fails to increase the heart rate in vivo in the presence of ryanodine (519). The Anderson group has confirmed the importance of the $\mathrm{Ca}^{2+}$ clock in regulation of SAN automaticity, and showed that CaMKII inhibition (using transgenic mice or peptides) reduces the heart rate during $\beta$-adrenergic challenge (but not in basal conditions) (562).

Several lines of experimental and computational evidence support the role of the $\mathrm{Ca}^{2+}$ clock and the 'coupled clock' system in contributing to the pacemaker potential (578). Notably, membrane currents play a fundamental role not only in AP generation, but also in resetting the $\mathrm{Ca}^{2+}$ clock via $\mathrm{Ca}^{2+}$-induced $\mathrm{Ca}^{2+}$ release, i.e., allowing the refilling of the SR with $\mathrm{Ca}^{2+}$, which is important to ensure that the threshold of $\mathrm{SR} \mathrm{Ca}^{2+}$ load needed for the next spontaneous $\mathrm{Ca}^{2+}$ release is reached.

\section{SAN Heterogeneity: Ion Channel and Gap Junction Distribution}

The SAN has a complex 3-dimensional architecture with central and peripheral or 'paranodal' components made up of distinct ion channel and gap junction expression profiles. Central and peripheral cells have progressively different AP characteristics and conduction properties (Figure 2C). Experimental and computational studies have demonstrated that SAN heterogeneity is necessary to maintain normal pacemaking activity and impulse conduction.

Figure 2C shows typical central and peripheral SAN APs. Boyett and colleagues have suggested that AP properties show a gradual transition from the central to peripheral SAN, termed the 'gradient' model (76), whereas others have suggested that only a few distinct types of nodal cells exist and they are interspersed with each other and with atrial cells in a 'mosaic model' (515). Regardless of the proposed model of cell heterogeneity, it is well documented that central SAN APs have a slow upstroke velocity, relatively long AP duration (APD), and less negative maximum diastolic $\mathrm{E}_{\mathrm{m}}$ compared to peripheral $\mathrm{SAN}$ and atrial APs (265). These AP changes are accompanied by differential expression of several ion channels, with the peripheral SAN cells often having an intermediate expression profile between the central SAN and atrial myocytes. 
One of the main differences between central and peripheral SAN myocytes is the differential expression of Nav1.5, with little or no expression in the central SAN $(101,477)$ and no measurable $\mathrm{I}_{\mathrm{Na}}$. Nav1.5 expression increases from the central to peripheral SAN and increases even more in the working atrial myocardium, resulting in increasing amounts of $\mathrm{I}_{\mathrm{Na}}$, which contributes to the progressive increase in upstroke velocity of APs from central to peripheral SAN to atrial myocardium (226). Other $\mathrm{Na}^{+}$channel isoforms have also been found in the central and peripheral SAN, including Nav1.2 and Nav1.4 in the human SAN (101). However, at the mRNA level, their expression levels were >100-fold lower than Nav1.5. Interestingly, in the mouse neuronal Na channels (TTX-sensitive, Nav1.1) are expressed throughout the SAN and block of these channels with nM concentrations of TTX results in a significant slowing of pacemaking without an impact on SAN conduction (281). The functional role of neuronal $\mathrm{Na}$ channels in contributing to pacemaking and conduction in the human SAN remains to be determined.

In both human and rabbit SAN, isoform switching from predominantly Cav1.2 in the atria to Cav1.3 in the central SAN has been found, with the peripheral SAN having intermediate expression of the two isoforms in the rabbit (477) and an expression profile similar to the atria in the human (101). This isoform switch likely reflects the different roles of $\mathrm{I}_{\mathrm{CaL}}$ in the central SAN, where it contributes to diastolic depolarization and the AP upstroke and is therefore activated at more negative $\mathrm{E}_{\mathrm{m}}$, to the atria in which $\mathrm{I}_{\mathrm{CaL}}$ is predominantly involved in the AP plateau.

Although the peripheral or paranodal SAN region often has intermediate molecular and functional properties compared to the central SAN and atrial myocardium, recent work by Chandler et al. has revealed increased expression (at the mRNA level) of several $\mathrm{K}^{+}$ channels and accessory subunits in the peripheral human SAN compared to both the central SAN and atria. These include greater expression of Kv4.2, Kir6.1, TASK1, SK2, and KCNE3 (formerly MiRP2) (101). The functional significance of these channels in the peripheral SAN remains unknown.

A key feature of the SAN is its ability to overcome the source-sink mismatch to activate the surrounding atrial myocardium. Differential expression of gap junction proteins plays an important role in this phenomenon. Gap junctions, comprised of connexins $(\mathrm{Cx})$, are nonspecific ion channels that electrically couple neighboring myocytes and allow an AP to propagate from cell to cell. The central SAN is devoid of both $\mathrm{Cx} 40$ and Cx43 (the largeand medium-conductance isoforms, respectively, responsible for cell-cell coupling in the working myocardium), and instead, the small conductance Cx45 is expressed (101, 225, 477). Therefore, the central SAN myocytes are relatively weakly coupled, which results in slow conduction through the node, but importantly, provides electrical insulation from the surrounding hyperpolarized atrial myocardium. Toward the periphery, electrical coupling improves with expression of both $\mathrm{Cx} 43$ and $\mathrm{Cx} 45$. Stronger coupling at the periphery of the SAN allows the SAN periphery to drive the atrial myocardium.

\section{SAN Dysfunction}

Sinus node dysfunction, also referred to as sick sinus syndrome (SSS) is a congenital or acquired pathology of the SAN. SAN dysfunction can manifest clinically as sinus 
bradycardia, sinus pause, sinus arrest, and tachy-brady syndrome (SAN dysfunction in the setting of atrial fibrillation, AF). SAN dysfunction remains one of the most common indications for permanent pacemaker implantation (335).

Inherited Syndromes-As discussed below, SAN dysfunction is primarily a disease of aging (271). However, mutations affecting the voltage clock (HCN4, SCN5A), the $\mathrm{Ca}^{2+}$ clock (RyR2, CASQ2), or both (ANK2) have been identified and can be a primary cause of SAN dysfunction and will be highlighted here. For a more comprehensive discussion of genetic causes of SAN dysfunction and conduction system disease, see reviews by Park and Fishman (375) and Nof et al. (360).

HCN4: $\mathrm{HCN} 4$ is the major isoform responsible for $\mathrm{I}_{\mathrm{f}}$ in the human SAN and mutations in HCN4 have been identified in patients with SAN dysfunction (330, 361, 437, 497). A single nucleotide deletion in HCN4 (1631delC) was identified in a patient with bradycardia and chrontropic incompetence (the inability to increase heart rate with increased activity) (437). Accordingly, the 1631delC mutant lacks the cyclic nucleotide binding domain, making it unresponsive to cAMP. Additional mutations have been identified in patients with bradycardia, including 2 missense mutations that result in $\mathrm{HCN}$ channels that activate at more hyperpolarized voltages and have smaller currents during diastolic depolarization (330, $361)$.

Nav Channels: Although the cardiac Na channel is expressed only in the periphery, but not the central SAN $(101,477), 14$ SCN5A mutations have been linked to inherited forms of SAN dysfunction (414). SCN5A mutations associated with SAN dysfunction have been shown to result in non-functional channels, reduced $\mathrm{I}_{\mathrm{Na}}$ current density, or altered biophysical properties of the channel which result in a narrowing of the $\mathrm{I}_{\mathrm{Na}}$ current window $(46,456)$. Single cell simulations revealed that SCN5A mutants had little impact on the pacemaking in central SAN cells, but slowed pacemaking in the periphery. Interestingly, two-dimensional tissue simulations revealed that reduced $\mathrm{I}_{\mathrm{Na}}$ in the periphery exposed the central SAN to more hyperpolarized $\mathrm{E}_{\mathrm{m}}$, thus slowing the pacemaker rate of the central SAN and predisposing to sinus node exit block, both clinical features of sinus node dysfunction (93).

$\mathrm{Ca}^{2+}$ Handling Proteins: As discussed above, the $\mathrm{Ca}^{2+}$ clock is an important contributor to diastolic depolarization and pacemaking in the SAN. Therefore, it is not surprising that mutations in $\mathrm{Ca}^{2+}$ handling proteins that give rise to catecholaminergic polymorphic ventricular tachycardia (CPVT, see also His-Purkinje System below) are also associated with sinus bradycardia. Mutations in RyR2 (the main SR $\mathrm{Ca}^{2+}$ release channel in cardiomyocytes) have been identified in patients with CPVT and SAN dysfunction (59, 391). CASQ2 encodes cardiac calsequestrin, the major $\mathrm{Ca}^{2+}$ binding protein within the SR. Mutations in CASQ2 are associated with aberrant $\mathrm{SR} \mathrm{Ca}^{2+}$ release, $\mathrm{CPVT}$, and sinus bradycardia (390). These genetic causes of SAN dysfunction lend further support to the $\mathrm{Ca}^{2+}$ clock hypothesis of SAN pacemaking.

ANK-B: ANK2 encodes ankyrin-B, an adaptor protein responsible for targeting ion channels and transporters to specialized membrane domains (333). Mutations in ANK2 are 
associated with long QT syndrome (334) and SAN dysfunction (279). Heterozygous mice $\left(\mathrm{AnkB}^{+-}\right.$) also have SAN dysfunction and reduced expression and/or abnormal targeting of $\mathrm{NCX}, \mathrm{Na}^{+} / \mathrm{K}^{+}$ATPase (NKA), IP3 receptors, and Cav1.3 (279). Accordingly, a reduction in $\mathrm{I}_{\mathrm{NCX}}$ and $\mathrm{I}_{\mathrm{CaL}}$ were also observed in isolated SAN cells from $\mathrm{AnkB}^{+/-}$mice. Therefore, mutations in ANK2 may lead to SAN dysfunction via both the voltage and $\mathrm{Ca}^{2+}$ clocks.

\section{Acquired Syndromes}

Aging: SAN dysfunction is largely a disease of aging, the incidence of which increases exponentially with age (271). Previous reports primarily attributed SAN dysfunction in the elderly to fibrosis and structural remodeling of the atria $(132,283)$. However, more recent studies have challenged this notion and have not confirmed the presence of SAN fibrosis in aged human, cat, or rat hearts $(7,581)$. On the other hand, specific evidence for age-related remodeling of ionic currents and ion channels in the SAN is mounting. For example, a decrease in AP upstroke velocity in the SAN periphery of aged hearts is believed to be a consequence of an age-related decrease in $\mathrm{I}_{\mathrm{Na}}$ (8). Indeed, a decrease in expression of Nav1.5 has been demonstrated in the SAN of aged rat hearts (581). As discussed above in regard to SCN5A mutations, reductions in $\mathrm{I}_{\mathrm{Na}}$ in the SAN periphery can lead to exposure of the central SAN to hyperpolarized $\mathrm{E}_{\mathrm{m}}$, thus slowing the central pacemaker rate (93).

An age-related decrease in Kv1.5 ( $\mathrm{I}_{\mathrm{Kur}}$ ) in the rat SAN has also been found (478), which may partly explain the observed increase in AP duration with aging (8). In the guinea pig heart, an age-related reduction in $\mathrm{I}_{\mathrm{CaL}}$ was observed, commencing in the central SAN and continuing on to the periphery (242). This reduction in $\mathrm{I}_{\mathrm{CaL}}$ leads to reduced depolarization reserve and excitability of the SAN. A loss of $\mathrm{Cx} 43$ has also been documented in the aged guinea pig SAN (243), which may be partly responsible for SAN exit block, a feature commonly observed in age-related SAN dysfunction.

Interestingly, fibrosis and ion channel remodeling may not be mutually exclusive mechanisms. Mice heterozygous for SCN5A (responsible for Nav1.5 and $\mathrm{I}_{\mathrm{Na}}$ ) have agerelated fibrosis in the SAN (210) as well as in atria and ventricles (507). Thus, it is reasonable to assume that structural and ionic remodeling may synergistically contribute to SAN dysfunction in the aged population.

Heart Failure: SAN dysfunction and severe bradycardia are responsible for a significant number of deaths in heart failure (HF) patients, especially patients with advanced HF (164, 464). Indeed, widespread remodeling of ion channels has been documented in several HF models. For example, downregulation of HCN2 and HCN4 has been found in the SAN of the failing canine heart (pacing-induced HF) (595). In a rabbit model of pressure and volume overload HF, a decrease in $\mathrm{I}_{\mathrm{f}}$ and $\mathrm{I}_{\mathrm{Ks}}$ in the SAN has been reported (517). Extensive ionic remodeling has also been observed in the SAN of the failing rat heart following myocardial infarction (580). Recently, Swaminathan et al. revealed a novel mechanism of SAN dysfunction in a mouse model of AngII-induced HF that implicates oxidized CaMKII (470). Briefly, they found that in HF activation of NADPH oxidase leads to an increase in oxidized CaMKII, which triggers apoptosis in SAN myocytes. Mathematical modeling revealed that SAN apoptosis leads to a decrease in SAN cell numbers, resulting in reduced depolarizing 
source current and increased electrotonic loading of the surviving SAN myocytes. The authors also found elevated oxidized CaMKII in HF patients who required pacemaker implantation as well as in right atrial tissue from canines with pacing-induced HF (470). Thus, multiple mechanisms including ion channel remodeling, structural remodeling, and increased SAN apoptosis may contribute to SAN dysfunction in HF.

\section{Atrium Function}

The first phase of the cardiac cycle, atrial contraction, is initiated by the P wave of the ECG, which represents electrical depolarization of the atria. Atrial depolarization then causes contraction of the atrial musculature. Contraction of the atria occurs late in ventricular diastole, when the drop in ventricular pressure and increase in atrial pressure allows opening of the atrioventricular valves and rapid emptying of the contents of the atria into the ventricles. Normally atrial contraction confers a minor, additive effect toward ventricular filling. However, atrial contribution in humans appears to be more significant during exercise, during fast heart rates, with aging, and particularly in patients with heart disease (14). Loss of normal electrical conduction in the heart, as seen during AF, may abolish atrial systole.

\section{Ionic Mechanisms and Molecular Bases}

During a normal heartbeat, spontaneous SAN depolarization activates the neighboring atrial myocardium. Atrial $\mathrm{E}_{\mathrm{m}}$ depolarization is accomplished via activation of the voltagedependent $\mathrm{Na}^{+}$channels, which carry $\mathrm{I}_{\mathrm{Na}}$ that produces the rapid AP upstroke (phase 0) and favors rapid atrial conduction velocity (also permitted by $\mathrm{Cx} 43$, the major cardiac connexin found in the working myocardium of atria, and strong expression of Cx40). Subsequent activation of L-type $\mathrm{Ca}^{2+}$ channels produces a small influx of $\mathrm{Ca}^{2+}$ into the cell $\left(\mathrm{I}_{\mathrm{CaL}}\right)$, which triggers a much larger $\mathrm{Ca}^{2+}$-induced $\mathrm{Ca}^{2+}$ release from the SR through the cardiac RyRs, thus initiating contraction, as the released $\mathrm{Ca}^{2+}$ binds to the myofilaments. The $\mathrm{Ca}^{2+}$ transient also feeds back to cause $\mathrm{I}_{\mathrm{CaL}} \mathrm{Ca}^{2+}$-dependent inactivation to prevent excessive $\mathrm{Ca}^{2+}$ loading. For atrial myocyte relaxation to occur, $\mathrm{Ca}^{2+}$ has to be extruded from the cell via the electrogenic NCX and plasmalemmal $\mathrm{Ca}^{2+}$-ATPase, and re-sequestered into the SR via the SR Ca ${ }^{2+}$-ATPase (SERCA). The latter is controlled by the inhibitory proteins PLB and sarcolipin. $\mathrm{K}^{+}$channels are mostly responsible for atrial $\mathrm{E}_{\mathrm{m}}$ repolarization. The transient outward $\mathrm{K}^{+}$current $\left(\mathrm{I}_{\mathrm{to}}\right)$ produces a rapid early repolarization (phase 1 ) immediately following the AP upstroke, while the delayed-rectifier $\mathrm{K}^{+}$currents with slow, rapid, and ultra-rapid activation kinetics $\left(\mathrm{I}_{\mathrm{Ks}}, \mathrm{I}_{\mathrm{Kr}}\right.$ and $\mathrm{I}_{\mathrm{Kur}}$, respectively) and the $\mathrm{Na}^{+}-\mathrm{K}^{+}$ATPase current $\left(\mathrm{I}_{\mathrm{NKA}}\right.$ ) control AP plateau (phase 2), repolarization (phase 3), and APD. The basaland muscarinic-receptor-activated inward-rectifier $\mathrm{K}^{+}$channels responsible for $\mathrm{I}_{\mathrm{K} 1}$ and $\mathrm{I}_{\mathrm{K}, \mathrm{ACh}}$, respectively, predominantly conduct at negative $\mathrm{E}_{\mathrm{m}}$ and as such are critical for maintaining a normal resting $\mathrm{E}_{\mathrm{m}}\left(\mathrm{RMP}\right.$, phase 4 ). Notably, $\mathrm{I}_{\mathrm{Kur}}$ and $\mathrm{I}_{\mathrm{K}, \mathrm{ACh}}$ contribute little to ventricular repolarization, providing opportunities for atrial-selective antiarrhythmic drugs, as discussed below. Atrioventricular differences in $\mathrm{I}_{\mathrm{Na}}$ inactivation properties also confer atrial selectivity to certain $\mathrm{Na}$ channel blockers, including ranolazine (88). Figure 3 depicts simulated atrial APs and CaT (from (193)) and the major ionic currents that are 
active during the cardiac cycle. The genes encoding the ion channel subunits that compose these currents are also summarized in Figure 3.

\section{Atrial Regional Heterogeneity}

Atrial APs exhibit regional variability. Within the canine right atrium, myocytes from different regions show systematic variations in AP morphology and duration that reflect spatial variation in ionic current densities, with voltage- and time-dependent properties being constant across regions (169). Namely, cells from the crista terminalis have a "spikeand-dome" morphology and the longest APD (corresponding to the largest $\mathrm{I}_{\mathrm{CaL}}$ ). Atrial appendage and pectinate muscle cells have intermediate APDs, with appendage cells having a small phase 1 and high plateau (due to a small $\mathrm{I}_{\mathrm{to}}$ ); and cells from the atrioventricular ring area have the shortest APD (corresponding to the smallest $\mathrm{I}_{\mathrm{CaL}}$ ). $\mathrm{I}_{\mathrm{K} 1}$ and $\mathrm{I}_{\mathrm{Kur}}$ are similar in all regions, whereas $\mathrm{I}_{\mathrm{Kr}}$ is larger in atrioventricular ring cells compared with other regions. Three different outward current patterns (types 1-3) were observed in human atrial appendage myocytes, based on the relative magnitude of transient outward and delayed rectifier $\mathrm{K}^{+}$currents (Figure 4 ). Type 1 was the most abundant, and characterized by a large $\mathrm{I}_{\text {to }}$ and a clear $\mathrm{I}_{\mathrm{K}}$, type 2 was the least abundant and displayed only $\mathrm{I}_{\mathrm{K}}$, whereas a prominent $\mathrm{I}_{\text {to }}$ and negligible $\mathrm{I}_{\mathrm{K}}$ characterized type 3. Consistent differences in AP morphology were observed, with type 2 cells having a higher plateau and steeper phase 3 slope and type 3 cells showing a triangular AP and lesser phase 3 slope compared with type 1 cells (541).

The left atrium has shorter APs and refractory period compared to the right atrium, which has been attributed to larger $\mathrm{I}_{\mathrm{Kr}}(284)$. $\mathrm{I}_{\mathrm{Ks}}, \mathrm{I}_{\mathrm{Kur}}, \mathrm{I}_{\mathrm{to}}$, and $\mathrm{I}_{\mathrm{CaL}}$ were all comparable in the canine right and left atria (284), although $\mathrm{I}_{\text {Kur }}$ was found to be $\sim 20 \%$ larger in myocytes from the right $v s$. left atrium of sinus rhythm patients (94). The AP was even shorter in the pulmonary vein (PV) myocytes. $\mathrm{I}_{\mathrm{Ks}}$ and $\mathrm{I}_{\mathrm{Kr}}$ were greater in the $\mathrm{PV}$, consistent with greater Kv11.1 (ERG) and Kv7.1 (formerly KvLQT1) abundance, whereas transient outward $\mathrm{K}^{+}$ current and L-type $\mathrm{Ca}^{2+}$ current were significantly smaller. Inward rectifier current density in the PV myocytes was approximately half that in the left atrium (and Kir2.3 was less expressed), potentially accounting for the less negative RMP in PVs $(157,327)$. Regional differences in atrial repolarization may be important in AF, as discussed below.

\section{Atrial Fibrillation: Mechanisms and lonic Remodeling}

$\mathrm{AF}$ is the erratic and rapid activation of the atria, which is reflected in the ECG by an undulating baseline that replaces the regular $\mathrm{P}$ waves, and irregular QRS complexes. AF is the most common sustained arrhythmia encountered in clinical practice, with a prevalence of $1-2 \%$ in the general population, which increases with age. The disease is associated with increased morbidity and mortality and is responsible for over one-third of all embolic strokes. Current drugs for AF treatment have limited efficacy and may increase the risk of malignant ventricular arrhythmias. Thus it is likely for the disease to progress from paroxysmal AF (pAF) to extensive electrical, structural, contractile, and neurohormonal (mal)adaptive responses leading to chronic AF (cAF).

Animal and clinical studies have suggested that AF is a reentrant arrhythmia sustained by reentrant circuits propagating in a remodeled atrial tissue substrate (238). Rapid electrical 
impulse generation outside of the SAN (ectopic/triggered activity), particularly around the pulmonary veins, can trigger reentry in a vulnerable substrate or, when occurring repetitively at high frequency, contribute to AF maintenance by serving as a driver through so-called 'fibrillatory conduction'. These mechanisms are thoroughly reviewed in a recent article by Wakili et al. (531).

Ectopic activity from atrial foci could result from automatic firing, which occurs when an increase in time-dependent depolarizing inward currents carried by $\mathrm{Na}^{+}$or $\mathrm{Ca}^{2+}$ or a decrease in repolarizing outward $\mathrm{K}^{+}$-currents causes progressive time-dependent cell depolarization. When threshold potential is reached, the cell fires, producing automatic activity (Figure 5). Triggered activity also results from early or delayed afterdepolarizations (EADs or DADs) occurring during or after repolarization of the atrial AP. EADs during AP phase 2 occur predominantly at slow heart rates in the setting of reduced repolarization reserve and prolonged APD due to increased inward $\mathrm{Ca}^{2+}$ and $\mathrm{Na}^{+}$or decreased outward $\mathrm{K}^{+}$ currents. Although several pathological conditions resulting in reduced repolarization reserve (e.g., long-QT syndrome) have been associated with increased susceptibility to AF induction, the role of phase-2 EADs during fast atrial rates in $\mathrm{AF}$ is uncertain. On the other hand, EADs can also arise from $\mathrm{Ca}^{2+}$-handling abnormalities that activate depolarizing NCX current (late phase-3 EADs), which have been implicated in the initiation of $\operatorname{AF}(87,376)$ via non-equilibrium reactivation of $\mathrm{I}_{\mathrm{Na}}$ (156). DADs arise from a transient inward current $\mathrm{I}_{\mathrm{ti}}$ through forward mode NCX, which is evoked by diastolic increase in $\left[\mathrm{Ca}^{2+}\right]_{\mathrm{i}}$ due to abnormal spontaneous $\mathrm{Ca}^{2+}$ release from the SR (Figure 5).

Reentry can occur when an electrical impulse is able to re-excite areas that have already recovered, thereby providing a perpetuation of electrical activity. Reentry can be caused by a fixed anatomical obstacle, or be functional reentry. For reentry to be sustained, all points in the reentrant path need to become excitable before the arrival of the reentrant impulse (termed 'excitable gap'). When wavelength (i.e., the distance an impulse travels within a single refractory period) decreases due to shortening of the effective refractory period (ERP) or due to conduction slowing (Figure 5), reentry will be more likely and more reentrant circuits can fit in the same area, making AF more stable and less likely to terminate.

Changes in atrial function or structure (collectively termed 'atrial remodeling') can support AF induction and/or maintenance. Several studies have investigated the molecular and ionic mechanisms involved in the remodeling of the atria of patients with AF, and suggest that structural, electrophysiological, and contractile remodeling are critical factors in the disease progression, i.e., they contribute to the development of a substrate that facilitates the tendency for persistence of AF (AF begets $\mathrm{AF}$ ) $(348,531)$. Structural remodeling involves changes in atrial myocyte and tissue morphology (e.g., cell hypertrophy, fibrosis) $(148,348$, 558). Electrical remodeling includes changes in $\mathrm{Ca}^{2+}$ - and $\mathrm{K}^{+}$-currents leading to shortening of the APD and effective refractory period (ERP), and loss of rate adaptation of both atrial repolarization and refractoriness (558). Typically, the human atrial APD at 90\% repolarization $\left(\mathrm{APD}_{90}\right)$ shortens when paced at faster frequencies, but in myocytes isolated from cAF patients this shortening is severely attenuated. A growing body of experimental evidence points to perturbations in intracellular $\mathrm{Ca}^{2+}$ handling as important players in $\mathrm{AF}$ induced atrial remodeling $(147,149)$, with intracellular $\mathrm{Ca}^{2+}$ transients $(\mathrm{CaTs})$ being 
reduced, despite unaltered $\mathrm{SR} \mathrm{Ca}^{2+}$ content $(193,295,350,521)$. CaTs decay more slowly in cAF compared to sinus rhythm $(193,521)$. Elevated diastolic $\left[\mathrm{Ca}^{2+}\right]_{\mathrm{i}}$ has been reported and attributed to enhanced leak of $\mathrm{Ca}^{2+}$ from the SR (350). CaT amplitude increases with the pacing rate in normal atrial myocytes (314), but we importantly showed that this is impaired when simulating cAF conditions (193). Our simulations also indicated that APD rate adaptation in sinus rhythm atrial cells involves accumulation of intracellular $\mathrm{Na}^{+}$ $\left(\left[\mathrm{Na}^{+}\right]_{\mathrm{i}}\right)$ at high frequencies, which causes outward shifts in NCX and NKA currents. The model also predicted that E-C coupling remodeling in cAF would reduce $\mathrm{Na}^{+}$accumulation, thus causing a blunted APD rate-dependent response (193). Myofilament protein changes in $\mathrm{AF}$ are also likely to contribute to atrial contractile dysfunction (40).

Here we summarize the current knowledge of the ionic bases underlying AF-associated electrical and $\mathrm{Ca}^{2+}$ handling remodeling, especially focusing on data from cAF patients (Table 1, reviewed previously in (196)). Figure 3 provides a graphical representation of the main changes occurring in the electrophysiological and $\mathrm{Ca}^{2+}$ handling processes in human cAF. Understanding the molecular mechanisms of excitation-contraction-coupling remodeling in the fibrillating human atria is important to identify new potential targets for AF therapy.

EC coupling remodeling can occur at the level of ion channels/transporters expression, or by modification of ion channel/transporter properties (for example, trafficking or phosphorylation). Altered protein kinase and phosphatase activity may importantly contribute to EC coupling remodeling in AF. Indeed, CaMKII has been found to be more expressed and more phosphorylated in human $\operatorname{cAF}(350,481)$. Similar PKA activity was found in cAF $v s$. sinus rhythm in goats (199), but El-Armouche et al. detected a higher total activity of type 1 and type $2 \mathrm{~A}$ phosphatases in human $\mathrm{cAF}$, causing inhomogeneous changes in protein phosphorylation in different cellular compartments (160). This may specifically amplify PKA and CaMKII effects on certain targets without having significant effects on others (e.g., higher phosphatase activity/lower phosphorylation in thick $v s$. thin myofilaments, cell membrane $v s$. SR) (160). Thus, there is growing interest in the potential role of CaMKII and protein phosphatase inhibitors in preventing arrhythmogenic remodeling in $\mathrm{cAF}$.

Nav Channels-Bosch et al. reported that $\mathrm{I}_{\mathrm{Na}}$ density and voltage-dependence of activation were not altered in human AF (69), the steady-state inactivation was shifted to the right (69), and no changes were detected in mRNA levels of the $\mathrm{Na}^{+}$channel gene $S C N 5 \mathrm{~A}$ (82). In contrast, Sossalla et al. provided recent evidence that expression of Nav1.5 and peak $\mathrm{I}_{\mathrm{Na}}$ density is decreased (slightly) in the atrial myocardium of patients with cAF (459). Although it is unclear whether altered fast $\mathrm{I}_{\mathrm{Na}}$ contributes to the electrical remodeling in human $\mathrm{AF}, \mathrm{Na}^{+}$channel blockers with $\mathrm{E}_{\mathrm{m}}$ - and frequency-dependent action preferentially suppress AF because of the high excitation rate and less negative atrial vs. ventricular RMP, which promote drug binding in atria. Vernakalant and ranolazine, which mainly block atrial $\mathrm{Na}^{+}$channels, are clinically effective (402). The former is in clinical use for cardioversion of $\mathrm{AF}$ in Europe, the latter has efficacy for AF and is being tested in prospective clinical trials. 
It has recently been shown the late $\mathrm{Na}^{+}$current component $\left(\mathrm{I}_{\mathrm{NaL}}\right)$ is significantly increased in cAF patients (459). Sossalla et al. (459) proposed that this increase could be due to the increase in neuronal $\mathrm{Na}^{+}$channel isoforms (Nav1.1 expression is increased), or mediated by CaMKII, which is increased in $\mathrm{AF}(350,481)$ and known to regulate $\mathrm{I}_{\mathrm{NaL}}(527)$, or caused by oxidative stress $(329,529)$. However, our simulations suggested that an increased $\mathrm{I}_{\mathrm{NaL}}$ does not contribute significantly to repolarization in $\mathrm{cAF}$, where the overall $\mathrm{APD}_{90}$ was still shorter than that in normal healthy cells (193). On the other hand, an increase in $\mathrm{I}_{\mathrm{NaL}}$ may cause cellular $\mathrm{Na}^{+}$and $\mathrm{Ca}^{2+}$ overload and lead to contractile dysfunction and electrical instability (via reverse-mode NCX) (49).

Cav Channels-Reduction in $\mathrm{I}_{\mathrm{CaL}}$ density ( $-50 \% \mathrm{vs}$. sinus rhythm) is one of the most consistent features of electrophysiological remodeling in human AF (as seen in $(112,148$, 193, 509, 521, 560)). Christ et al. (112) demonstrated that decreased $\mathrm{I}_{\mathrm{CaL}}$ density in cAF is not accompanied by altered expression of the corresponding a $1 \mathrm{c}$ and $\beta 2$ a channel subunits (although other studies found different results (83)), and proposed that lower basal $\mathrm{I}_{\mathrm{CaL}}$ is due to decreased channel phosphorylation in $\mathrm{AF}$, which results from an altered ratio of protein kinase/phosphatase activity in favor of increased phosphatase activity. An analogous explanation was proposed for the blunted effect of CaMKII inhibition on $\mathrm{I}_{\mathrm{CaL}}$ in human cAF (350). It has been shown that blocking $\mathrm{I}_{\mathrm{CaL}}$ with nifedipine in normal human atrial cells results in an AP characteristic typically seen in AF (509) with respect to morphology, duration and impaired rate-dependent adaptation, i.e., reduction in $\mathrm{I}_{\mathrm{CaL}}$ seems to be a critical component of the remodeled atrial electrical phenotype. However, Workman et al. found that nifedipine did not significantly alter ERP in sinus rhythm myocytes (although APD was shorter), thus supporting the idea that $\mathrm{I}_{\mathrm{CaL}}$ downregulation may not be sufficient by itself to explain the remodeled atrial electrical phenotype (560). There is no evidence of $\mathrm{I}_{\mathrm{CaT}}$ in human atrial myocytes $(289,455)$, but $\mathrm{I}_{\mathrm{CaT}}$ is present in atrial myocytes of other species $(290,351,430)$.

HCN Channels-The hyperpolarization-activated pacemaker current, $\mathrm{I}_{\mathrm{f}}$, has been found to be increased in human AF compared to sinus rhythm, at least at the mRNA level (274), and could contribute to ectopic atrial pacemaker activity. However, functional evidence for $\mathrm{I}_{\mathrm{f}}$ involvement is lacking at present.

Kv Channels-Human cAF is associated with strong reduction of $\mathrm{I}_{\mathrm{to}}$ density $(69,79,94$, $148,191,510,560)$ and downregulation of its channel a-subunit $\mathrm{Kv} 4.3(82,84)$. $\mathrm{I}_{\mathrm{Kur}}$ was reduced in $\mathrm{cAF}(79,94,113,148,510)$, paralleled by diminished expression of Kv1.5 (82, $84,510)$. However, others have reported no changes in $\mathrm{I}_{\text {Kur }}$ density $(69,191,560)$.

Inconsistent results regarding $\mathrm{I}_{\mathrm{Kur}}$ function have been commented on previously by Christ $e t$ $a l$. and attributed to different strategies for identification of $\mathrm{I}_{\mathrm{Kur}}$ (e.g., pharmacological or with $\mathrm{I}_{\mathrm{to}_{0}}$-inactivating prepulse), and to a fraction of $\mathrm{I}_{\mathrm{Kur}}$ that is not accounted for by $\mathrm{Kv} 1.5$ (113). The reduction in $\mathrm{I}_{\mathrm{to}}$ and $\mathrm{I}_{\mathrm{Kur}}$ explains the slight prolongation in earlier phases of the AP $(193,508)$.

It has been shown that CaMKII (increased in $\mathrm{cAF}$ ) positively regulates $\mathrm{I}_{\text {to }}$ in human atrial myocytes in acute conditions, as the application of the CaMKII inhibitor KN-93 caused loss of channel function (481). The authors speculated that, by reducing the extent of inactivation 
of $\mathrm{I}_{\mathrm{to}}$, upregulation of CaMKII during $\mathrm{AF}$ reduces $\mathrm{Ca}^{2+}$ influx and therefore minimizes $\mathrm{Ca}^{2+}$ overload. On the other hand, CaMKII overexpression in cAF may impact channel expression, thus contributing to $\mathrm{I}_{\text {to }}$ downregulation, as recently shown in CaMKIIoverexpressing transgenic mice (528).

Experimental evidence suggests that block of $\mathrm{I}_{\mathrm{Kur}}$ enhances force of contraction of isolated human atrial trabeculae both in patients in sinus rhythm and AF $(428,449,552)$. We have recently predicted that block of $\mathrm{I}_{\mathrm{Kur}}$ results in prolongation and elevation of the AP plateau, which augments the CaT amplitude that would elicit a positive inotropic effect (193). Taken together, these studies suggest that $\mathrm{I}_{\mathrm{Kur}}$ might be a potentially useful atrial-specific target to potentially counteract hypocontractility associated with $\mathrm{cAF}$. A slight AP prolongation associated to $\mathrm{I}_{\mathrm{Kur}}$ blockade may also be beneficial. Numerous compounds have been screened for high Kv1.5 selectivity, characterized electrophysiologically in isolated cardiac myocytes and tissue, and tested for their antiarrhythmic activity in various animal models of AF. Despite these efforts, proof-of-concept of antiarrhythmic efficacy in human is still lacking (402).

The delayed rectifier $\mathrm{K}^{+}$currents have proven much harder to record and study in isolated human atrial cells (171). Nevertheless, their contribution is likely to be small in cells that lack an appreciable plateau phase (541). The block of the rapidly activating delayed rectifier $\mathrm{K}^{+}$current, $\mathrm{I}_{\mathrm{Kr}}$, has been shown to prolong human atrial APD in the late phase of repolarization by a small amount (552), and to date no experimental evidence has suggested its involvement in AF-induced electrical remodeling. Recently, Caballero et al. provided the first demonstration that cAF significantly increased the amplitude of the slow delayed rectifier $\mathrm{K}^{+}$current, $\mathrm{I}_{\mathrm{Ks}}$, in both atria (94). They suggested that $\mathrm{I}_{\mathrm{Ks}}$ increase could contribute to $\mathrm{cAF}$-induced shortening of APD and to further promote fibrillatory conduction, especially with current accumulation at high frequencies.

Inward Rectifying Channels-In cAF, increases in both current density (146, 148, 510, $523,560)$ and mRNA levels $(146,148)$ have been reported. Increased $I_{K 1}$ causes a more negative resting $\mathrm{E}_{\mathrm{m}}$ in $\mathrm{cAF} v s$. sinus rhythm human atrial myocytes $(146,193,523)$.

Patients with chronic AF exhibit agonist-independent constitutive $\mathrm{I}_{\mathrm{K}, \mathrm{ACh}}$ activity that contributes to the enhanced basal inward rectifier current and may result from abnormal channel phosphorylation by $\operatorname{PKC}(145,146,523)$. Constitutively active $\mathrm{I}_{\mathrm{K}, \mathrm{ACh}}$ is considered to support the maintenance of $\mathrm{AF}$, together with increased $\mathrm{I}_{\mathrm{K} 1}$, by stabilizing reentrant activity sustained by rotors (faster activation, less meander) (374). The recently reported $\mathrm{I}_{\mathrm{K}, \mathrm{ACh}}$ blocker NTC-801 was suggested to exert antifibrillatory action by atrial-selective ERP prolongation (310), but no data are yet available in native human tissue (402).

The ATP-sensitive $\mathrm{K}^{+}\left(\mathrm{I}_{\mathrm{KATP}}\right)$ channels generate an inward rectifying current that activates with a decrease in intracellular ATP concentration (589). Gene expression and electrophysiological studies in patients with AF demonstrated reduced mRNA levels of Kir6.2 (84) and current activation (28), but increased current was also reported (561). It is conceivable that structural heart disease and atrial dilation could alter the metabolic and mechanosensitive gating of KATP channels, thus providing a substrate for AF (371). 
Recent studies show predominant atrial expression of mRNA in humans for several other $\mathrm{K}^{+}$ channels (TWIK1 and TASK1) that function similarly to the voltage-independent inward rectifying $\mathrm{K}^{+}$channels responsible for $\mathrm{I}_{\mathrm{K} 1}(178,296,425)$. TWIK1 and TASK1 belong to a family of two-pore domain $\mathrm{K}^{+}$channel proteins $\left(\mathrm{K}_{2 \mathrm{P}}\right)$ that are responsible for background $\mathrm{K}^{+}$currents and can be regulated by $\mathrm{pH}$, oxygen, stretch, temperature, drugs, lipids, and second messengers $(205,296,425)$. Inhibition of $\mathrm{K}_{2 \mathrm{P}}$ channels in human atria is expected to prolong atrial APD and increase the effective refractory period, which suggests the possibility of targeting these channels in atrial-selective anti-arrhythmogenic drugs.

$\mathrm{Ca}^{2+}$-activated $\mathrm{K}^{+}$Channels-Although there is controversy regarding the role of small conductance $\mathrm{Ca}^{2+}$-activated $\mathrm{K}^{+}(\mathrm{SK})$ channels in atrial repolarization under physiological conditions (reviewed by (311)), I ISK does appear to contribute to AF-related remodeling. An increase in $\mathrm{I}_{\mathrm{SK}}$ due to increased SK2 trafficking has been reported in a rabbit atrial model mimicking PV ectopy (373). SK2 expression was found increased in the PVs in a canine atrial tachypacing model, in which $\mathrm{I}_{\mathrm{SK}}$ increase resulted from increased SK1 expression (398). Overexpression of SK3 in mice also promotes AF (313). Upregulation of $\mathrm{I}_{\mathrm{SK}}$ is expected to result in abbreviated APD and ERP, thus promoting reentry. On the other hand, $K C N N 2$ null mice have AF resulting from prolonged APD and triggered activity (292).

$\mathrm{Ca}^{2+}$ Handling Proteins-Increased expression $(160,429,521)$ and abnormal function of NCX $(193,521)$ are implicated in human AF pathophysiology. An increase in $\mathrm{I}_{\mathrm{NCX}}$ may be an adaptive response to cellular $\mathrm{Ca}^{2+}$ loading and contribute to diminish the $\mathrm{Ca}^{2+}$ overload induced by rapid atrial activation (along with $\mathrm{I}_{\mathrm{CaL}}$ downregulation). Indeed, the decay rate of caffeine-evoked CaT (attributable to $\mathrm{Ca}^{2+}$ removal by NCX) is shown to be faster in human cAF $v s$. sinus rhythm myocytes $(193,350,521)$. $\mathrm{Na}^{+}$overload-induced $\mathrm{Ca}^{2+}$ influx via reverse-mode $\mathrm{NCX}$ has been implicated in $\mathrm{Ca}^{2+}$ overload and related arrhythmogenesis, whereas increase $\mathrm{Ca}^{2+}$ extrusion via forward-mode has been linked to DADs $(49,393)$. Indeed, $\mathrm{Na}^{+}$and $\mathrm{Ca}^{2+}$ loading are more favored at increased atrial rates (i.e., during $\mathrm{AF}$ ). However, more studies are needed to assess whether DADs are important in initiating arrhythmias in $\mathrm{AF}$, and the underlying role of $\mathrm{NCX}$ in mediating them, since an increased $\mathrm{I}_{\mathrm{K} 1}$ in cAF will tend to oppose the occurrence of such DADs. These studies will help determine if blocking NCX represents a novel therapeutic strategy in suppressing arrhythmia triggers in $\mathrm{cAF}$.

Spontaneous $\mathrm{Ca}^{2+}$-release events $\left(\mathrm{Ca}^{2+}\right.$ sparks) and $\mathrm{Ca}^{2+}$ waves through leaky RyR channels have been reported in myocytes from cAF patients $(103,350,518,521)$ despite unaltered SR $\mathrm{Ca}^{2+}$ content. One potential contributor to RyR hyperactivity may be oxidative stress, which is known to play a critical role in AF pathophysiology (329) and increase RyR open probability. Neef et al. suggested that the CaMKII-dependent increase in $\mathrm{SR} \mathrm{Ca}^{2+}$ leak caused by RyR hyperphosphorylation in AF is a potential arrhythmogenic mechanism (350), because elimination of $\mathrm{Ca}^{2+}$ via inward $\mathrm{I}_{\mathrm{NCX}}$ could lead to cell depolarization and cause DADs. Voigt et al. measured directly single RyRs isolated from cAF patients and demonstrated a higher channel open probability in cAF that responded to CaMKII inhibition (522). Thus CaMKII inhibition may reduce the propensity for atrial arrhythmias. 
A decrease in SERCA activity, associated with lower SERCA protein expression $(160,521)$, is evident in human cAF and explains the slower CaT decay compared to sinus rhythm (160, 193, 521). On the other hand, reduced inhibition of SERCA by hyperphosphorylated PLB (160) in cAF could help to maintain a normal SR $\mathrm{Ca}^{2+}$ load despite increased RyR activity.

NKA-Workman et al. found no difference in NKA pump current in myocytes from cAF patients compared to sinus rhythm, and concluded that $\mathrm{I}_{\mathrm{NKA}}$ is not involved in AF-induced electrophysiological remodeling in patients (559). Our simulations show lower NKA current underlying the AP because of reduced $\mathrm{Na}^{+}$loading in cAF. Intracellular $\left[\mathrm{Na}^{+}\right]$changes may contribute to the human cAF phenotype, as we postulated in our modeling study (193) but have not yet been measured.

Ankyrin-B-Ankyrin-B (encoded by ANK2) is an adaptor protein expressed in excitable cells that targets ion channels (e.g., $\mathrm{Na}^{+}$and $\mathrm{Ca}^{2+}$ channels), transporters (e.g., NKA and NCX), and signaling molecules to specific membrane domains. Ankyrin-B loss-of-function mutations in humans lead to Long QT syndrome, AF, sinus node dysfunction and stressinduced ventricular arrhythmias (334). Recently, reduced ankyrin-B expression has been demonstrated in atrial samples of patients with paroxysmal AF, and supported an association between ankyrin-B and AF (125). A new potential molecular mechanism underlying ankyrin-associated $\mathrm{AF}$ has been proposed involving disrupted Cav1.3 (atrial L-type $\mathrm{Ca}^{2+}$ channels) membrane targeting in atrial myocytes (125).

Connexins-While an important role for connexins in AF is strongly supported by connexin gene mutations associated with $\mathrm{AF}$ (see below), controversial results on the role of connexin in clinical and experimental AF models have been reported (reviewed in (256)).

Alterations in both total connexin expression and distribution have been described, but the results show wide variations, with opposing results even within the same model. Transgenic animal models have also reported contradictory results, with studies indicating a clear increase (207) or no change (494) in atrial tachyarrhythmia susceptibility with Cx40 knockout. Small-molecule drugs enhancing gap junction conductance have been developed as potential treatments for $\mathrm{AF}$, and lead to improvement in some models (ischemia and mitral valve disease-related AF). However, little or no change is reported in other clinically relevant models $(200,278,451)$. Thus, the role of connexin abnormalities in AF and the potential value of modulating connexin function to treat $\mathrm{AF}$ remain unclear.

While gap junctional coupling is usually considered to be the primary mechanism for AP propagation, there is evidence that other mechanisms are important. In particular, absence or reduction in $\mathrm{Cx} 43$ function produced only a moderate reduction of cardiac propagation velocity in mice $(201,582)$. One possible explanation for these experimental findings is that ephaptic (i.e., field effect) coupling may be significant. Field or ephaptic coupling refers to the initiation of an AP in a non-activated downstream cell by the electrical field caused by an activated upstream cell. Computer simulations showed that, under certain conditions, local accumulation of ions in the junctional extracellular cleft may alter local membrane potential, thus indicating that ephaptic coupling may play a role, but strongly depends on parameters like $\mathrm{Na}^{+}$channel conductance and distribution, and the width of the extracellular cleft at the intercalated disk $(297,336)$. Membrane-tunneling nanotubes serving as cytosolic 
bridges between cells (211) were recently suggested as another mechanism of electrical cellto-cell coupling. This theory, however, still needs further investigation.

Regional Heterogeneity in Atrial Remodeling-Caballero et al. have recently looked at differences in current density and AF-induced alterations in the right $v s$. left human atrium. They found heterogeneity in the repolarizing currents between the atria in sinus rhythm, and demonstrated that $\mathrm{cAF}$ reduced the $\mathrm{I}_{\text {to }}$ amplitude and density more markedly in the left than in the right atrium, thus creating a right-to-left gradient, whereas $\mathrm{I}_{\mathrm{Kur}}$ was more markedly reduced in the right than in the left atrium, thus dissipating the left-to-right gradient detected in sinus rhythm (94). They also provided the first demonstration that cAF significantly increased the amplitude of the slow delayed rectifier $\mathrm{K}^{+}$current, $\mathrm{I}_{\mathrm{Ks}}$, in both atria (94). They suggested that $\mathrm{I}_{\mathrm{Ks}}$ increase could contribute to cAF-induced shortening of APD and to further promote fibrillatory conduction, especially with current accumulation at high frequencies. However, the data concerning intra-atrial heterogeneities in repolarizing currents in human atrial myocytes are still limited, and it is unclear whether and how these changes may contribute to the perpetuation of arrhythmia (193). Recently, Voigt et al. found significant left-to-right gradients in $\mathrm{I}_{\mathrm{K} 1}$ and constitutively active $\mathrm{I}_{\mathrm{K}, \mathrm{ACh}}$ in patients with paroxysmal AF, which were dissipated in $\mathrm{CAF}$, raising the idea that this may contribute to left-to-right dominant frequency gradients that are often more evident in paroxysmal AF vs. cAF (523). It has also been shown that cAF increases the effects of $\beta 1$-adrenoceptor stimulation on repolarizing currents by means of a chamber-specific upregulation of the receptors, which are overexpressed in the left $v s$. right atria. This, together with the ion channel derangements produced by cAF, could shorten the APD thus contributing to the long-term stabilization of the arrhythmia (188).

\section{Role of the Autonomic Nervous System in AF}

The autonomic nerves extensively innervate the heart, and the nervous system is important for cardiac function and arrhythmogenesis by modulating many ion channels. Indeed, simultaneous sympathovagal discharges commonly precede arrhythmias, and both sympathetic and vagal activation have been shown capable of producing proarrhythmic atrial and ventricular electrophysiological changes $(55,142)$ - see also ventricular section entitled "Role of the Autonomic Nervous System in Ventricular Arrhythmia". Both the stellate ganglion (a major source of cardiac sympathetic innervation) and the vagal nerves have complex structures containing mixed nerve types (reviewed in (106)). In addition to the complex anatomic and physiological interactions between various nerve structures, cardiac autonomic innervation is also the subject of remodeling, especially during disease states, as witnessed by the increased sympathetic nerve densities found in patients with cAF (353). Indeed, abnormal autonomic innervation may be important in the initiation and maintenance of $\mathrm{AF}$, and modulating autonomic function to reduce autonomic innervation or outflow has shown useful for AF control (see review (106)). Intrinsic cardiac nerves are found mostly in the atria and are intimately involved in atrial arrhythmogenesis. Histological study of human pulmonary vein-left atrium junction showed that numerous autonomic nerves are present $(475,503)$. Adrenergic and cholinergic nerves are strongly colocalized at tissue and cellular levels, which makes it difficult to selectively eliminate one or the other arms of the autonomic nervous systems, e.g., via catheter ablation (475).

Compr Physiol. Author manuscript; available in PMC 2016 July 01. 


\section{AF associated with ion channel genetic mutations}

The familial form of AF is uncommon. However, in the past decade mutations in various ion channels have been identified and linked the genetic form of AF with ion channelopathies (see recent reviews $(95,312)$ ). Mutations in a number of genes have been associated with $\mathrm{AF}$, but they are rare and do not explain the majority of cases of familial AF. These include genes encoding $\mathrm{K}^{+}\left(K C N Q 1, K C N A 5, K C N E 5, K C N J 2\right.$, and KCNE2) and $\mathrm{Na}^{+}(S C N 5 A$, $S C N 1 B, S C N 2 B$, and $S C N 3 B$ ) channels, $\mathrm{K}^{+}$-adenosine triphosphate channels (ABCC9), nucleoporin-155 (NUP155), gap junction protein connexin 40 (GJA5), and atrial natriuretic peptide (NPPA).

Nav Channels-Both loss- and gain-of-function variants in SCN5A have been associated with AF (131), and loss-of-function mutations in Na channel $\beta 1$ and $\beta 2$-subunits ( $S C N 3 B$ and $S C N 4 B)$ are associated with $\mathrm{AF}(368,546)$. The electrophysiological mechanisms by which Na mutations cause AF are not clearly understood (312). Increased $\mathrm{I}_{\mathrm{Na}}$ and $\mathrm{I}_{\mathrm{NaL}}$ can induce triggered activity and stabilize high-frequency rotors. Conversely, reduced $\mathrm{I}_{\mathrm{Na}}$ and $\mathrm{I}_{\mathrm{NaL}}$ density can promote reentry by shortening APD and shortening the atrial reentry wavelength, but also destabilizes high-frequency rotors (264).

Kv Channels-A missense mutation in Kv7.1 (KCNQ1) resulting in the amino acid change S140G was first identified in a 4-generation family causing a gain-of-function phenotype that increases $I_{\mathrm{Ks}}$ when the mutated channel was expressed with the $\beta$-subunits KCNE1 (formerly minK) and KCNE2 (formerly MiRP1) (109). A de novo gain-of-function mutation $(\mathrm{V} 141 \mathrm{M})$ was found responsible for a severe form of AF and short-QT syndrome in utero (224). Interestingly, a missense $K C N Q 1$ mutation, $\mathrm{R} 14 \mathrm{C}$, was identified in one family with a high prevalence of hypertension (372). This caused a gain-of-function only when cells were placed in a hypotonic solution, suggesting that an environmental factor like hypertension, which promotes atrial stretch and thereby unmasks an inherited defect in ion channel kinetics, is required for AF to be manifested. Gain-of-function in $\mathrm{I}_{\mathrm{Ks}}$ secondary to a mutation in KCNE5 (encoding the KCNE5 or MiRP4 $\beta$-subunit) was also reported and associated with AF (403).

Mutations in $K C N E 2$ have been also identified and liked to familial AF. The mutation R27C caused a gain-of-function when coexpressed with Kv7.1, but had no effect when expressed with Kv11.1 (hERG), unlike long QT syndrome-associated KCNE2 mutations (577).

Mutations M23L and I57T were identified in patients with early-onset lone AF, and caused a significant gain-of-function effect upon coexpression with Kv7.1 and Kv7.1+KCNE1 (356). The mutation V17M in $K C N E 3$ was found in a proband with early-onset lone AF and led to gain-of-function of several cardiac currents (Kv4.3/KCNE3 and Kv11.1/KCNE3) (307). A gain-of-function mutation in Kir2.1, caused by a mutation in $K C N J 2$, was found in a family with $\mathrm{AF}$ (563). Overall, $\mathrm{K}^{+}$channel gain-of-function mutations are likely to initiate and maintain AF by reducing APD and ERP in atrial myocytes.

A KATP channel mutation has been shown to confer risk for adrenergic AF originating from the vein of Marshall (370), and it has been proposed that KATP channel deficit could play a broader role in the pathogenesis of electrical instability (371). 
Loss-of-function mutations in $K C N A 5$, the gene encoding $\mathrm{Kv} 1.5$, have been also linked to $\operatorname{AF}(114,369,575)$. In the first report, this loss of channel function was shown to translate into AP prolongation and EADs in human atrial myocytes, increasing vulnerability to stressprovoked triggered activity (369). Gain-of-function mutations in KCNA5 have been found in patients with early-onset lone AF. This supports the notion that both increased and decreased $\mathrm{K}^{+}$-currents enhance AF susceptibility (114).

Connexins-GJA5 encodes connexin-40, a gap junction protein in the atrium that plays a critical role in mediating coordinated AP conduction via cell-to-cell electrical coupling. Mutations in this gene have been associated with $\operatorname{AF}(187,557)(467)$, and their functional analysis revealed abnormal intracellular transport in addition to a reduction in electrical coupling between cells $(187,467)$. This can result in conduction heterogeneity, micro-reentrant circuits, and AF.

Non-ion channels-A frame shift mutation has been identified in a large family with AF in the atrial natriuretic peptide precursor (NPPA). NPPA encodes atrial natriuretic peptide, which modulates ionic currents in cardiac myocytes and can play a role in shortening of the atrial conduction time, which could be a potential substrate for atrial re-entrant arrhythmias (222).

A mutation in NUP155, which encodes a member of the nucleoporins, has been associated with AF, characterized by a neonatal onset, with autosomal recessive inheritance (592). The mechanism by which NUP155 may be associated with AF could be related to the modulation of $\mathrm{Ca}^{2+}$ handling proteins and ion channels and expression of its possible target genes, like HSP70.

AF associated with other monogenic diseases-AF has been described in other cardiac monogenic diseases as a concomitant disease, e.g., hypertrophic cardiomyopathy, in which the disease is probably related to structural changes in the atria caused by the underlying cardiac pathology. AF can also be present in other life-threatening ion channelopathies like long-QT syndrome (LQTS) (43, 307), Brugada syndrome (BrS) (338), and short-QT syndrome (SQTS) (134). A recent study demonstrated pleiotropy in $K C N Q 1$, whereby a discrete missense mutation (R231C) is capable of both long-QT syndrome and familial AF (34). Additionally, a mutation at the same residue (R231H) was linked to familial AF in multiple unrelated families suggesting that mutations that disrupt voltage sensor of Kv7.1 and increase constitutive activity lead to higher AF susceptibility (33).

\section{Atrioventricular Node}

\section{Function}

The AVN is located at the base of the atrial septum, at the apex of an area known as the triangle of Koch (Figure 1A) (291). The triangle is bounded by the ostium of the coronary sinus, the tendon of Todaro and the tricuspid valve (Figure 6A). Two pathways lead into the compact AVN: the transitional zone and the inferior nodal extension, comprising the fast and slow pathways for AV conduction, respectively (460). This 'dual pathway electrophysiology' (332) refers to the fastest (and therefore 'normal') route of AP 
propagation from the SAN through the AVN that uses the atrial septum and transitional zone, as opposed to the slowest pathway that uses the terminal crest and inferior nodal extension (232). Distal to the compact AVN is the penetrating bundle, which is embedded in the central fibrous body and emerges on the crest of the ventricular septum, where it becomes the His bundle.

The AVN serves several important functions, including providing a conduction delay between the atria and ventricles in order to allow atrial systole to take place before initiation of ventricular systole. The AVN also has a relatively long refractory period in order to protect the ventricles from atrial tachyarrhythmias by producing conduction block of high frequency atrial APs. Finally, the AVN can also serve as a back-up pacemaker if the SAN fails due to the intrinsic pacemaking ability of the AVN. Distinct ion channel and gap junction expression profiles throughout the nodal structures allow for the AVN to perform these diverse and vital functions.

\section{Ionic Mechanisms and Molecular Bases}

The compact AVN and inferior nodal extension are comprised of nodal-like $(\mathrm{N})$ myocytes that have AP properties and ion channel expression somewhat similar to that of the central SAN $(60,197,198,342)$. APs from these myocytes have a relatively depolarized diastolic $\mathrm{E}_{\mathrm{m}}(-50$ to $-60 \mathrm{mV})$, diastolic depolarization, a slow $\mathrm{I}_{\mathrm{CaL}}$-mediated upstroke, and relatively long APD $(60,342)$. Not surprisingly then, the $\mathrm{N}$ myocytes of the human compact AVN have similar ion channel expression to that of the human central SAN, including robust expression of HCN4 $\left(\mathrm{I}_{\mathrm{f}}\right)$, decreased expression of Kir2.1 $\left(\mathrm{I}_{\mathrm{K} 1}\right)$, decreased expression of $\operatorname{Nav1.5}\left(\mathrm{I}_{\mathrm{Na}}\right)$, and a phenotypic switch from Cav1.2 to Cav1.3 $\left(\mathrm{I}_{\mathrm{CaL}}\right)$ compared to the working atrial myocardium $(101,178,197)$. A few differences in ion channel expression (at the mRNA level) were observed, however, between myocytes of the compact AVN and central SAN in the human. Whereas the central SAN shows significantly decreased expression of $\mathrm{Kv} 4.3\left(\mathrm{I}_{\mathrm{to}}\right), \mathrm{Kv} 1.5\left(\mathrm{I}_{\mathrm{Kur}}\right)$, and $\mathrm{Kv} 11.1\left(\mathrm{I}_{\mathrm{Kr}}\right)$ relative to the atrial myocardium (101), the compact AVN does not show such robust down-regulation of these $\mathrm{K}^{+}$channels and instead, shows a significant increase in expression of Kv1.4 and Kv4.2 (both $\mathrm{I}_{\mathrm{to}}$ ) compared to the atrial myocardium (197). This altered $\mathrm{K}^{+}$channel expression may suggest different ionic mechanisms responsible for early and late repolarization in the central SAN vs. the compact AVN. Differences in expression of key $\mathrm{Ca}^{2+}$ handling proteins between the human central SAN and compact AVN were also observed, with the SAN showing robust down-regulation of SERCA2 and RyR2 compared to the atrial myocardium (101), whereas the AVN has similar expression of SERCA2 compared to the atrium and only a slight downregulation of RyR2 (197). The functional significance of this differential $\mathrm{Ca}^{2+}$ handling protein expression remains unknown, but is interesting to consider from the standpoint of $\mathrm{Ca}^{2+}$ clock functionality in the SAN and AVN.

Although the AVN is not a primary pacemaker, if the SAN fails AVN pacemaking can occur, although at a slower rate. For example, Dobrzynski and colleagues observed a near doubling of the cycle length in the excised rabbit heart as pacemaking shifted to the AVN following SAN removal (152). It is thought that under normal circumstances, the hyperpolarizing electrotonic influences of the atrial myocardium prevent spontaneous AVN 
activation and pacemaking. This conclusion results from studies in which the AVN was dissected from surrounding atrial and His tissue, resulting in a dramatic acceleration of rate (260). In the human, rabbit, and rat, HCN4 is abundantly expressed throughout the AVN (27) and is likely responsible for $\mathrm{I}_{\mathrm{f}}$ in the AVN and thus an important player in pacemaking. Interestingly, knock-out of HCN4 not only causes sinus bradycardia, but also high-degree AV block (36), suggesting that $\mathrm{I}_{\mathrm{f}}$ also plays an important role in normal AVN conduction.

\section{AVN Heterogeneity: Ion Channel and Gap Junction Distribution}

In addition to the compact node, the AVN is comprised of the transitional zone and inferior nodal extension (the fast and slow pathways into the compact node, respectively) and the penetrating bundle distal to the compact node (Figure 6A). The transitional zone is made up of atrio-nodal (AN) myocytes, the penetrating bundle is comprised of nodal-His $(\mathrm{NH})$ myocytes, and the inferior nodal extension and compact node are mainly comprised of nodal-like (N) myocytes (198). As discussed above, $\mathrm{N}$ cells have nodal-like AP morphology and ion channel expression, whereas the $\mathrm{AN}$ and $\mathrm{NH}$ myocytes are more intermediate in nature. APs from $\mathrm{AN}$ and $\mathrm{NH}$ myocytes have more negative diastolic $\mathrm{E}_{\mathrm{m}}$ compared to $\mathrm{N}$ myocytes and a faster AP upstroke (Figure 6B-5D) (60).

Although HCN4 is expressed throughout the AVN, Munk et al. showed that only approximately $10 \%$ of rod-shaped AN myocytes exhibit $\mathrm{I}_{\mathrm{f}}$, whereas nearly $100 \%$ of ovalshaped $\mathrm{N}$ and $\mathrm{NH}$ myocytes exhibit the current (342). Munk et al. also reported that $100 \%$ of AN myocytes exhibit $\mathrm{I}_{\mathrm{Na}}$, whereas only $30 \%$ of $\mathrm{N}$ and $\mathrm{NH}$ myocytes have $\mathrm{I}_{\mathrm{Na}}(342)$. Accordingly, Nav1.5 is absent or poorly expressed in the inferior nodal extension and compact node ( $\mathrm{N}$ myocytes), and has intermediate expression in the human transitional zone (AN myocytes) compared to the working atrial myocardium $(197,198,583)$.

In addition to differential ion channel expression throughout the AVN, there is also a diversity of gap junction expression, which contributes to the emergent function of the AVN. It has been known since the early work of Pollack (389) that cell-cell coupling in the AVN is poor. Indeed, there is a paucity of gap junctions in the AVN as well as a lack of Cx43 in the compact AVN and inferior nodal extension of the rat, rabbit, and human (27, 197, 198). In contrast, the small-conductance $C x 45$ is mainly expressed in these regions $(119,120)$. Expression of $\mathrm{Cx} 43$ is also reduced in the transitional zone of the rat, rabbit, and human, but is expressed in the penetrating bundle of the rabbit and human (but not rat) (27, 197, 198). The large-conductance $\mathrm{Cx} 40$ is not expressed in the inferior nodal extension of the rat and human, but is expressed in the compact AVN and penetrating bundle $(27,197)$.

What are the functional consequences of this differential ion channel and gap junction expression? In a series of mathematical simulations in which ionic currents were scaled proportional to mRNA expression, Inada et al. showed that computed APs were indeed as expected, with the compact node and inferior nodal extension showing pacemaking activity and APs from these regions also displayed the slowest upstroke velocity (235). In a further series of simulations, it was also demonstrated that slow conduction through the human AVN depends on both the low expression of $\mathrm{Cx} 43$ and Nav1.5, as simulating just one of these conditions did not fully recapitulate the slow conduction recorded experimentally (150). 


\section{AVN Dysfunction}

Conduction through the AVN can be pathologically slowed, resulting in heart block. In firstdegree heart block, APs still propagate through the AVN, but are slowed, resulting in a prolongation of the P-R interval on the ECG. In second-degree heart block, only some of the APs propagate through the AVN resulting in some $\mathrm{P}$-waves without accompanying QRS complexes. Third-degree heart block is the absence of conduction from the atria to the ventricles. In this case, a ventricular escape rhythm is often present, which can originate from the His-Purkinje system (see below). The incidence of heart block increases with age (271) and with underlying cardiovascular disease, including HF (123), but heart block can also be congenital.

Inherited Syndromes-As in the SAN, mutations in SCN5A can also cause AVN dysfunction and heart block. In particular, progressive cardiac conduction defect (PCCD), also called Lev-Lenègre disease, is characterized by progressive dysfunction in impulse propagation through the His-Purkinje system (discussed below) that can result in complete AV block and even sudden death (396). Several loss-of-function mutations in SCN5A have been associated with PCCD $(58,426,534)$ and these patients may also exhibit BrS or LQTS $(272,396)$. Watanabe et al. recently identified mutations in SCN1B (the modulatory $\beta$ subunit of Nav1.5) in 3 families with heart block with or without BrS (547). Interestingly, mutations in KCNJ2 (responsible for Kir2.1 and $\mathrm{I}_{\mathrm{K} 1}$ ) have also been associated with sinus bradycardia and heart block $(11,590)$. This is surprising given that Kir2.1 and $\mathrm{I}_{\mathrm{K} 1}$ are largely absent from both the SAN and AVN. However, heart block may arise due to depolarization and loss of excitability in the working myocardium, thus hindering the spread of impulses from the conduction system to the working myocardium.

Acquired Syndromes-AV block is a common clinical feature of HF and is associated with increased mortality (123), yet very little is known about the structural and ionic remodeling that occur in the AVN as a result of HF. Early histological studies of the AVN of humans with HF documented fibrosis and hypertrophy $(367,466)$. These findings were confirmed recently in a detailed study of the AVN in failing rat hearts following myocardial infarction (579). Yanni et al. found AVN dysfunction accompanied by fibrosis, apoptosis, cellular hypertrophy, and importantly, a downregulation of HCN4 in failing hearts (579). These histological and molecular features likely contribute to slowing of AV conduction and heart block in HF.

\section{His-Purkinje System}

Function-The His-Purkinje system represents the ventricular portion of the specialized conduction system and is essential for proper excitation and contraction of the ventricles. The His bundle is the insulated component of the AV conduction axis and, in normal hearts, provides the only AV conduction pathway. The His bundle then bifurcates to form the right and left bundle branches, which run toward the apex of the heart and are insulated from the underlying myocardium by connective tissue sheaths (13). This ensures that the AP is conducted to the apex of the ventricles without first activating the base of the heart. Purkinje networks are formed at the terminations of the bundle branches and are complex threedimensional structures with both free-running and subendocardial fibers. At specific sites, 
the insulating sheath is lost, allowing the Purkinje network to excite the ventricular myocardium (486).

The main function of the His-Purkinje system is to rapidly conduct the AP throughout the ventricles to ensure rapid and efficient ventricular excitation and therefore, coordinated contraction. In addition to rapid conduction of the ventricular AP, the His-Purkinje system can also act as a backup pacemaker in the event of complete heart block. The cells of the Purkinje network are therefore very specialized in order to produce both rapid conduction and, if necessary, a pacemaker potential.

Ionic Mechanisms and Molecular Bases-One factor contributing to fast conduction in the Purkinje fibers is abundant expression of both the large- and intermediateconductance gap junctions, Cx40 and Cx43 $(26,178,190)$. Unlike the SAN and AVN, there is little or no expression of the small-conductance $\mathrm{Cx} 45$ (26). Another contributor to fast conduction is the Purkinje AP itself. Unlike the SAN and AVN, the Purkinje AP is not nodal like, but rather has a faster upstroke velocity, higher amplitude, and is longer in duration than the ventricular AP $(21,381,406)$. The fast upstroke and large amplitude of the AP contribute to fast conduction. Computer simulations have suggested that differences between the Purkinje and ventricular APs are due to the presence of $\mathrm{I}_{\mathrm{CaT}}$ in the Purkinje cells but not in the ventricular muscle and increased density of $\mathrm{I}_{\mathrm{Na}}$ and $\mathrm{I}_{\mathrm{NaL}}$ and decreased density of $\mathrm{I}_{\mathrm{CaL}}, \mathrm{I}_{\mathrm{Kr}}, \mathrm{I}_{\mathrm{Ks}}$, and $\mathrm{I}_{\mathrm{K} 1}$ in Purkinje cells (25). For a complete review of ionic currents in Purkinje fibers, see Dun and Boyden (154).

The profile of ion channel expression in Purkinje fibers appears to support the observed AP differences between Purkinje cells and the ventricular myocardium. For example, rabbit Purkinje fibers have increased expression of Nav1.5 mRNA compared to the ventricular myocardium (26), which may contribute to the fast AP upstroke. Rabbit Purkinje fibers also have lower expression of Cav1.2, Kv11.1, Kv7.1, and Kir2.1 mRNA (26), which may contribute to lower densities of $\mathrm{I}_{\mathrm{CaL}}, \mathrm{I}_{\mathrm{Kr}}, \mathrm{I}_{\mathrm{Ks}}$, and $\mathrm{I}_{\mathrm{K} 1}$, respectively, and would contribute to the increased APD observed in Purkinje fibers.

Purkinje fibers can also show pacemaking activity, although it is slower than that of the SAN and AVN. Normally, pacemaking in the Purkinje fibers is suppressed by 'overdrive suppression', in which the Purkinje fibers are excited during sinus rhythm at frequencies higher than their intrinsic rate. This leads to an increase in $\left[\mathrm{Na}^{+}\right]_{\mathrm{i}}$ and enhanced $\mathrm{Na}^{+} / \mathrm{K}^{+}$ pump activity that causes membrane hyperpolarization and therefore a suppression of diastolic depolarization $(75,263)$. However, during conditions of AV block, the Purkinje fibers are capable of pacing the ventricles.

Similar to other pacemaking tissues, several ionic currents likely contribute to diastolic depolarization in Purkinje fibers, including $\mathrm{I}_{\mathrm{f}}(139,140)$. Accordingly, robust expression of HCN channels has been documented in the Purkinje fibers of several species, including human $(26,178,448)$. There is lower density of $\mathrm{I}_{\mathrm{K} 1}(122)$ in Purkinje fibers that is accompanied by reduced expression of Kir2.1 $(26,178)$, which likely facilitates pacemaking (25). Purkinje fibers are also susceptible to $\mathrm{Ca}^{2+}$ waves occurring as a result of spontaneous $\mathrm{Ca}^{2+}$ release from the SR, which leads to $\mathrm{Ca}^{2+}$ extrusion via NCX and a net transient inward 
current $\left(\mathrm{I}_{\mathrm{ti}}\right)$ that can contribute to diastolic depolarization (73). Thus, it appears as if the $\mathrm{Ca}^{2+}$ clock may have a role in pacemaking in Purkinje fibers. This same mechanism, however, also leads to pathological DADs and ectopic beats arising from the Purkinje fibers $(71,73)$, which have been shown to be significant contributor to arrhythmia in a number of cardiac pathologies $(71,72,99)$.

Involvement in Disease-The His-Purkinje system plays a role in the initiation and/or maintenance of ventricular arrhythmias in a number of cardiac pathologies, both acquired and genetic. For example, slowing of conduction in the His-Purkinje network can lead to bundle branch reentry and ventricular tachycardia (VT). The most common form of this arrhythmia, often occurring in patients with dilated cardiomyopathy, involves retrograde activation of the left bundle branch and antegrade activation of the right bundle branch (29). The long AP of Purkinje cells coupled with the voltage- and time-dependent properties of $\mathrm{I}_{\mathrm{CaL}}$ also make Purkinje fibers susceptible to EADs due to reactivation of $\mathrm{I}_{\mathrm{CaL}}(217,241)$. These EADs may initiate torsade de pointes arrhythmias in patients with long QT syndrome (41).

As described above, Purkinje cells are also susceptible to DADs and triggered APs due to spontaneous SR $\mathrm{Ca}^{2+}$ release (73). Triggered APs arising from the Purkinje fibers are known to be an important initiator of ventricular arrhythmias following myocardial infarction (MI) (240, 473). Accordingly, Boyden and colleagues found that Purkinje cells isolated from the infarct zone of the canine heart 48 hours after MI have 5 times as many spontaneously occurring $\mathrm{Ca}^{2+}$ wavelets than do normal Purkinje cells, suggesting a role for Purkinjemediated DADs in arrhythmias following MI $(71,72)$. Purkinje-mediated DADs have also been implicated in the initiation of arrhythmias in CPVT. Purkinje cells isolated from a mouse model of CPVT (RyR2 ${ }^{\mathrm{R} 4496 \mathrm{C}}$ ) showed high susceptibility to DADs and triggered APs (99). Optical mapping studies of these hearts revealed that focal arrhythmic activity originated from the Purkinje fibers.

\section{Ventricle}

Function

Passive filling of blood from the atria into the ventricles occurs while the ventricles are relaxed and the ventricular blood pressure is less than the atrial pressure. Following atrial depolarization, ventricular depolarization can be observed on an ECG as the QRS complex. Ventricular depolarization causes a rise in cytosolic $\mathrm{Ca}^{2+}$ which triggers the ventricular muscle to contract (systole), and in turn, pressure rises inside the ventricles causing the atrioventricular valves to close (isovolumetric contraction). Once the pressure inside the ventricles exceeds the arterial pressure, both the pulmonary and aortic valves open, allowing for proper ejection of blood into the pulmonary and systemic circulation. During systole, ventricular repolarization occurs and is observed at the $\mathrm{T}$ wave of the ECG. Repolarization allows for removal of cytosolic $\mathrm{Ca}^{2+}$ and relaxation of ventricular myocytes (diastole). Collectively, the electrical properties of the ventricles (depolarization and repolarization) can be described on an ECG as the QT interval. Alterations in the duration of the QT interval in disease, typically observed as a prolongation, act as an indication of altered functional properties of ion channels or regulatory proteins during inherited or acquired 
diseases $(417,438,485)$. The dysfunction of ion channels can lead to a disruption in the normal propagation of the AP waveform ultimately leading to arrhythmia. In particular, prolongation of the QT interval increases the risk for polymorphic ventricular tachyarrhythmias, such as torsades de pointes (TdP) and may ultimately lead to ventricular fibrillation or sudden cardiac death.

\section{Ionic Mechanisms and Molecular Bases}

From the AVN, the AP waveform propagates into the ventricular tissue via the conductive cells of the bundle of His and Purkinje fibers. Similar to the atrial AP, ventricular $\mathrm{E}_{\mathrm{m}}$ depolarization and the rapid upstroke of the ventricular AP occurs due to the fast activation of voltage dependent $\mathrm{Na}^{+}$channels (Nav), which conduct a large, inward $\mathrm{I}_{\mathrm{Na}}$. The ventricular AP reaches a more positive $\mathrm{E}_{\mathrm{m}}(\sim 20 \mathrm{mV} v s .0 \mathrm{mV})$, has a faster upstroke velocity ( $\sim 372 \mathrm{~V} / \mathrm{s} v s .140 \mathrm{~V} / \mathrm{s})$, and has a longer plateau phase than the atrial $\operatorname{AP}(193,194)$. Rapid inactivation of Nav channels and the activation of transient outward $\mathrm{Kv}$ channels that conduct outward $\mathrm{I}_{\text {to }}$ (which is a summation of $\mathrm{I}_{\mathrm{to}, \mathrm{f}}$ and $\mathrm{I}_{\mathrm{to}, \mathrm{s}}$ ) lead to a partial repolarization of the ventricular $\mathrm{E}_{\mathrm{m}}$ known as the 'notch' phase of the ventricular AP $(37,351)$. L-type Cav channels also activate in response to $\mathrm{E}_{\mathrm{m}}$ depolarization, but the time course of activation is slower than Nav channels (Cav channels peak within $20 \mathrm{~ms} v \mathrm{~s}$. Nav channels $<1 \mathrm{~ms}$ ). When activated, inward $\mathrm{I}_{\mathrm{CaL}}$ initiates $\mathrm{Ca}^{2+}$-induced $\mathrm{Ca}^{2+}$ release from the SR, via cardiac RyRs and increases $\left[\mathrm{Ca}^{2+}\right]_{\mathrm{i}}$. The rise in $\left[\mathrm{Ca}^{2+}\right]_{i}$ generates a contraction as $\mathrm{Ca}^{2+}$ binds to the myofilaments of the ventricular myocyte. $\left[\mathrm{Ca}^{2+}\right]_{\mathrm{i}}$ is extruded in a similar manner as the atria via the electrogenic NCX and $\mathrm{Ca}^{2+}$-ATPase across the plasmalemma and resequestered into the SR via SERCA (47). The delayed rectifier Kv channels are the slowest to activate. These channels activate during the plateau phase to conduct outward $\mathrm{I}_{\mathrm{K}}$ predominantly consisting of $\mathrm{I}_{\mathrm{Kr}}$ and $\mathrm{I}_{\mathrm{Ks}}$, which differ in time- and voltage-dependence, regional distribution, and drug sensitivity (331). During the plateau phase, the AP remains depolarized and refractory for hundreds of milliseconds because of the balance between inward $\mathrm{I}_{\mathrm{CaL}}$ and outward $\mathrm{I}_{\mathrm{K}}$. This phase is essential for the E-C coupling and the duration of the plateau phase is important for normal propagation of the AP waveform. As Cav channels inactivate during the plateau phase, the outward $\mathrm{I}_{\mathrm{K}}$ predominates, and repolarization occurs. The inward rectifying $\mathrm{I}_{\mathrm{K} 1}$ (carried by Kir channels) also contributes to repolarization. Kir channels are most permeable at negative $E_{m}$ and contribute to setting the resting $E_{m}$ of ventricular myocytes $(306,354)$. Figure 7 displays a simulated human ventricular AP with corresponding $\mathrm{Ca}^{2+}$ transient (CaT) and the major ionic currents that shape the ventricular AP waveform (194).

\section{Species Differences}

Many studies of cardiac cellular electrophysiology are performed in non-human species such as mouse, rat, guinea pig, rabbit, or canine. Species-specific differences of the ventricular AP are prevalent in, but not limited to, ion channel or regulatory protein expression, AP repolarization, arrhythmia mechanisms, rate-dependent behaviors, and drug responses (e.g., Figure 8D). These distinct ionic current profiles and AP waveforms correlate with interspecies differences in heart rate (HR) as well (Figure 8A). Smaller animals typically, have high HR such as mouse or rats ( 600 or 400 bpm, respectively); whereas, larger mammals have a slower HR such as rabbits or dogs ( 200 or 100 bpm, respectively). 
Humans have a much slower HR of around $60 \mathrm{bpm}$. These profound differences need to be kept in mind when interpreting data from various animal species.

One of the most obvious differences in the ventricular AP of mice and rats compared to larger species is the triangular shape and lack of a distinct plateau phase. The ventricular APD of rodents lasts $\sim 35 \mathrm{~ms}$; whereas, the ventricular AP of human, canine, rabbit, and guinea pig display a prominent plateau phase and a long APD lasting hundreds of milliseconds. Differences in expression of repolarizing $\mathrm{K}^{+}$channels account mostly for the interspecies heterogeneity of the ventricular AP waveform, but variations in $\mathrm{Na}^{+}$and $\mathrm{Ca}^{2+}$ channel expression and current densities are also species-specific.

Kv Channels-Of the voltage-gated ion channels, Kv channels are the most diverse superfamily of ion channels and diversity is not restricted to cell type or cell function. Interspecies differences in $\mathrm{K}^{+}$channel expression or function in the ventricles have greater impact on AP shape and duration compared to $\mathrm{Na}^{+}$or $\mathrm{Ca}^{2+}$ channels.

$\mathrm{I}_{\mathrm{to}}$ activates and inactivates rapidly subsequent to $\mathrm{E}_{\mathrm{m}}$ depolarization and is present in most mammalian ventricular myocytes such as rat, mouse, rabbit, canine, and human $(22,44,56$, $183,218,244,298,491,512,550)$. $\mathrm{I}_{\text {to }}$ can be dissected into two distinct components, $\mathrm{I}_{\mathrm{to}, \mathrm{f}}$ and $\mathrm{I}_{\mathrm{to}, \mathrm{s}}$ that differ in biophysical properties and conducting a-subunits (359). $\mathrm{I}_{\mathrm{to}, \mathrm{f}}$ and $\mathrm{I}_{\mathrm{to}, \mathrm{s}}$ both activate and inactivate rapidly, but $\mathrm{I}_{\mathrm{to}, \mathrm{s}}$ recovers very slowly from steady-state inactivation compared to $\mathrm{I}_{\mathrm{to}, \mathrm{f}}$. In rat and mouse, $\mathrm{I}_{\mathrm{to}}$ is large and is the predominant repolarizing $\mathrm{K}^{+}$-current (206). The high density of $\mathrm{I}_{\mathrm{to}}$ contributes to early repolarization and lack of plateau phase in the ventricular AP of these species. In humans and canine, $\mathrm{I}_{\text {to }}$ rapidly, but only partially, repolarizes the membrane during the notch phase of the ventricular AP. As discussed earlier, $\mathrm{I}_{\text {to }}$ density in human and canine is a reflection of the protein and mRNA expression levels of KChIP2; whereas regional heterogeneities in $\mathrm{I}_{\mathrm{to}, \mathrm{f}}$ in mice and rats is a reflection of the expression levels of Kv4.2 (143, 144, 409, 555). Additionally, in canine and humans, $\mathrm{Kv} 4.3$ is the principle a-subunit conducting $\mathrm{I}_{\mathrm{to}, \mathrm{f}}$ and Kv1.4 conducts $I_{t o, s}(144,266,299,409,551)$. In mice and rats, both Kv4.2 and Kv4.3 asubunits have been shown to conduct $\mathrm{I}_{\mathrm{to}, \mathrm{f}}$, and similarly $\mathrm{Kv} 1.4$ protein or mRNA is expressed ventricular myocytes conducting $\mathrm{I}_{\mathrm{to}, \mathrm{s}}(172,203,204)$. $\mathrm{I}_{\mathrm{to}}$ in rabbits mainly consists of $\mathrm{I}_{\mathrm{to}, \mathrm{s}}$ (conducted via Kv1.4), and in guinea pigs, $\mathrm{I}_{\mathrm{to}, \mathrm{f}}$ has not been detected in atrial or ventricular myocytes $(166,170,236)$. Indeed, disruption of either $K c n d 2$ (encoding Kv4.2) and Kcnip2 (encoding KChIP2) or Kcna4 (encoding Kv1.4) in mice eliminates ventricular $\mathrm{I}_{\mathrm{to}, \mathrm{f}}$ and $\mathrm{I}_{\mathrm{to}, \mathrm{s}}$, respectively, and increases the risk of APD prolongation and arrhythmias $(32,204,268)$. Decreases in $\mathrm{I}_{\mathrm{to}, \mathrm{f}}$ cause marked alterations in ventricular repolarization that lead to APD prolongation in human and canine HF (349).

The delayed rectifier $\mathrm{K}^{+}$-current $\left(\mathrm{I}_{\mathrm{K}}\right)$ is a major outward current responsible for the repolarization of the plateau phase to the resting $E_{m}$ of the ventricular AP in humans, rabbit, canine, and guinea pig (423). $\mathrm{I}_{\mathrm{K}}$ consists of a slowly activating $\left(\mathrm{I}_{\mathrm{Ks}}\right)$ and rapidly activating $\left(\mathrm{I}_{\mathrm{Kr}}\right)$ components that differ in sensitivity to drugs, regional distribution, time-, and voltagedependent properties $(422,443)$. $\mathrm{I}_{\mathrm{Ks}}$ and $\mathrm{I}_{\mathrm{Kr}}$ were first dissected in guinea pig atrial and ventricular cells and later discovered in human, canine, and rabbit myocytes $(227,286,300$, $418,511,512,514) . \mathrm{I}_{\mathrm{Kr}}$ is conducted via Kv11.1 a-subunits (otherwise known as the ether- 
a-go-go related-ERG1 or hERG for the human protein) and activates rapidly upon depolarization (421). $\mathrm{I}_{\mathrm{Kr}}$ inactivation occurs at a much faster rate $\left(\tau_{\text {inact }}<20 \mathrm{~ms}\right)$ than activation ( $\tau_{\text {act }}>100 \mathrm{~ms}$ ) and $\mathrm{I}_{\mathrm{Kr}}$ remains mostly inactivated during the AP upstroke and plateau phase $(351,490)$. Therefore, during early-repolarization, Kv11.1 channels recover from inactivation and $\mathrm{I}_{\mathrm{Kr}}$ primarily drives ventricular repolarization during basal conditions. Kv11.1 exists as two splice variants (Kv11.1a and Kv11.1b) and evidence suggests that Kv11.1 interacts with several KCNE $\beta$-subunits (KCNE1 and KCNE2) that may be important for native $\mathrm{I}_{\mathrm{Kr}}$ function $(1,277,305,324)$.

$\mathrm{I}_{\mathrm{Ks}}$ is conducted by a macromolecular complex that minimally consists of Kv7.1 a-subunits (formerly known as KvLQT1 or KCNQ1) and KCNE1 $\beta$-subunits (formerly known as minK or IsK) $(31,420)$. Co-assembly of Kv7.1 and KCNE1 is critical for native $\mathrm{I}_{\mathrm{Ks}}$ and $\mathrm{KCNE} 1$ increases unitary conductance, positively shifts the voltage dependence of activation, slows activation and deactivation kinetics, and suppresses inactivation of Kv7.1. Kv7.1 can interact with the other KCNE subunits (KCNE2-5) that are expressed at varying levels in the human heart $(308,309)$. Each KCNE subunit uniquely alters $\mathrm{I}_{\mathrm{Ks}}$ function when coexpressed in heterologous systems. Co-expression of KCNE2 with Kv7.1 generates small, constitutive currents by increasing the open probability of Kv7.1 at negative or resting $\mathrm{E}_{\mathrm{m}}$ and co-expression with KCNE3 generates large, constitutive currents $(434,484)$. Coexpression of Kv7.1 with KCNE4 or KCNE5 reduces outward current and shifts the voltage dependence of activation to very positive $\mathrm{E}_{\mathrm{m}}(42)$. Typically, in most large mammals (such as rabbit, canine, and human), $\mathrm{I}_{\mathrm{Ks}}$ density has been measured to be much lower than $\mathrm{I}_{\mathrm{Kr}}$, and as stated, $\mathrm{I}_{\mathrm{Kr}}$ plays a prominent role in ventricular repolarization in the absence of $\beta$ adrenergic stimulation (245). However, in guinea pig ventricles $\mathrm{I}_{\mathrm{Ks}}$ plays a greater role in normal repolarization because it is much larger, activation kinetics are faster, and deactivation kinetics are slower than human $\mathrm{I}_{\mathrm{Ks}}(227,454)$. Therefore, rabbit and/or canine $\mathrm{I}_{\mathrm{Ks}}$ more resemble human $\mathrm{I}_{\mathrm{Ks}}$ and are more suitable to use when studying the function and regulation of $\mathrm{I}_{\mathrm{Ks}}(212,213,227,286,300,418)$. During $\beta$-adrenergic stimulation, PKA phosphorylation of the Kv7.1 N-terminus causes an increase of $\mathrm{I}_{\mathrm{Ks}}$ that is important for normal ventricular AP shortening $(321,525,532,533)$. Mutations associated with congenital arrhythmia syndromes (type 1 long QT syndrome) may disrupt the $\beta$-adrenergic upregulation of $\mathrm{I}_{\mathrm{Ks}}$ and arrhythmogenic events are typically triggered during $\beta$-adrenergic stimulation, emphasizing the importance of $\mathrm{I}_{\mathrm{Ks}}$ to normal ventricular repolarization (35, 214). Additionally, binding of AKAP9 (Yotiao) to the zipper motif on the C-terminus of Kv7.1 is important for recruitment of PKA and protein phosphatases to Kv7.1 and ultimately, $\beta$-adrenergic upregulation of $\mathrm{I}_{\mathrm{Ks}}$. Congenital mutations within the genes encoding KCNE1 and AKAP9 are also linked to type 5 and type 11 long QT syndromes (LQT5 and LQT11), respectively and can disrupt $\beta$-adrenergic regulation of $\mathrm{I}_{\mathrm{Ks}}(104,462)$.

The interspecies differences of the contribution of $\mathrm{I}_{\mathrm{Kr}}$ and $\mathrm{I}_{\mathrm{Ks}}$ to ventricular repolarization can also be observed selective drug block. Experimental studies in isolated ventricular myocytes and computational simulations of the ventricular AP show that complete block of $\mathrm{I}_{\mathrm{Ks}}$ does not significantly alter APD or AP morphology in humans or dog $(194,247,416)$. However, blockage of $\mathrm{I}_{\mathrm{Kr}}$ in humans or dog does cause APD prolongation and alters repolarization kinetics in human myocytes (Figure 8D). This coincides with the assumption that human $\mathrm{I}_{\mathrm{Ks}}$ contributes minimally to normal repolarization, but is critical to APD 
shortening during $\beta$-adrenergic stimulation. Furthermore, when the repolarization reserve is compromised (by drugs or diseases that reduce $\mathrm{I}_{\mathrm{Kr}}$ or $\mathrm{I}_{\mathrm{K} 1}$ ) $\mathrm{I}_{\mathrm{Ks}}$ may play a more prominent role in preventing ventricular APD prolongation. Interestingly, computational simulations predict that blocking $\mathrm{I}_{\mathrm{Kr}}$ prolongs the human ventricular APD and when blocking both $\mathrm{I}_{\mathrm{Kr}}$ and $\mathrm{I}_{\mathrm{Ks}}$ the prolongation is even greater $(194,248)$. Due to the unusually large contribution of $\mathrm{I}_{\mathrm{Ks}}$ to normal repolarization in guinea pig, blocking $\mathrm{I}_{\mathrm{Ks}}$ without $\beta$-adrenergic stimulation significantly prolongs the ventricular APD (Figure 8D); whereas in human, dog, and rabbit no prolongation occurs $(68,194,247,282,511,520)$.

In adult rat and mouse, $\mathrm{I}_{\mathrm{Kr}}$ and $\mathrm{I}_{\mathrm{Ks}}$ are mostly immeasurable $(246,568)$. Several delayed rectifier $\mathrm{K}^{+}$-currents have been identified in adult mouse or rat ventricular myocytes $\left(\mathrm{I}_{\mathrm{K}, \text { slow1 }}, \mathrm{I}_{\mathrm{K}, \text { slow2 } 2}, \mathrm{I}_{\mathrm{ss}}\right)(22,216,567)$. Rodent ventricular $\mathrm{I}_{\mathrm{ss}}$ is a steady-state non-inactivating outward $\mathrm{K}^{+}$-current that resembles human atrial $\mathrm{I}_{\mathrm{Kur}}$ and is inhibited by high concentrations of 4-AP (54). We recently incorporated rodent delayed rectifier $\mathrm{K}^{+}$-currents, rodent $\mathrm{I}_{\mathrm{to}}$, and rodent $\mathrm{I}_{\mathrm{K} 1}$ into a computational model of a rabbit ventricular AP and showed the progression of how repolarizing $\mathrm{K}^{+}$-currents alter the AP waveform (339). Altering $\mathrm{I}_{\mathrm{to}}$ voltage-

dependence and kinetics of activation and inactivation to resemble current properties in mice

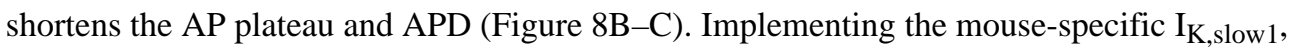
$\mathrm{I}_{\mathrm{K}, \text { slow2 }}$, and $\mathrm{I}_{\mathrm{sS}}$ shortened the APD further and eliminated the AP plateau (Figure 8B-C). Lastly, $\mathrm{I}_{\mathrm{K} 1}$ was reduced to a similar magnitude observed in isolated mouse myocytes and caused prolongation of the late repolarization phase and AP triangulation (Figure 8B-C). This transformation of a rabbit-like ventricular AP to an AP that is more representative of a mouse or rat suggests that the species-dependent AP differences are largely accounted for by the heterogeneity of repolarizing $\mathrm{K}^{+}$-currents.

Inward Rectifying Channels- $\mathrm{I}_{\mathrm{K} 1}$ is important for late phase repolarization of the ventricular $\mathrm{AP}(306)$. $\mathrm{I}_{\mathrm{K} 1}$ is also the primary conducting current during diastole that sets the resting $E_{m}$ (351). Indeed, $I_{K 1}$ is present in ventricular myocytes from most species (mouse, rat, canine, rabbit, guinea pig, and human) and $\mathrm{I}_{\mathrm{K} 1}$ is conducted through Kir2.x a-subunits $(153,302,354,355,450,474,512)$. Kir a-subunits differ from Kv a-subunits in that they only consist of two transmembrane segments ( $\mathrm{Kv}$ a-subunits have six), are voltageindependent, conduct large, inward $\mathrm{K}^{+}$-current at $\mathrm{E}_{\mathrm{m}}$ more negative than $\mathrm{E}_{\mathrm{K}}$, and conduct small, outward $\mathrm{K}^{+}$-current at $\mathrm{E}_{\mathrm{m}}$ more positive than $\mathrm{E}_{\mathrm{K}}$ (354). In mice, there is evidence suggesting two proteins conduct $\mathrm{I}_{\mathrm{K} 1}$. Disruption of the genes that encode Kir2.1 and Kir2.2 ( $K C N J 2$ and $K C N J 12$, respectively) caused a reduction in $\mathrm{I}_{\mathrm{K} 1}$ compared to wild-type mouse ventricular myocytes $(587,588)$. In humans, Kir 2.1 is generally considered the main asubunit underlying $\mathrm{I}_{\mathrm{K} 1}$ with predominant expression in the ventricles compared to the atria $(136,178,543)$. A recent study comparing canine and human ventricular myocytes showed that Kir2.1 mRNA expression was significantly higher in canine than human compared to other Kir2.x isoforms. Additionally, Kir2.1-4 mRNA or protein was indeed present, and Kir2.1 and Kir2.3 mRNA or protein were expressed at similar levels in myocytes isolated from human (248). These data suggest the possibility that heteromeric Kir2.x channels may conduct $\mathrm{I}_{\mathrm{K} 1}$ in humans (432). Mutations in the gene, KCNJ2, encoding Kir2.1 cause a dominant-negative effect on $\mathrm{I}_{\mathrm{K} 1}$ and are linked to congenital arrhythmia syndromes such as Andersen-Tawil syndrome (type 7 long QT syndrome) which may lead to periodic paralysis, 
ventricular arrhythmias, and dysmorphic features $(476,488)$. To date, no mutations in genes encoding other Kir2.x a-subunits have been reported, supporting the predominant role Kir2.1 has in conducting human $\mathrm{I}_{\mathrm{K} 1}$.

$\mathrm{I}_{\text {KATP }}$ is another inward rectifier $\mathrm{K}^{+}$-current important for the ventricular AP and is important for cardioprotection in ischemic conditions $(351,425,469)$. mRNA of two isoforms, Kir6.1 and Kir6.2, are expressed in human ventricles and can bind to two ATPbinding cassette proteins, SUR1 and SUR2. Kir6.2 is most likely more abundant, and is associated with SUR2A $(92,173,178)$. Kir6.x a-subunits conduct $\mathrm{I}_{\text {KATP }}$ and are typically closed in normal conditions due to high levels of intracellular ATP in normally functioning ventricular tissue. The channels open during metabolic insult subsequent to increased cardiac output, hypoxia, or ischemia $(92,237,599)$. Increasing $\mathrm{I}_{\mathrm{KATP}}$ acts to shorten the ventricular APD to reduce calcium entry and reduce contractility, which ultimately decreases energy consumption protecting the cell. Opening of Kir6.x channels is thought to be cardioprotective due to ischemic preconditioning, which is lost in Kir6.2 knockout mice. The Kir6.2 knockout mice were also more vulnerable to ventricular arrhythmia and sudden cardiac death when exposed to decompensated HF, exercise stress, or hemodynamic stress $(253,303,468,571)$. Additional studies revealed that Kir6.1 or SUR1 knockout mice do not affect ventricular $\mathrm{I}_{\mathrm{KATP}}$, but atrial $\mathrm{I}_{\mathrm{KATP}}$ was abolished (442). In dogs, specific blockade of Kir6.x channels prevented ischemic preconditioning as well. Together, these results suggest the importance of $\mathrm{I}_{\mathrm{KATP}}$ and Kir6.2 has in ischemic preconditioning in several species.

Nav Channels-Conducting $\mathrm{I}_{\mathrm{Na}}$, the principal Nav a-subunit expressed in mammalian ventricular myocytes is Nav1.5, encoded by SCN5A (584). Although, Nav1.5 is blocked by tetrodotoxin (TTX) at $\mu \mathrm{M}$ concentrations, it is considered TTX-resistant compared to other Nav subunits that are blocked by nM concentrations of TTX. Nav1.5 has a single amino acid change from phenylalanine to cysteine in the pore region of domain I that causes a large reduction in TTX sensitivity (424). In functional studies, Nav1.5 are found roughly homogenously distributed in the t-tubules and external sarcolemma, whereas non-cardiac Nav isoforms (whose role is still poorly understood) are more concentrated at the t-tubules (80). Experimental results using immunocytochemistry in isolated rat ventricular myocytes revealed that Nav channels are localized at the sarcolemma and t-tubule, and interestingly at intercalated disks (117). These data suggest that different pools of Nav1.5 may serve a different functional purpose in different regions of the myocyte (i.e. channels at intercalated disks may be important for conduction or channels at $t$-tubules may be important for sarcolemma depolarization). Protein or mRNA of several other TTX-sensitive Nav asubunits (Nav1.1, Nav1.2, Nav1.3, Nav1.4, Nav1.6, and Nav2.1) have also been identified in ventricular myocytes of human, mouse, rat, and rabbit, but a clear role of these Nav channels has not been established $(178,267,316,351,382,430)$. A study comparing RNA isolated from whole hearts showed that mouse and rat hearts expressed higher levels TTX-sensitive Nav channels overall compared to humans $(61,137,598)$. The protein sequences of the different Nav channels are highly conserved across species implying the channel structure is likely also conserved.

Several mutations in SCN5A have been linked to type 3 long QT syndrome (LQT3), and typically cause an enhancement in $\mathrm{I}_{\mathrm{NaL}}$ (540). Normally, up to $99 \%$ of Nav channels are 
inactivated within a few milliseconds, but a small fraction of Nav channels may remain activated during the plateau phase and is defined as $\mathrm{I}_{\mathrm{NaL}}$. In situations where $\mathrm{I}_{\mathrm{NaL}}$ is increased (e.g. LQT3 or HF), ventricular APD prolongation occurs and increases the propensity to ventricular arrhythmia. Recently, genome- and phenome-wide association studies (GWAS and PheWAS, respectively) also suggest that single nucleotide polymorphisms (SNP) at chromosome 3 SCN5A-SCN10A loci associate with patient QRS duration and subsequent ventricular and atrial arrhythmia susceptibility. Interestingly, SNPs in SCN1OA (encoding the neuronal TTX-resistant Nav1.8 a-subunit) specifically associated with AF (405) and is consistent with a previous study of a large population that associated SCN10A SNPs with QRS duration and propensity for cardiac arrhythmia (100).

Cav Channels-The predominant $\mathrm{Ca}^{2+}$-current in the mammalian ventricles is $\mathrm{I}_{\mathrm{CaL}}$ and is conducted via CACNAIC-encoded Cav1.2 a1-subunits (457). $\mathrm{I}_{\mathrm{CaL}}$ is inactivated by both $\mathrm{Ca}^{2+}$-dependent (CDI) and voltage-dependent (VDI) mechanisms during the ventricular plateau phase (255). In the ventricular myocyte (and all other cardiac myocytes), Cav1.2 exists as a macromolecular complex associated with ancillary subunits such as $\beta 2 \mathrm{a}, \alpha 2 \delta$, and $\gamma(23,118,234,380)$. Therefore, in heterologous systems, Cav1.2 expression alone does not recapitulate native-like $\mathrm{I}_{\mathrm{CaL}}$, but rather requires co-expression with ancillary subunits, specifically $\beta 2 \mathrm{a}$. $\mathrm{I}_{\mathrm{CaL}}$ activates at more depolarized $\mathrm{E}_{\mathrm{m}}$ than the atrial specific $\mathrm{I}_{\mathrm{CaT}}$ (when $\mathrm{E}_{\mathrm{m}}$ is more positive than $-20 \mathrm{mV}$ compared to $-50 \mathrm{mV}$, respectively) and undergoes voltageand $\mathrm{Ca}^{2+}$-dependent inactivation more slowly $(38,91,97,98,378)$. Therefore, $\mathrm{L}-$ type $\mathrm{Ca}^{2+}$ channels and T-type $\mathrm{Ca}^{2+}$-channels have been referred to as high voltage-activated and low voltage-activated, respectively. The specific biophysical properties of $\mathrm{I}_{\mathrm{CaL}}$ are important for triggering SR $\mathrm{Ca}^{2+}$-release and can influence repolarization and ventricular APD. Mature human ventricular myocytes almost exclusively express Cav1.2 (178). Contrary to these findings, studies reported the presence of $\mathrm{I}_{\mathrm{CaT}}$ and/or Cav3.1 mRNA in neonatal mouse, rat, and rabbit ventricular myocytes $(379,553,554)$. Furthermore, $\mathrm{I}_{\mathrm{CaT}}$ and Cav3.1 mRNA is reexpressed in feline or rat disease models of ventricular hypertrophy $(320,362)$.

CACNAIC mutations (G406R and G402R) are linked to the extremely rare Timothy syndrome (formerly LQT8) and are associated with extreme QT prolongation, developmental delay, syndactyly, immune deficiency, cognitive deficits, and ventricular fibrillation.(461) Both mutations cause a gain-of-function phenotype by disrupting Cav1.2 inactivation that leads to an increase in $\mathrm{I}_{\mathrm{CaL}}$ and ventricular APD prolongation. In a transgenic mouse model of Timothy syndrome, $\mathrm{I}_{\mathrm{CaL}}$ was increased, ventricular $\mathrm{APD}_{90}$ was prolonged, $\left[\mathrm{Ca}^{2+}\right]_{\mathrm{i}}$ was elevated, and there was an increased frequency of EAD- and DADinduced arrhythmogenic events (110). These observed functional changes in $\mathrm{I}_{\mathrm{CaL}}$ are similar to the HF and CaMKII effects on $\mathrm{I}_{\mathrm{CaL}}$ discussed below.

\section{Atrioventricular Differences}

Ventricular myocytes maintain a slightly more hyperpolarized resting $\mathrm{E}_{\mathrm{m}}(\sim-85 \mathrm{mV})$ compared to atrial myocytes $(\sim-80 \mathrm{mV})$ and the plateau phase of a ventricular myocyte AP reaches a more depolarized $\mathrm{E}_{\mathrm{m}}(\sim 20 \mathrm{mV})(406,430,544)$. The ventricular AP plateau phase is also longer, $\mathrm{V}_{\mathrm{MAX}}$ of the AP upstroke is faster, and repolarization occurs at a faster rate 
than the atrial AP. Ventricular myocytes are also larger and have a greater surface:volume ratio than atrial myocytes due to a higher density of t-tubules.

The hyperpolarized resting $\mathrm{E}_{\mathrm{m}}$ is likely due to the larger $\mathrm{I}_{\mathrm{K} 1}$ measured and higher expression of Kir2.1 mRNA (encoded by KCNJ2) in ventricular myocytes $(136,161,178,183,543)$. In the atria, the predominant $\mathrm{I}_{\mathrm{K} 1}$ conducting a-subunit is Kir2.3 (encoded by KCNJ4) (178, 430). Ventricular $I_{t o, s}$ is larger in humans, which is consistent with a high ventricular expression of Kv1.4 and KChIP2 mRNA (178). However, $\mathrm{I}_{\mathrm{to}, \mathrm{f}}$ is less and the $\mathrm{V} 1 / 2$ of activation and inactivation are more positive in human ventricles compared to atrial tissue. These observations correspond to a lower expression of Kv4.3 mRNA and protein in human ventricles $(9,178)$. $\mathrm{I}_{\mathrm{Kur}}$ and $\mathrm{I}_{\mathrm{K}, \mathrm{Ach}}$ and their respective transcripts, Kv1.5 and Kir3.1 mRNA, are almost absent in human ventricular myocytes; whereas, both $\mathrm{K}^{+}$currents contribute significantly to the atrial AP $(135,151,161,178,430,542,586)$. However, a mutation in KCNJ5 (encoding Kir3.4) was recently linked to LQT13 in one family and Western blot analysis revealed the presence of Kir3.4 (and Kir3.1) in human ventricular tissue suggesting the role of $\mathrm{I}_{\mathrm{K}, \mathrm{ACh}}$ may be underestimated in ventricles (576). Additionally, $\mathrm{I}_{\mathrm{Kr}}$ and $\mathrm{I}_{\mathrm{Ks}}$ density and the mRNA expression are similar in human atrial and ventricular myocytes $(178,431)$.

The human ventricular AP morphology has a longer plateau phase due to an overall lower density of $\mathrm{K}^{+}$-currents activated during the notch phase (i.e. smaller $\mathrm{I}_{\text {to }}$ and $\mathrm{I}_{\mathrm{Kur}}$ during early repolarization). As ventricular repolarization occurs later in the AP time-course, more $\mathrm{I}_{\mathrm{Kr}}$ recovers from inactivation and contributes to a fast rate of repolarization compared to the atrium.

The principle $\mathrm{Na}$ channel a-subunit that conducts $\mathrm{I}_{\mathrm{Na}}$ in both atrial and ventricular myocytes is Nav1.5 (encoded by SCN5A) (178, 181, 430, 539). Studies using immunohistochemistry in rats suggested that Nav1.5 is expressed predominantly in intercalated discs and also in lateral membranes and the T-tubules (407). Importantly, differences in drug sensitivity and inactivation properties are present between $\mathrm{I}_{\mathrm{Na}}$ from either chamber and may be related to a higher availability of $\mathrm{I}_{\mathrm{Na}}$ or, to a lesser extent, a lower expression of the ancillary subunit, $\beta 1$, in the ventricles $(88,178)$. $\beta 1$ shifts the $V 1 / 2$ of inactivation of Nav1.5 to more positive $\mathrm{E}_{\mathrm{m}}$ (137). A more convincing argument on why inactivated state-dependent $\mathrm{Na}^{+}$channel blocker sensitivity is higher for atrial $\mathrm{I}_{\mathrm{Na}}$ is due to a depolarized resting $\mathrm{E}_{\mathrm{m}}$. As a result, this increases the probability of atrial Nav1.5 channels to be in an inactivated state at rest. Therefore, inactivated state-dependent $\mathrm{Na}^{+}$channel blockers have a higher propensity to block atrial $\mathrm{I}_{\mathrm{Na}}$ vs. ventricular $\mathrm{I}_{\mathrm{Na}}$; whereas, open state-dependent $\mathrm{Na}^{+}$channel blockers are not atrial selective (89).

Functional $\mathrm{I}_{\mathrm{CaL}}$ is present in atrial and ventricular myocytes and is conducted by Cav1.2 (encoded by CACNAIC) (457). In humans, mRNA expression of Cav1.2 is the highest of Cav channels in the atria and ventricles $(178,430)$. The mRNA of a secondary L-type Cav channel, Cav1.3, is expressed at higher levels in atrial cells compared to ventricular cells of human, mouse, and rabbit myocytes, although overall expression of Cav1.3 is low compared to Cav1.2 $(178,318,319,399)$. However, the contribution of Cav1.3 to the AP is greater in the SAN and AVN (see SAN and AVN sections above). In normal mammalian ventricular 
myocytes, $\mathrm{I}_{\mathrm{CaT}}$ is almost undetectable, but $\mathrm{I}_{\mathrm{CaT}}$ is present in canine, feline, guinea pig, and rat atrial myocytes $(290,351,430)$. Additionally, the mRNA expression of the $\mathrm{I}_{\mathrm{CaT}}$ conducting a-subunit, Cav3.1, is very low in humans, yet expression in ventricular myocytes is lower than in atrial myocytes (178). A Cav channel ancillary subunit, $\alpha 2 \delta 2$, which modulates both $\mathrm{I}_{\mathrm{CaL}}$ and $\mathrm{I}_{\mathrm{CaT}}$ was found to be expressed higher in human atrial myocytes than ventricular myocytes, suggesting an explanation for chamber-specific functional properties of these currents $(178,179)$.

Protein and mRNA expression of NCX1 are higher in human ventricular myocytes $v s$. atrial $(178,537)$. Subsequent studies that reduced maximal $\mathrm{I}_{\mathrm{NCX}}$ by $30 \%$ in a human atrial computational model from an existing ventricular model predicted an increased fraction of NCX active during the cardiac cycle $(193,194)$. This result is likely due to the atrial AP morphology causing a larger $\mathrm{I}_{\mathrm{CaL}}$ and slightly larger CaT that favors inward $\mathrm{I}_{\mathrm{NCX}}$. These simulations emphasize how the electrogenicity of $\mathrm{NCX}$ is sensitive to both $\mathrm{E}_{\mathrm{m}},\left[\mathrm{Ca}^{2+}\right]_{\mathrm{i}}$, and $\left[\mathrm{Na}^{+}\right]_{\mathrm{i}}$.

Gap junction hemichannels allow for direct electrical and metabolic coupling between adjacent cardiac myocytes (57). While both $\mathrm{Cx} 40$ (encoded by GJA5) and $\mathrm{Cx} 43$ (encoded by GJA1) protein and mRNA are highly expressed in atrial myocytes, $\mathrm{Cx} 43$ is the predominant ventricular connexin $(178,254,483,526)$. Expression of $\mathrm{Cx} 40$ is much stronger in atrial vs. ventricular tissue in humans, dogs, rabbits, guinea pigs, and mice $(178,254,319,430,516$, 526). Additionally, in humans, $\mathrm{Cx} 45$ mRNA was expressed at low levels compared to $\mathrm{Cx} 40$ and $\mathrm{Cx} 43$ in the atria and ventricles, respectively (178). The importance of $\mathrm{Cx} 43$ for ventricular conduction was observed in several studies that involved heterozygous or homozygous knockouts of $\mathrm{Cx} 43$ in mice. Both studies reported minimal effects in the atria; whereas, ventricular conduction was severely impaired highlighting the predominant role Cx43 has in the ventricles $(483,502)$.

SK channels are voltage-independent and have been identified to conduct an apaminsensitive $\mathrm{K}^{+}$current predominantly in normal human and mouse atrial myocytes compared to ventricular myocytes (569). Specifically, SK2 mRNA (KCNN2) expression was lower in human ventricular myocardium compared to the atria (161). In mice, SK1 and SK2 mRNA are expressed higher in the atria; whereas, SK3 mRNA is equally expressed in the atria and ventricles (495). $\mathrm{I}_{\mathrm{SK}}$ is important for late phase atrial repolarization and inhibition of $\mathrm{I}_{\mathrm{SK}} \mathrm{can}$ prolong the APD. In the rat, rabbit, dog, and human, $\mathrm{I}_{\mathrm{SK}}$ does not have a significant contribution to ventricular repolarization $(115,311,347)$. Subsequent studies have provided a possible role for $\mathrm{I}_{\mathrm{KAS}}$ in ventricular repolarization, but only in pathogenic situations when other $\mathrm{K}^{+}$channels are downregulated (3). $\mathrm{I}_{\mathrm{SK}}$ is upregulated in diseased myocytes from rabbit, rat, and human and may be important in human arrhythmogenesis $(102,115,202$, 229).

Understanding critical differences in ionic current densities, ion channel expression, drug sensitivities, or voltage- and time-dependent properties between ventricular and atrial myocytes are important for chamber specificity of anti-arrhythmic drug therapy. Utilization of a chamber specific approach for therapeutic intervention may aid in the prevention or reoccurrence of specific ventricular or atrial arrhythmias. 


\section{Ventricular Regional Differences}

Regional heterogeneity of the ventricular AP morphology has been thoroughly studied. AP differences exist when comparing the transmural heterogeneity across the ventricular wall, between the left and right chambers of the ventricles, and from the apical region to the base. Without electrical coupling via gap junctions, these differences are exacerbated, and the intrinsic AP of an isolated cell is due to the unique expression profile and function of ion channels and regulatory proteins of that particular cell $(70,556)$.

Transmural Differences-Three distinct AP waveforms have been distinguished from three predominant cell types contributing to the transmural heterogeneity of ventricular repolarization: the epicardial, midmyocardial (M-cells), and endocardial myocytes. The most notable differences among these three cell types are the large appearance of a 'spike and dome' (large notch phase) in the epicardical myocytes, and the M-cells having a prolonged APD by $\sim 100 \mathrm{~ms}$ compared to epi- and endocardial myocytes $(20,573)$. The APD of epicardial myocytes is shorter than endocardial myocytes; whereas, endocardial myocytes have a less pronounced notch phase (452). The transmural differences throughout the APD of epicardial, M-cells, and endocardial myocytes are important for determining the duration and shape of the T-wave on an ECG $(239,572)$. Drugs or diseases that selectively reduce $\mathrm{K}^{+}$-currents $\left(\mathrm{I}_{\mathrm{to}}, \mathrm{I}_{\mathrm{Kr}}\right.$, or $\left.\mathrm{I}_{\mathrm{Ks}}\right)$ or increase $\mathrm{I}_{\mathrm{Na}}$ or $\mathrm{I}_{\mathrm{CaL}}$ typically cause a greater APD prolongation of the M-cell than epi- or endocardial myocytes, in turn increasing the transmural heterogeneity of repolarization. The amplified transmural APD heterogeneity may culminate into reentrant arrhythmias (17). Therefore, abnormalities in transmural repolarization can be distinguished on an ECG and can be used for prognosis and treatment $(15,16,572)$.

The distinct notch phase in the AP waveform of epicardial myocytes has mainly been attributed to a large $\mathrm{I}_{\mathrm{to}}$ recorded from human, canine, feline, rabbit, and rat myocytes (116, $166,176,299,301,346,551)$. The ancillary subunit, KChIP2, modifies the function of Kv4.3 a-subunits, which conduct canine and human $\mathrm{I}_{\text {to }}(10,144,249)$. KChIP2 mRNA expression is highest in epicardial myocytes and lowest in endocardial myocytes (178, 409, 430). Kv4.3 transmural expression is not different, but only the KChIP2 expression correlates with the $\mathrm{I}_{\mathrm{to}, \mathrm{f}}$ gradient and prominence of the notch phase (epi > M-cells > endo). Kv4.2 mRNA has been shown to be minimally expressed in human and canine ventricular myocytes, but is important for $\mathrm{I}_{\text {to }}$ generation in mouse and rats $(143,144,178,409,430$, 594).

Another important finding is that $\mathrm{I}_{\mathrm{Ks}}$ recorded from M-cells is lower than that recorded from epi- or endocardial canine myocytes $(300,301) . \mathrm{I}_{\mathrm{Ks}}$ is important for normal repolarization of the ventricular AP and the reduction in $\mathrm{I}_{\mathrm{Ks}}$ contributes to the prolonged APD of M-cells. The $\mathrm{I}_{\mathrm{Ks}}$ macromolecular channel complex minimally consists of Kv7.1 a-subunit and KCNE1 $\beta$-subunit (formerly known as minK), encoded by $K C N Q 1$ and $K C N E 1$, respectively $(31,420) . K C N Q 1 \mathrm{mRNA}$ was found to be highest in left ventricular epicardium $v s$. endocardium and M-cells, and other studies have suggested that KCNE1 expression is unchanged transmurally $(178,377,430)$. Additionally, a dominant negative isoform of Kv7.1, encoded by $K C N Q 1 b$, was found expressed at high levels in M-cells, which could 
explain the reduction of $\mathrm{I}_{\mathrm{Ks}}$ (377). Drugs that specifically modulate $K C N Q 1$ splicing have been implicated in reducing $K C N Q 1 b$ and shortening the APD in canine M-cell (280). These findings could have great impact in treating disease that involves remodeling of $\mathrm{I}_{\mathrm{Ks}}$ or other repolarizing currents. In general, the more prominent $\mathrm{I}_{\mathrm{Ks}}$ in epi- and endocardial myocytes is protective against EADs and stimulus reentry compared to M-cells (86). There is a lack of clear evidence of transmural differences in the human or canine ventricles for $\mathrm{I}_{\mathrm{Kr}}$ and $\mathrm{I}_{\mathrm{K} 1}$, also important for ventricular repolarization, $(15,70,300,471)$.

Transmural differences in $\mathrm{I}_{\mathrm{Na}}$ have been identified, whereas recordings performed in canine M-cells show that $\mathrm{I}_{\mathrm{NaL}}$ in increased compared to epi- and endocardial myocytes, but these findings were not observed in guinea pig myocytes (600). A larger $\mathrm{I}_{\mathrm{NaL}}$ could contribute to the longer APD observed in M-cells. Several studies have also suggested that there is a larger $\mathrm{I}_{\mathrm{Na}}$ present or higher levels of Nav1.5 and $\beta 1$ mRNA in endocardial myocytes compared to epicardial myocytes isolated from rat, canines or humans and this coincides to a faster upstroke velocity $\left(\mathrm{V}_{\mathrm{MAX}}\right)$ of the endocardial $\mathrm{AP}(178,408,471)$. Another depolarizing current that is found to be larger in canine M-cells than epi- or endocardial myocytes is the sodium-calcium exchange current $\left(\mathrm{I}_{\mathrm{NCX}}\right)$ and the increased $\mathrm{I}_{\mathrm{NCX}}$ may contribute to the lengthened APD of M-cells (601).

Several studies suggest that $\mathrm{I}_{\mathrm{CaL}}$ is not different from canine epicardial, M-cells, or endocardial myocytes isolated from the left ventricle $(30,121)$. However, one study did suggest that canine endocardial myocytes have larger $\mathrm{I}_{\mathrm{CaL}}$ and the functional properties of $\mathrm{I}_{\mathrm{CaL}}$ differ in all three regions (535). Interestingly, in human Cav1.2 mRNA expression is highest in epicardial myocytes along with the transcripts for several important calcium handling proteins (RyR2, NCX1, SERCA2, calcineurin-a, and CALM3) (175, 178, 189, $293,392,536,566)$. The high expression of calcium handling proteins in human or canine epicardial myocytes results in a faster onset and time-to-peak of contraction, and a more rapid relaxation than endocardial myocytes $(121,175)$. Cx 43 protein, the main connexin expressed in ventricular myocytes, is expressed at higher levels in M-cells or endocardial cells than epicardial cells in dogs and mice, but there are no differences in humans or rats (70, 385, 570). Surprisingly, the atrial-specific Cx40 mRNA had a higher expression in left endocardium $v s$. left epicardium, although overall expression was less than Cx43 mRNA in the ventricles (178).

Left vs. Right Ventricle-The transmural AP gradient exists across the three layers of myocardium in the left and right ventricle, but overall, the left ventricular APD is longer compared to the right ventricular APD $(70,285,346)$. The shorter APD of right ventricular myocytes has been attributed to a greater $\mathrm{I}_{\text {to }}$ recorded from isolated canine and human right ventricular myocytes $(138,524)$. Indeed, mRNA and protein expression of KChIP2, a protein that modifies Kv4.3 a-subunits and increases $\mathrm{I}_{\mathrm{to}, \mathrm{f}}$ is expressed at higher levels in human and canine right ventricular myocytes compared to left ventricular myocytes (70, 138, 524). Canine expression of KChIP2 mRNA and protein closely match the differences of $\mathrm{I}_{\mathrm{to}, \mathrm{f}}$ in left and right ventricular myocytes and the transmural gradient of $\mathrm{I}_{\mathrm{to}}(400)$. Human and canine differences in density of $\mathrm{I}_{\mathrm{to}}$ tend to be controlled by the variable expression of $\mathrm{KChIP} 2$ and not the expression of Kv4.3. However, in rat and mouse, Kv4.2 and Kv4.3 a- 
subunits conduct $\mathrm{I}_{\mathrm{to}, \mathrm{f}}$, and differential expression of $\mathrm{Kv} 4.2 \mathrm{mRNA}$ and protein correlate with regional differences in $\mathrm{I}_{\text {to }}(144,249,409,555)$.

Another contributing factor to the shorter APD of the right ventricles is the density of $\mathrm{I}_{\mathrm{Ks}}$. Like $\mathrm{I}_{\mathrm{to}}$, $\mathrm{I}_{\mathrm{Ks}}$ measured from canine myocytes was larger in M-cells isolated from the right ventricle compared to the left (524). The larger $\mathrm{I}_{\mathrm{Ks}}$ correlates with larger protein expression of KCNE1 in right ventricular myocytes as well (401). KCNE1 expression modulates the $\mathrm{I}_{\mathrm{Ks}}$ conducting Kv7.1 a-subunit by slowing the time course of activation and deactivation, suppressing inactivation, positively shifting the voltage dependence of activation, and increasing the single unitary conductance $(31,420)$. No differences in other repolarizing $\mathrm{K}^{+}$currents such as $\mathrm{I}_{\mathrm{Kr}}$ or $\mathrm{I}_{\mathrm{K} 1}$ have been observed between left or right ventricular myocytes (524). In tissue from the right ventricular septum of dog, a higher expression of KChIP2, Kv7.1, and NCX1 mRNA was reported, and the APD of myocytes from the right ventricular septum was shorter than the left as expected (400).

AP waveform conduction velocity in the ventricles relies on the availability of Nav1.5 channels and gap junction coupling via $\mathrm{Cx} 43$ (556). Although, differences in expression of Nav1.5 and Cx43 in the left or right ventricle have not been demonstrated, pharmacological block or reduced expression of Nav1.5 or $\mathrm{Cx} 43$ in mice slows conduction velocity more in the right $v s$. left ventricle $(506,507)$. These observations depict how the effects of regional heterogeneity may increase susceptibility to arrhythmogenesis. Differences in the origin of arrhythmia also exist; for example, in $\mathrm{BrS}$, ventricular arrhythmias are initiated in the right ventricular outflow tract by either conduction slowing or unidirectional impulse block (177, 337). Congenital $\mathrm{BrS}$ is linked to mutations in SCN5A in up to an estimated $30 \%$ of all cases, and these mutations decrease the function of Nav1.5 by reducing cell surface expression, shifting the voltage- and time-dependence of inactivation, delaying recovery of inactivation, or accelerating the time-course of inactivation $(18,107)$. Reduction of Nav1.5 function leads to a decrease in $\mathrm{I}_{\mathrm{Na}}$ and causes an increase in the notch phase and loss of AP dome of epicardial myocytes. As a result, transmural dispersion of repolarization increases and ultimately, increases the risk for reentrant arrhythmias and incidence of sudden cardiac death $(269,444)$.

Apex vs. Base-Apico-basal heterogeneity was first discovered in canine myocytes, whereby cells isolated from the apex had a shorter APD than cells isolated from the base of the left ventricular wall (472). Larger $\mathrm{I}_{\mathrm{to}}$ and $\mathrm{I}_{\mathrm{Ks}}$ correlated with the shorter APD in apical myocytes compared to basal. The same study showed that the increases in repolarizing currents are most likely a result of higher protein expression of KChIP2 ( $\left.\mathrm{I}_{\mathrm{to}}\right), \mathrm{Kv} 7.1\left(\mathrm{I}_{\mathrm{Ks}}\right)$, and KCNE1 $\left(\mathrm{I}_{\mathrm{Ks}}\right)$ in both human and canine apical myocytes than basal myocytes (472). No apico-basal differences were observed in densities of $\mathrm{I}_{\mathrm{CaL}}, \mathrm{I}_{\mathrm{K} 1}$, or $\mathrm{I}_{\mathrm{Kr}}$, and the protein expression of the corresponding pore forming a-subunits (Cav1.2, Kir2.1, and Kv11.1) and $\beta$-subunits (KCNE2). In contrast, the APD of rabbit, ferret, and rat apical myocytes have been shown to be longer than basal myocytes $(70,78,111,548)$. In rabbit, $\mathrm{I}_{\mathrm{Kr}}$ is paradoxically larger in apical myocytes, but $\mathrm{I}_{\mathrm{Ks}}$ is much smaller in apical myocytes compared to basal. However, this study did not take into account apico-basal differences of $\mathrm{I}_{\mathrm{to}}$. 


\section{Ventricular Arrhythmia and Disease}

Ventricular arrhythmia can describe a broad range of abnormal electrical activity that may lead to ventricular tachycardias and can culminate in ventricular fibrillation and sudden cardiac death. The mechanisms of arrhythmia in the ventricles are similar to the atria and are referenced in the atrial section above (see section Atrial Fibrillation: Mechanisms and Ionic Remodeling and Figure 5). Typically, tachycardias are dependent on a triggering stimulus (e.g., ectopic foci) and a substrate for sustainability (e.g., reentrant loop). Alterations in ion channel function or expression can disrupt the morphology of the AP waveform, which can ultimately lead to abnormal propagation of the heart's electrical impulse and arrhythmia. Ion channel dysfunction or expression remodeling can occur in diseases that can be inherited (LQTS, BrS, CPVT, etc.) or acquired (HF, MI, etc.).

Over the past several years, molecular and biophysical studies have linked a genotypephenotype correlation between several multigenerational inherited cardiac arrhythmia syndromes and mutations within genes encoding ion channels or ion channel regulatory proteins. These arrhythmia syndromes (otherwise known as 'channelopathies') include LQTS, SQTS, BrS, CPVT, familial lone AF, and familial bradycardia. Table 2 displays inherited ventricular arrhythmia syndromes and the association of each disease with a specific gene and the specific cardiac current affected. Of note, mutations in different ion channels often lead to the same pathological phenotype. For example, mutations in genes encoding Kv, Nav, and Cav channels can all lead to AP prolongation and manifest as LQTS. Similarly, various mutations are now being linked to CPVT, including mutations in RyR2, CASQ2, CALM1, and KCNJ2 (Kir2.1). Thus, there is substantial overlap in the many genotypes that can all lead to a similar disease phenotype.

$\mathrm{HF}$ is one of the leading causes of death in the United States each year and the prevalence continues to increase with an aging population (186). HF is associated with deficiencies in cardiac function that is a result of structural and electrophysiological remodeling of the cardiac tissue. Remodeling significantly increases the risk of arrhythmia in HF patients, and nearly half of deaths reported in HF patients are a result of ventricular arrhythmias (158, 262). Remodeling of cardiac electrophysiology is due to alterations in expression and function of ion channel and/or ion channel regulatory proteins. A common observation in failing ventricular myocytes isolated from humans or animal models of HF is the prolongation of the ventricular APD and a higher incidence of EADs or DADs compared to control cells $(5,56,250,410)$. These observations may be a direct result in the ventricular remodeling of ion channels, which increases the likelihood of arrhythmia and sudden cardiac death. In the following sections, we will discuss the underlying molecular and/or biophysical mechanism of ion channel remodeling in the ventricular myocyte during HF.

Nav Channels-HF-induced abnormalities may affect both the expression and posttranslational modifications of Nav1.5 and contribute to ventricular APD prolongation. Several studies have suggested that peak $\mathrm{I}_{\mathrm{Na}}$ is reduced in $\operatorname{HF}(270,349,499,504,596)$. Other studies show an increase in $\mathrm{I}_{\mathrm{NaL}}$ in both tachypaced HF-induced canine and human HF ventricular myocytes (499-501, 504). Similar results were observed in HF-induced mice by transgenic overexpression of CaMKII $\delta \mathrm{C}$, whereby $\mathrm{I}_{\mathrm{NaL}}$ was markedly increased (315, 
527). Together, these observations could be a result of post-translational modification of

Nav1.5 by CaMKII phosphorylation. A decrease in peak $\mathrm{I}_{\mathrm{Na}}$ may lead to conduction slowing or ventricular arrhythmias via stimulus reentry; whereas, an increase in $\mathrm{I}_{\mathrm{NaL}}$ may alter $\left[\mathrm{Na}^{+}\right]_{\mathrm{i}}$ or $\left[\mathrm{Ca}^{2+}\right]_{\mathrm{i}}$ homeostasis, delay repolarization, cause ventricular APD prolongation, and increase the risk of ventricular arrhythmias (215). Furthermore, CaMKII expression and activation is increased in $\mathrm{HF}$, and inhibition of CaMKII is protective of HF by reducing pathological signaling and arrhythmias $(12,221,591)$. These arrhythmogenic mechanisms are similar to observed biophysical phenotypes associated with congenital arrhythmia syndromes (LQT3 or BrS) involving mutations in SCN5A (45).

One study reported no alterations in mRNA expression of Nav1.5 and $\beta 1$ in samples from human or canine HF ventricular myocytes compared to control (504). However, a more recent study suggested that in human HF, non-functional truncated Nav1.5 mRNA splice variants are increased, but the role of this splice variant remains unknown $(180,446)$.

Cav Channels-In most human studies of isolated ventricular HF myocytes, no changes in $\mathrm{I}_{\mathrm{CaL}}$ have been observed, but there are reports of decreased $\mathrm{I}_{\mathrm{CaL}}$ in $\mathrm{HF}(4,50,349,384)$. Several studies involving tachypaced HF-induced dogs, tachypaced HF-induced rabbits, or pressure/volume overload HF-induced rabbits have also yielded no decrease in $\mathrm{I}_{\mathrm{CaL}}$, albeit, strong reductions in contractile force and $\mathrm{Ca}^{2+}$-transients $(250,365,387,413)$. Furthermore, increases in $\mathrm{I}_{\mathrm{CaL}}$ subsequent to $\beta$-adrenergic stimulation were blunted in ventricular $\mathrm{HF}$ myocytes $(250,341,413)$. Other studies using single channel recordings have suggested that although, the number of Cav1.2 channels at the cell membrane is reduced in human HF, overall $\mathrm{I}_{\mathrm{CaL}}$ density is unchanged due to an increased open probability $(108,209,433)$. An increase in open probability likely correlates to increased phosphorylation of Cav1.2. Indeed, CaMKII (and PKA) phosphorylation enhances peak $\mathrm{I}_{\mathrm{CaL}}$ and slows inactivation, which results in an increase in $\mathrm{Ca}^{2+}$ influx $(155,585)$. Together, the increased open probability of Cav1.2, increased $\mathrm{Ca}^{2+}$ entry, and increased $\mathrm{SR} \mathrm{Ca}^{2+}$ release leads to higher $\left[\mathrm{Ca}^{2+}\right]_{\mathrm{i}}$ in $\mathrm{HF}$ and may lead to DADs via $\mathrm{I}_{\mathrm{NCX}}$ removal of $\mathrm{Ca}^{2+}$. Rabbit ventricular AP simulations suggest that impairment of $\mathrm{Ca}^{2+}$-dependent inactivation (CDI) of $\mathrm{I}_{\mathrm{CaL}}$ can lead to development of EADs during a prolonged ventricular APD by a similar mechanism (340). Ventricular APD prolongation alone, without the HF-induced alterations of $\mathrm{I}_{\mathrm{CaL}}$, may also trigger arrhythmogenic EADs by increasing the probability of Cav1.2 channels to reactivate $(288,363,444)$.

Several studies have also attempted to determine the molecular regulation in Cav1.2 expression and alterations of $\mathrm{I}_{\mathrm{CaL}}$ density in HF. Two studies reported no change in Cav1.2 mRNA expression in human HF ventricular myocytes $(433,440)$. Other studies reported alternative splicing events; whereas, Cav1.2 mRNA underwent isoform switching and the regulatory subunit, $\beta 3 \mathrm{a}$, was truncated $(233,574)$.

Kv Channels-As previously stated, a typical feature of isolated ventricular myocytes of HF humans or animal models is APD prolongation and increased EAD susceptibility (4, $349,444)$. These common findings are sometimes a direct result of reductions in the repolarization reserve, which are also observed in several forms of congenital arrhythmia syndromes such as type 1 or type 2 LQTS (LQT1 or LQT2). Indeed, HF-induced 
remodeling may cause a reduction in several repolarizing $\mathrm{K}^{+}$-currents. The most consistent change to ionic currents during HF is the downregulation of $\mathrm{I}_{\mathrm{to}}$. A reduction of $\mathrm{I}_{\mathrm{to}}$ has been reported in isolated ventricular myocytes from human HF patients, tachypaced HF-induced dogs, tachypaced HF-induced rabbits, and pressure/volume overload HF-induced rabbits $(56,249,250,345,388,413,492,493)$. The reduction in $\mathrm{I}_{\text {to }}$ corresponds to decrease in protein and mRNA expression of Kv4.3 and no change in $\mathrm{I}_{\text {to }}$ voltage-dependence or kinetics $(6,249,345,410,493,565,597)$. The majority of these studies also conclude that KChIP2 expression is unchanged in HF ruling out KChIP2 regulation of Kv4.3 as a cause of decreased $\mathrm{I}_{\mathrm{to}}$. In tachypaced HF-induced dogs, reduced $\mathrm{I}_{\mathrm{to}}$ was directly linked to increases in CaMKII activation and calcineurin/NFAT signaling. This led to a reduced expression of Kv4.3 mRNA and protein (565). Although, $\mathrm{I}_{\mathrm{to}}$ is important for the notch phase or early repolarization in the ventricular AP, downregulation of $\mathrm{I}_{\text {to }}$ may contribute to APD prolongation. Additionally, computational simulations of a rabbit ventricular AP that incorporate CaMKII-dependent effects on $\mathrm{I}_{\text {to }}$ together with $\mathrm{I}_{\mathrm{to}}$ heterogeneity can exacerbate transmural dispersion of repolarization, increasing the vulnerability to reentrant arrhythmias (195).

The delayed rectifier $\mathrm{K}^{+}$-currents, $\mathrm{I}_{\mathrm{Kr}}$ and $\mathrm{I}_{\mathrm{Ks}}$, play a key role to late phase ventricular repolarization and have a direct effect on the ventricular APD. However, there is more ambiguity in whether or not $\mathrm{I}_{\mathrm{Kr}}$ and $\mathrm{I}_{\mathrm{Ks}}$ are reduced in HF. Downregulation of $\mathrm{I}_{\mathrm{Kr}}$ and $\mathrm{I}_{\mathrm{Ks}}$ has been shown from isolated ventricular myocytes of tachypaced HF-induced rabbits in one study, but only $\mathrm{I}_{\mathrm{Ks}}$ has been reported to be decreased from tachypaced HF-induced canine myocytes $(287,492)$. In humans, $\mathrm{I}_{\mathrm{Ks}}$ was decreased in HF myocytes isolated from the right ventricle; whereas, $\mathrm{I}_{\mathrm{Kr}}$ was unchanged (288). Interestingly, a recent study specifically blocked $\mathrm{I}_{\mathrm{Kr}}$ in isolated non-failing or HF left ventricular wedge preparations. $\mathrm{I}_{\mathrm{Kr}}$ block prolonged APD in control preparations as expected. However, they found that $\mathrm{I}_{\mathrm{Kr}}$ block in HF cells caused less prolongation of the ventricular APD compared to non-failing cells, suggesting the possibility of reduced functional $\mathrm{I}_{\mathrm{Kr}}$ in HF myocytes (223). No differences have been observed in mRNA expression of Kv11.1 (KCNH2) or Kv7.1 (KCNQ1) between HF or control patients $(249,545)$. However, the mRNA expression of KCNE1, which modifies $\mathrm{I}_{\mathrm{Ks}}$ by slowing activation/deactivation kinetics and positively shifting the voltagedependence of activation, was found to be increased in HF patients in several studies (67, 545). In $\mathrm{HF}$, reductions in $\mathrm{I}_{\mathrm{Ks}}$ or $\mathrm{I}_{\mathrm{Kr}}$ will delay repolarization, leading to ventricular APD prolongation and thus, contribute to a higher EAD propensity.

Inward Rectifying Channels-Decreased density of $\mathrm{I}_{\mathrm{K} 1}$ has been reported in multiple studies involving ventricular myocytes from human HF patients, tachypaced HF-induced dogs, tachypaced HF-induced rabbits, and pressure/volume overload HF-induced rabbits $(56,250,287,288,388,413)$. Reductions in $\mathrm{I}_{\mathrm{K} 1}$ may contribute to reduced repolarization reserve, ventricular APD prolongation, and may increase risk for DAD-induced ventricular arrhythmias $(363,388,444)$. Conversely, two reports in tachypaced HF-induced rabbits found no changes in $\mathrm{I}_{\mathrm{K} 1}(413,492)$. Although the majority of studies find a reduction of $\mathrm{I}_{\mathrm{K} 1}$ in $\mathrm{HF}$ ventricular myocytes, the molecular mechanism for $\mathrm{I}_{\mathrm{K} 1}$ downregulation in $\mathrm{HF}$ is not understood. Kir2.1 mRNA expression appears to be unchanged in human HF, suggesting post-translational modification reduces $\mathrm{I}_{\mathrm{K} 1}(249,543)$. 
$\mathrm{Ca}^{2+}$ Handling Proteins-HF causes significant changes in the function and regulation of $\mathrm{Ca}^{2+}$ handling proteins such as NCX, RyR, and SERCA2a. Most studies suggest that NCX function, mRNA expression, and protein expression is increased in isolated ventricular myocytes from human HF patients, tachypaced HF-induced dogs, and pressure/volume overload HF-induced rabbits $(53,365,386,404,465)$. However, one study involving human left ventricular myocytes reported no change in NCX function (383). Similar studies commonly revealed that $\mathrm{Ca}^{2+}$-reuptake into the SR by SERCA2a is decreased along with mRNA and protein expression in $\operatorname{HF}(53,261,365,386,439,458,465)$. SERCA is regulated by PLB. When PLB is dephosphorylated, it reduces SERCA function by decreasing SERCA's affinity for $\mathrm{Ca}^{2+}$. $\beta$-adrenergic stimulation typically triggers PKA phosphorylation of PLB, thus increasing SERCA reuptake of $\mathrm{Ca}^{2+}$ into the SR (174). In HF, PLB expression is not altered, but phosphorylation of PLB is decreased, which contributes to the reduced function of SERCA $(231,441)$.

Although, NCX is a reversible transporter, it normally extrudes one $\mathrm{Ca}^{2+}$ ion for three $\mathrm{Na}^{+}$ ions generating a net depolarizing current, $\mathrm{I}_{\mathrm{NCX}}$. Since SERCA function is reduced in $\mathrm{HF}$, the myocyte has a higher requirement for $\mathrm{NCX}$ to remove $\mathrm{Ca}^{2+}$ from the cytosol and increased activity of $\mathrm{I}_{\mathrm{NCX}}$ could lead to ventricular APD prolongation $(24,219,220)$. Alternatively, in $\mathrm{HF}$ diastolic $\left[\mathrm{Na}^{+}\right]_{\mathrm{i}}$ is elevated and $\mathrm{Ca}^{2+}$-transients are dampened; therefore, reverse NCX function ( $\mathrm{Ca}^{2+}$ influx) may be favored (549).

Lastly, $\mathrm{SR} \mathrm{Ca}{ }^{2+}$ leak is enhanced at any given $\mathrm{SR} \mathrm{Ca}^{2+}$ load and is linked to an increase open probability of the RyR in human HF, tachypaced HF-induced dogs, and pressure/ volume overload HF-induced rabbits $(52,447)$. It was originally shown that PKA phosphorylation of RyR2 increases the open probability of RyR2 by favoring disassociation of RyR2 with FKBP12.6 (an RyR inhibitory protein) (322). In HF, RyR2 was found to be hyperphosphorylated, explaining the increase $\mathrm{SR} \mathrm{Ca}^{2+}$ leak via RyR2. Several groups have since been unable to recapitulate these results and the role of PKA hyperphosphorylation in HF remains controversial today $(48,51,127,163,182,184,294,463,505,564)$. However, there is more concise evidence that CaMKII phosphorylation of RyR2 is increased in human and rabbit $\mathrm{HF}$ and inhibition of CaMKII reduces SR $\mathrm{Ca}^{2+}$ leak $(2,126,129,130,259)$.

Oxidation by reactive oxygen species (ROS) can also activate RyR2 and CaMKII; therefore, in HF where ROS is elevated, a synergistic activation of RyR2 contributes to further SR $\mathrm{Ca}^{2+}$ leak $(162,397,445,480)$.

In all, the combination of 1) increased NCX function, 2) decreased SERCA function and SR $\mathrm{Ca}^{2+}$ reuptake, and 3) increased open probability of RyR and SR $\mathrm{Ca}^{2+}$ leak create significant cellular dysfunction in HF. These will lead to a decreased $\mathrm{SR} \mathrm{Ca}^{2+}$ load, dampened $\mathrm{Ca}^{2+}$ transients, decreased contractility, and increased cytosolic $\mathrm{Ca}^{2+}$. The $\mathrm{Ca}^{2+}$ instabilities present in HF increase risk for DADs, ventricular arrhythmias, and ultimately, ventricular fibrillation.

In general, HF leads to severe impairment in electrophysiological function due to remodeling of several ion channels and regulatory proteins as discussed. It is likely that significant synergism exists among these mechanisms and that arrhythmias arise via the interplay of multiple aspects of HF-induced remodeling. Indeed, a recent study from our 
group found that pharmacological inhibition of $\mathrm{I}_{\mathrm{K} 1}$ or an increase in RyR sensitivity that facilitates $\mathrm{SR} \mathrm{Ca}^{2+}$ release were insufficient separately to promote arrhythmia in intact normal rabbit hearts following local sympathetic stimulation. However, pharmacologically inducing both of these HF-like phenotypes simultaneously led to a significantly increased propensity to focal ventricular tachycardia lasting several minutes following a single induction (Figure 9) (343). These findings suggest that multiple factors likely conspire to the increased arrhythmic risk in HF, such that a multi-targeted approach might provide optimal anti-arrhythmic treatment.

\section{Role of the Autonomic Nervous System in Ventricular Arrhythmia}

In addition to ionic remodeling, cardiac pathology (including HF and myocardial infarction) often leads to significant remodeling of the structure and function of the cardiac autonomic nerves. Remodeling of sympathetic neurotransmission is particularly arrhythmogenic and is paradoxically associated with both hyper- and hypo-innervation and as well as altered neurotransmitter release. Regional hyper-innervation was one of the first types of nerve remodeling to be linked to arrhythmia in humans (96) and has now been well documented in many species and various cardiac pathologies (reviewed in (105)). Indeed, our group recently demonstrated the mechanistic basis by which localized sympathetic stimulation leads to the generation of ectopic beats (344). Recently, however, three clinical studies have revealed that the degree of sympathetic hypo-innervation (quantified with nuclear imaging) is a significant predictor of ventricular arrhythmia risk $(66,358)$, predicting cardiac arrest independent of infarct size and ejection fraction (165). Thus, it seems as if the explanation for these contradictory findings lies in heterogeneity of sympathetic transmission. Indeed, Rubart and Zipes have postulated that heterogeneous remodeling of the sympathetic nerves leads to differential remodeling of myocardial electrophysiological properties (as discussed above) and an increased risk for ventricular arrhythmia (415). In addition, there is now evidence of cholinergic transdifferentiation of the cardiac sympathetic nerves in HF, meaning that instead of producing and releasing norepinephrine, the cardiac sympathetic nerves undergo a phenotypic switch to produce the parasympathetic neurotransmitter, acetylcholine (252). The electrophysiological consequences of this transdifferentiation have yet to be determined, but these provocative findings add yet another layer to the complex regulation of ion channels in HF.

\section{Conclusion}

Regionally diverse electrophysiological properties and function are inherently due to the heterogeneity of ion channel expression throughout the heart. Understanding this diversity and the ionic basis of electrophysiological activity is fundamentally important for the investigation of arrhythmia mechanisms and responses to ion-channel blocking drugs. In heart disease, it is important to elucidate how ionic remodeling alters the regional specificity of ion channel expression and function. To accomplish these goals in the future, an improved understanding of the mechanisms underlying normal and abnormal activity of the human heart will require comparative studies of cardiac gene/protein expression and modification, electrophysiology, and excitation-contraction coupling throughout various regions of the heart, both in healthy and pathophysiological situations. Subsequent studies that relate human $v s$. animal heterogeneity and disease-induced remodeling, along with in 
silico-based strategies will be useful approaches for translating information from animal to human disease. Additional development and validation of integrative multi-scale computational models of the human (or species-specific) heart in health and disease that incorporates regional heterogeneity, as well as ionic, structural, contractile, neurohormonal maladaptive responses across scales is needed. These experiments and models will be useful to mechanistically link subcellular and cellular abnormalities to potentially patient-specific clinical phenotypes, and guide the selection of appropriate anti-arrhythmic treatment.

\section{References}

1. Abbott GW, Sesti F, Splawski I, Buck ME, Lehmann MH, Timothy KW, Keating MT, Goldstein SA. MiRP1 forms IKr potassium channels with HERG and is associated with cardiac arrhythmia. Cell. 1999; 97:175-187. [PubMed: 10219239]

2. Ai X, Curran JW, Shannon TR, Bers DM, Pogwizd SM. Ca2+/calmodulin-dependent protein kinase modulates cardiac ryanodine receptor phosphorylation and sarcoplasmic reticulum $\mathrm{Ca} 2+$ leak in heart failure. Circ Res. 2005; 97:1314-1322. [PubMed: 16269653]

3. Aiba T, Tomaselli GF. Electrical remodeling in the failing heart. Curr Opin Cardiol. 2010; 25:29_ 36. [PubMed: 19907317]

4. Aiba T, Tomaselli GF. Electrical remodeling in the failing heart. Curr Opin Cardiol. 2010; 25:2936. [PubMed: 19907317]

5. Akar FG, Rosenbaum DS. Transmural electrophysiological heterogeneities underlying arrhythmogenesis in heart failure. Circ Res. 2003; 93:638-645. [PubMed: 12933704]

6. Akar FG, Wu RC, Juang GJ, Tian Y, Burysek M, Disilvestre D, Xiong W, Armoundas AA, Tomaselli GF. Molecular mechanisms underlying K+ current downregulation in canine tachycardiainduced heart failure. Am J Physiol Heart Circ Physiol. 2005; 288:H2887-H2896. [PubMed: 15681701]

7. Alings AM, Abbas RF, Bouman LN. Age-related changes in structure and relative collagen content of the human and feline sinoatrial node. A comparative study. European heart journal. 1995; 16:1655-1667. [PubMed: 8881862]

8. Alings AM, Bouman LN. Electrophysiology of the ageing rabbit and cat sinoatrial node--a comparative study. European heart journal. 1993; 14:1278-1288. [PubMed: 8223742]

9. Amos GJ, Wettwer E, Metzger F, Li Q, Himmel HM, Ravens U. Differences between outward currents of human atrial and subepicardial ventricular myocytes. J Physiol. 1996; 491(Pt 1):31-50. [PubMed: 9011620]

10. An WF, Bowlby MR, Betty M, Cao J, Ling HP, Mendoza G, Hinson JW, Mattsson KI, Strassle BW, Trimmer JS, Rhodes KJ. Modulation of A-type potassium channels by a family of calcium sensors. Nature. 2000; 403:553-556. [PubMed: 10676964]

11. Andelfinger G, Tapper AR, Welch RC, Vanoye CG, George AL, Benson DW. KCNJ2 mutation results in Andersen syndrome with sex-specific cardiac and skeletal muscle phenotypes. American journal of human genetics. 2002; 71:663-668. [PubMed: 12148092]

12. Anderson ME, Brown JH, Bers DM. CaMKII in myocardial hypertrophy and heart failure. J Mol Cell Cardiol. 2011; 51:468-473. [PubMed: 21276796]

13. Ansari A, Ho SY, Anderson RH. Distribution of the Purkinje fibres in the sheep heart. The Anatomical record. 1999; 254:92-97. [PubMed: 9892422]

14. Anter E, Jessup M, Callans DJ. Atrial fibrillation and heart failure: treatment considerations for a dual epidemic. Circulation. 2009; 119:2516-2525. [PubMed: 19433768]

15. Antzelevitch C. Drug-induced spatial dispersion of repolarization. Cardiology journal. 2008; 15:100-121. [PubMed: 18651395]

16. Antzelevitch C. The M Cell. Journal of cardiovascular pharmacology and therapeutics. 1997; $2: 73-$ 76. [PubMed: 10684444] 
17. Antzelevitch C. Role of spatial dispersion of repolarization in inherited and acquired sudden cardiac death syndromes. Am J Physiol Heart Circ Physiol. 2007; 293:H2024-H2038. [PubMed: 17586620]

18. Antzelevitch C, Brugada P, Brugada J, Brugada R. Brugada syndrome: from cell to bedside. Current problems in cardiology. 2005; 30:9-54. [PubMed: 15627121]

19. Antzelevitch C, Pollevick GD, Cordeiro JM, Casis O, Sanguinetti MC, Aizawa Y, Guerchicoff A, Pfeiffer R, Oliva A, Wollnik B, Gelber P, Bonaros EP Jr, Burashnikov E, Wu Y, Sargent JD, Schickel S, Oberheiden R, Bhatia A, Hsu LF, Haissaguerre M, Schimpf R, Borggrefe M, Wolpert C. Loss-of-function mutations in the cardiac calcium channel underlie a new clinical entity characterized by ST-segment elevation, short QT intervals, and sudden cardiac death. Circulation. 2007; 115:442-449. [PubMed: 17224476]

20. Antzelevitch C, Sicouri S, Litovsky SH, Lukas A, Krishnan SC, Di Diego JM, Gintant GA, Liu DW. Heterogeneity within the ventricular wall. Electrophysiology and pharmacology of epicardial, endocardial, and M cells. Circ Res. 1991; 69:1427-1449. [PubMed: 1659499]

21. Anumonwo JM, Tallini YN, Vetter FJ, Jalife J. Action potential characteristics and arrhythmogenic properties of the cardiac conduction system of the murine heart. Circulation Research. 2001; 89:329-335. [PubMed: 11509449]

22. Apkon M, Nerbonne JM. Characterization of two distinct depolarization-activated $\mathrm{K}+$ currents in isolated adult rat ventricular myocytes. J Gen Physiol. 1991; 97:973-1011. [PubMed: 1865177]

23. Arikkath J, Campbell KP. Auxiliary subunits: essential components of the voltage-gated calcium channel complex. Current opinion in neurobiology. 2003; 13:298-307. [PubMed: 12850214]

24. Armoundas AA, Hobai IA, Tomaselli GF, Winslow RL, O'Rourke B. Role of sodium-calcium exchanger in modulating the action potential of ventricular myocytes from normal and failing hearts. Circ Res. 2003; 93:46-53. [PubMed: 12805237]

25. Aslanidi OV, Sleiman RN, Boyett MR, Hancox JC, Zhang H. Ionic mechanisms for electrical heterogeneity between rabbit Purkinje fiber and ventricular cells. Biophysical journal. 2010; 98:2420-2431. [PubMed: 20513385]

26. Atkinson A, Inada S, Li J, Tellez JO, Yanni J, Sleiman R, Allah EA, Anderson RH, Zhang H, Boyett MR, Dobrzynski H. Anatomical and molecular mapping of the left and right ventricular His-Purkinje conduction networks. Journal of Molecular and Cellular Cardiology. 2011; 51:689701. [PubMed: 21741388]

27. Atkinson AJ, Logantha SJRJ, Hao G, Yanni J, Fedorenko O, Sinha A, Gilbert SH, Benson AP, Buckley DL, Anderson RH, Boyett MR, Dobrzynski H. Functional, anatomical, and molecular investigation of the cardiac conduction system and arrhythmogenic atrioventricular ring tissue in the rat heart. J Am Heart Assoc. 2013; 2:e000246. [PubMed: 24356527]

28. Balana B, Dobrev D, Wettwer E, Christ T, Knaut M, Ravens U. Decreased ATP-sensitive K(+) current density during chronic human atrial fibrillation. J Mol Cell Cardiol. 2003; 35:1399-1405. [PubMed: 14654366]

29. Balasundaram R, Rao HB, Kalavakolanu S, Narasimhan C. Catheter ablation of bundle branch reentrant ventricular tachycardia. Heart rhythm : the official journal of the Heart Rhythm Society. 2008; 5:S68-S72. [PubMed: 18456206]

30. Banyasz T, Fulop L, Magyar J, Szentandrassy N, Varro A, Nanasi PP. Endocardial versus epicardial differences in L-type calcium current in canine ventricular myocytes studied by action potential voltage clamp. Cardiovascular research. 2003; 58:66-75. [PubMed: 12667947]

31. Barhanin J, Lesage F, Guillemare E, Fink M, Lazdunski M, Romey G. K(V)LQT1 and 1sK (minK) proteins associate to form the I(Ks) cardiac potassium current. Nature. 1996; 384:78-80. [PubMed: 8900282]

32. Barry DM, Xu H, Schuessler RB, Nerbonne JM. Functional knockout of the transient outward current, long-QT syndrome, and cardiac remodeling in mice expressing a dominant-negative Kv4 alpha subunit. Circ Res. 1998; 83:560-567. [PubMed: 9734479]

33. Bartos DC, Anderson JB, Bastiaenen R, Johnson JN, Gollob MH, Tester DJ, Burgess DE, Homfray T, Behr ER, Ackerman MJ, Guicheney P, Delisle BP. A KCNQ1 mutation causes a high penetrance for familial atrial fibrillation. J Cardiovasc Electrophysiol. 2013; 24:562-569. [PubMed: 23350853] 
34. Bartos DC, Duchatelet S, Burgess DE, Klug D, Denjoy I, Peat R, Lupoglazoff JM, Fressart V, Berthet M, Ackerman MJ, January CT, Guicheney P, Delisle BP. R231C mutation in KCNQ1 causes long QT syndrome type 1 and familial atrial fibrillation. Heart Rhythm. 2011; 8:48-55. [PubMed: 20850564]

35. Bartos DC, Giudicessi JR, Tester DJ, Ackerman MJ, Ohno S, Horie M, Gollob MH, Burgess DE, Delisle BP. A KCNQ1 mutation contributes to the concealed type 1 long QT phenotype by limiting the Kv7.1 channel conformational changes associated with protein kinase A phosphorylation. Heart rhythm : the official journal of the Heart Rhythm Society. 2014; 11:459_ 468. [PubMed: 24269949]

36. Baruscotti M, Bucchi A, Viscomi C, Mandelli G, Consalez G, Gnecchi-Rusconi T, Montano N, Casali KR, Micheloni S, Barbuti A, DiFrancesco D. Deep bradycardia and heart block caused by inducible cardiac-specific knockout of the pacemaker channel gene Hcn4. Proceedings of the National Academy of Sciences of the United States of America. 2011; 108:1705-1710. [PubMed: 21220308]

37. Bassani RA. Transient outward potassium current and Ca2+ homeostasis in the heart: beyond the action potential. Brazilian journal of medical and biological research $=$ Revista brasileira de pesquisas medicas e biologicas / Sociedade Brasileira de Biofisica [et al]. 2006; 39:393-403.

38. Bean BP. Two kinds of calcium channels in canine atrial cells. Differences in kinetics, selectivity, and pharmacology. J Gen Physiol. 1985; 86:1-30. [PubMed: 2411846]

39. Bellocq C, van Ginneken AC, Bezzina CR, Alders M, Escande D, Mannens MM, Baro I, Wilde AA. Mutation in the KCNQ1 gene leading to the short QT-interval syndrome. Circulation. 2004; 109:2394-2397. [PubMed: 15159330]

40. Belus A, Piroddi N, Ferrantini C, Tesi C, Cazorla O, Toniolo L, Drost M, Mearini G, Carrier L, Rossi A, Mugelli A, Cerbai E, van der Velden J, Poggesi C. Effects of chronic atrial fibrillation on active and passive force generation in human atrial myofibrils. Circ Res. 2010; 107:144-152. [PubMed: 20466979]

41. Ben Caref E, Boutjdir M, Himel HD, El-Sherif N. Role of subendocardial Purkinje network in triggering torsade de pointes arrhythmia in experimental long QT syndrome. Europace : European pacing, arrhythmias, and cardiac electrophysiology : journal of the working groups on cardiac pacing, arrhythmias, and cardiac cellular electrophysiology of the European Society of Cardiology. 2008; 10:1218-1223.

42. Bendahhou S, Marionneau C, Haurogne K, Larroque MM, Derand R, Szuts V, Escande D, Demolombe S, Barhanin J. In vitro molecular interactions and distribution of KCNE family with KCNQ1 in the human heart. Cardiovascular research. 2005; 67:529-538. [PubMed: 16039274]

43. Benito B, Brugada R, Perich RM, Lizotte E, Cinca J, Mont L, Berruezo A, Tolosana JM, Freixa X, Brugada P, Brugada J. A mutation in the sodium channel is responsible for the association of long QT syndrome and familial atrial fibrillation. Heart Rhythm. 2008; 5:1434-1440. [PubMed: 18929331]

44. Benndorf K, Nilius B. Properties of an early outward current in single cells of the mouse ventricle. General physiology and biophysics. 1988; 7:449-466. [PubMed: 3234736]

45. Bennett PB, Yazawa K, Makita N, George AL Jr. Molecular mechanism for an inherited cardiac arrhythmia. Nature. 1995; 376:683-685. [PubMed: 7651517]

46. Benson DW, Wang DW, Dyment M, Knilans TK, Fish FA, Strieper MJ, Rhodes TH, George AL. Congenital sick sinus syndrome caused by recessive mutations in the cardiac sodium channel gene (SCN5A). The Journal of clinical investigation. 2003; 112:1019-1028. [PubMed: 14523039]

47. Bers DM. Cardiac excitation-contraction coupling. Nature. 2002; 415:198-205. [PubMed: 11805843]

48. Bers DM. Cardiac sarcoplasmic reticulum calcium leak: basis and roles in cardiac dysfunction. Annual review of physiology. 2014; 76:107-127.

49. Bers, DM. Excitation-Contraction Coupling and Cardiac Contractile Force. Dordrecht, The Netherlands: Kluwer Academic Publishers; 2001.

50. Bers, DM. Excitation-contraction coupling and cardiac contractile force. Dordrecht ; Boston: Kluwer Academic Publishers; 2001. 
51. Bers DM. Ryanodine receptor S2808 phosphorylation in heart failure: smoking gun or red herring. Circ Res. 2012; 110:796-799. [PubMed: 22427320]

52. Bers DM, Eisner DA, Valdivia HH. Sarcoplasmic reticulum Ca2+ and heart failure: roles of diastolic leak and Ca2+ transport. Circ Res. 2003; 93:487-490. [PubMed: 14500331]

53. Bers DM, Pogwizd SM, Schlotthauer K. Upregulated Na/Ca exchange is involved in both contractile dysfunction and arrhythmogenesis in heart failure. Basic Res Cardiol. 2002; 97(Suppl 1):I36-I42. [PubMed: 12479232]

54. Bertaso F, Sharpe CC, Hendry BM, James AF. Expression of voltage-gated K+ channels in human atrium. Basic research in cardiology. 2002; 97:424-433. [PubMed: 12395204]

55. Bettoni M, Zimmermann M. Autonomic tone variations before the onset of paroxysmal atrial fibrillation. Circulation. 2002; 105:2753-2759. [PubMed: 12057990]

56. Beuckelmann DJ, Nabauer M, Erdmann E. Alterations of K+ currents in isolated human ventricular myocytes from patients with terminal heart failure. Circ Res. 1993; 73:379-385. [PubMed: 8330380]

57. Beyer EC, Paul DL, Goodenough DA. Connexin family of gap junction proteins. The Journal of membrane biology. 1990; 116:187-194. [PubMed: 2167375]

58. Bezzina CR, Rook MB, Groenewegen WA, Herfst LJ, van der Wal AC, Lam J, Jongsma HJ, Wilde AAM, Mannens MMAM. Compound heterozygosity for mutations (W156X and R225W) in SCN5A associated with severe cardiac conduction disturbances and degenerative changes in the conduction system. Circulation Research. 2003; 92:159-168. [PubMed: 12574143]

59. Bhuiyan ZA, van den Berg MP, van Tintelen JP, Bink-Boelkens MTE, Wiesfeld ACP, Alders M, Postma AV, van Langen I, Mannens MMAM, Wilde AAM. Expanding spectrum of human RYR2-related disease: new electrocardiographic, structural, and genetic features. Circulation. 2007; 116:1569-1576. [PubMed: 17875969]

60. Billette J. Atrioventricular nodal activation during periodic premature stimulation of the atrium. The American journal of physiology. 1987; 252:H163-H177. [PubMed: 3812708]

61. Blechschmidt S, Haufe V, Benndorf K, Zimmer T. Voltage-gated Na+ channel transcript patterns in the mammalian heart are species-dependent. Progress in biophysics and molecular biology. 2008; 98:309-318. [PubMed: 19351521]

62. Bleeker WK, Mackaay AJ, Masson-Pévet M, Bouman LN, Becker AE. Functional and morphological organization of the rabbit sinus node. Circulation Research. 1980; 46:11-22. [PubMed: 7349910]

63. Bogdanov KY, Maltsev VA, Vinogradova TM, Lyashkov AE, Spurgeon HA, Stern MD, Lakatta EG. Membrane potential fluctuations resulting from submembrane $\mathrm{Ca} 2+$ releases in rabbit sinoatrial nodal cells impart an exponential phase to the late diastolic depolarization that controls their chronotropic state. Circulation Research. 2006; 99:979-987. [PubMed: 17008599]

64. Bogdanov KY, Vinogradova TM, Lakatta EG. Sinoatrial nodal cell ryanodine receptor and $\mathrm{Na}(+)-$ $\mathrm{Ca}(2+)$ exchanger: molecular partners in pacemaker regulation. Circulation Research. 2001; 88:1254-1258. [PubMed: 11420301]

65. Bois P, Bescond J, Renaudon B, Lenfant J. Mode of action of bradycardic agent, S 16257, on ionic currents of rabbit sinoatrial node cells. British Journal of Pharmacology. 1996; 118:1051-1057. [PubMed: 8799581]

66. Boogers MJ, Borleffs CJ, Henneman MM, van Bommel RJ, van Ramshorst J, Boersma E, DibbetsSchneider P, Stokkel MP, van der Wall EE, Schalij MJ, Bax JJ. Cardiac sympathetic denervation assessed with 123-iodine metaiodobenzylguanidine imaging predicts ventricular arrhythmias in implantable cardioverter-defibrillator patients. J Am Coll Cardiol. 2010; 55:2769-2777. [PubMed: 20538172]

67. Borlak J, Thum T. Hallmarks of ion channel gene expression in end-stage heart failure. FASEB journal : official publication of the Federation of American Societies for Experimental Biology. 2003; 17:1592-1608. [PubMed: 12958166]

68. Bosch RF, Gaspo R, Busch AE, Lang HJ, Li GR, Nattel S. Effects of the chromanol 293B, a selective blocker of the slow, component of the delayed rectifier $\mathrm{K}+$ current, on repolarization in human and guinea pig ventricular myocytes. Cardiovasc Res. 1998; 38:441-450. [PubMed: 9709405] 
69. Bosch RF, Zeng X, Grammer JB, Popovic K, Mewis C, Kuhlkamp V. Ionic mechanisms of electrical remodeling in human atrial fibrillation. Cardiovasc Res. 1999; 44:121-131. [PubMed: 10615396]

70. Boukens BJ, Christoffels VM, Coronel R, Moorman AF. Developmental basis for electrophysiological heterogeneity in the ventricular and outflow tract myocardium as a substrate for life-threatening ventricular arrhythmias. Circ Res. 2009; 104:19-31. [PubMed: 19118284]

71. Boyden PA, Barbhaiya C, Lee T, Ter Keurs HEDJ. Nonuniform Ca2+ transients in arrhythmogenic Purkinje cells that survive in the infarcted canine heart. Cardiovascular Research. 2003; 57:681693. [PubMed: 12618230]

72. Boyden PA, Dun W, Barbhaiya C, Ter Keurs HEDJ. 2APB- and JTV519(K201)-sensitive micro $\mathrm{Ca} 2+$ waves in arrhythmogenic Purkinje cells that survive in infarcted canine heart. Heart rhythm : the official journal of the Heart Rhythm Society. 2004; 1:218-226. [PubMed: 15851156]

73. Boyden PA, Pu J, Pinto J, Keurs HE. Ca(2+) transients and $\mathrm{Ca}(2+)$ waves in purkinje cells : role in action potential initiation. Circulation Research. 2000; 86:448-455. [PubMed: 10700450]

74. Boyett MR, Dobrzynski H, Lancaster MK, Jones SA, Honjo H, Kodama I. Sophisticated architecture is required for the sinoatrial node to perform its normal pacemaker function. $\mathbf{J}$ Cardiovasc Electrophysiol. 2003; 14:104-106. [PubMed: 12625620]

75. Boyett MR, Hart G, Levi AJ, Roberts A. Effects of repetitive activity on developed force and intracellular sodium in isolated sheep and dog Purkinje fibres. The Journal of Physiology. 1987; 388:295-322. [PubMed: 2443691]

76. Boyett MR, Honjo H, Kodama I. The sinoatrial node, a heterogeneous pacemaker structure. Cardiovascular Research. 2000; 47:658-687. [PubMed: 10974216]

77. Bozler E. The initiation of impulses in cardiac muscle. The American journal of physiology. 1943; 138:273-282.

78. Brahmajothi MV, Morales MJ, Reimer KA, Strauss HC. Regional localization of ERG, the channel protein responsible for the rapid component of the delayed rectifier, $\mathrm{K}+$ current in the ferret heart. Circ Res. 1997; 81:128-135. [PubMed: 9201036]

79. Brandt MC, Priebe L, Bohle T, Sudkamp M, Beuckelmann DJ. The ultrarapid and the transient outward $\mathrm{K}^{+}$current in human atrial fibrillation. Their possible role in postoperative atrial fibrillation. J Mol Cell Cardiol. 2000; 32:1885-1896. [PubMed: 11013132]

80. Brette F, Orchard CH. Density and sub-cellular distribution of cardiac and neuronal sodium channel isoforms in rat ventricular myocytes. Biochemical and biophysical research communications. 2006; 348:1163-1166. [PubMed: 16904633]

81. Brugada R, Hong K, Dumaine R, Cordeiro J, Gaita F, Borggrefe M, Menendez TM, Brugada J, Pollevick GD, Wolpert C, Burashnikov E, Matsuo K, Wu YS, Guerchicoff A, Bianchi F, Giustetto C, Schimpf R, Brugada P, Antzelevitch C. Sudden death associated with short-QT syndrome linked to mutations in HERG. Circulation. 2004; 109:30-35. [PubMed: 14676148]

82. Brundel BJ, Van Gelder IC, Henning RH, Tieleman RG, Tuinenburg AE, Wietses M, Grandjean JG, Van Gilst WH, Crijns HJ. Ion channel remodeling is related to intraoperative atrial effective refractory periods in patients with paroxysmal and persistent atrial fibrillation. Circulation. 2001; 103:684-690. [PubMed: 11156880]

83. Brundel BJ, van Gelder IC, Henning RH, Tuinenburg AE, Deelman LE, Tieleman RG, Grandjean JG, van Gilst WH, Crijns HJ. Gene expression of proteins influencing the calcium homeostasis in patients with persistent and paroxysmal atrial fibrillation. Cardiovasc Res. 1999; 42:443-454. [PubMed: 10533580]

84. Brundel BJ, Van Gelder IC, Henning RH, Tuinenburg AE, Wietses M, Grandjean JG, Wilde AA, Van Gilst WH, Crijns HJ. Alterations in potassium channel gene expression in atria of patients with persistent and paroxysmal atrial fibrillation: differential regulation of protein and mRNA levels for $\mathrm{K}^{+}$channels. J Am Coll Cardiol. 2001; 37:926-932. [PubMed: 11693772]

85. Bucchi A, Barbuti A, Baruscotti M, DiFrancesco D. Heart rate reduction via selective \&apos;funny\&apos; channel blockers. Current opinion in pharmacology. 2007; 7:208-213. [PubMed: 17267284] 
86. Burashnikov A, Antzelevitch C. Prominent I(Ks) in epicardium and endocardium contributes to development of transmural dispersion of repolarization but protects against development of early afterdepolarizations. J Cardiovasc Electrophysiol. 2002; 13:172-177. [PubMed: 11900293]

87. Burashnikov A, Antzelevitch C. Reinduction of atrial fibrillation immediately after termination of the arrhythmia is mediated by late phase 3 early afterdepolarization-induced triggered activity. Circulation. 2003; 107:2355-2360. [PubMed: 12695296]

88. Burashnikov A, Di Diego JM, Zygmunt AC, Belardinelli L, Antzelevitch C. Atrial-selective sodium channel block as a strategy for suppression of atrial fibrillation. Annals of the New York Academy of Sciences. 2008; 1123:105-112. [PubMed: 18375582]

89. Burashnikov A, Di Diego JM, Zygmunt AC, Belardinelli L, Antzelevitch C. Atrium-selective sodium channel block as a strategy for suppression of atrial fibrillation: differences in sodium channel inactivation between atria and ventricles and the role of ranolazine. Circulation. 2007; 116:1449-1457. [PubMed: 17785620]

90. Burashnikov E, Pfeiffer R, Barajas-Martinez H, Delpon E, Hu D, Desai M, Borggrefe M, Haissaguerre M, Kanter R, Pollevick GD, Guerchicoff A, Laino R, Marieb M, Nademanee K, Nam GB, Robles R, Schimpf R, Stapleton DD, Viskin S, Winters S, Wolpert C, Zimmern S, Veltmann C, Antzelevitch C. Mutations in the cardiac L-type calcium channel associated with inherited J-wave syndromes and sudden cardiac death. Heart Rhythm. 2010; 7:1872-1882. [PubMed: 20817017]

91. Burgess DE, Crawford O, Delisle BP, Satin J. Mechanism of inactivation gating of human T-type (low-voltage activated) calcium channels. Biophys J. 2002; 82:1894-1906. [PubMed: 11916848]

92. Burke MA, Mutharasan RK, Ardehali H. The sulfonylurea receptor, an atypical ATP-binding cassette protein, and its regulation of the KATP channel. Circ Res. 2008; 102:164-176. [PubMed: 18239147]

93. Butters TD, Aslanidi OV, Inada S, Boyett MR, Hancox JC, Lei M, Zhang H. Mechanistic links between $\mathrm{Na}+$ channel (SCN5A) mutations and impaired cardiac pacemaking in sick sinus syndrome. Circulation Research. 2010; 107:126-137. [PubMed: 20448214]

94. Caballero R, de la Fuente MG, Gómez R, Barana A, Amorós I, Dolz-Gaitón P, Osuna L, Almendral J, Atienza F, Fernández-Avilés F, Pita A, Rodríguez-Roda J, Pinto Á, Tamargo J, Delpón E. In Humans, Chronic Atrial Fibrillation Decreases the Transient Outward Current and Ultrarapid Component of the Delayed Rectifier Current Differentially on Each Atria and Increases the Slow Component of the Delayed Rectifier Current in Both. Journal of the American College of Cardiology. 2010; 55:2346-2354. [PubMed: 20488306]

95. Campuzano O, Brugada R. Genetics of familial atrial fibrillation. Europace : European pacing, arrhythmias, and cardiac electrophysiology : journal of the working groups on cardiac pacing, arrhythmias, and cardiac cellular electrophysiology of the European Society of Cardiology. 2009; 11:1267-1271.

96. Cao JM, Fishbein MC, Han JB, Lai WW, Lai AC, Wu TJ, Czer L, Wolf PL, Denton TA, Shintaku IP, Chen PS, Chen LS. Relationship between regional cardiac hyperinnervation and ventricular arrhythmia. Circulation. 2000; 101:1960-1969. [PubMed: 10779463]

97. Carbone E, Lux HD. Kinetics and selectivity of a low-voltage-activated calcium current in chick and rat sensory neurones. J Physiol. 1987; 386:547-570. [PubMed: 2445968]

98. Carbone E, Lux HD. Single low-voltage-activated calcium channels in chick and rat sensory neurones. J Physiol. 1987; 386:571-601. [PubMed: 2445969]

99. Cerrone M, Noujaim SF, Tolkacheva EG, Talkachou A, O\&apos;Connell R, Berenfeld O, Anumonwo J, Pandit SV, Vikstrom K, Napolitano C, Priori SG, Jalife J. Arrhythmogenic mechanisms in a mouse model of catecholaminergic polymorphic ventricular tachycardia. Circulation Research. 2007; 101:1039-1048. [PubMed: 17872467]

100. Chambers JC, Zhao J, Terracciano CM, Bezzina CR, Zhang W, Kaba R, Navaratnarajah M, Lotlikar A, Sehmi JS, Kooner MK, Deng G, Siedlecka U, Parasramka S, El-Hamamsy I, Wass MN, Dekker LR, de Jong JS, Sternberg MJ, McKenna W, Severs NJ, de Silva R, Wilde AA, Anand P, Yacoub M, Scott J, Elliott P, Wood JN, Kooner JS. Genetic variation in SCN10A influences cardiac conduction. Nat Genet. 2010; 42:149-152. [PubMed: 20062061]

101. Chandler NJ, Greener ID, Tellez JO, Inada S, Musa H, Molenaar P, DiFrancesco D, Baruscotti M, Longhi R, Anderson RH, Billeter R, Sharma V, Sigg DC, Boyett MR, Dobrzynski H. Molecular 
architecture of the human sinus node: insights into the function of the cardiac pacemaker. Circulation. 2009; 119:1562-1575. [PubMed: 19289639]

102. Chang PC, Turker I, Lopshire JC, Masroor S, Nguyen BL, Tao W, Rubart M, Chen PS, Chen Z, Ai T. Heterogeneous upregulation of apamin-sensitive potassium currents in failing human ventricles. J Am Heart Assoc. 2013; 2:e004713. [PubMed: 23525437]

103. Chelu MG, Sarma S, Sood S, Wang S, van Oort RJ, Skapura DG, Li N, Santonastasi M, Muller FU, Schmitz W, Schotten U, Anderson ME, Valderrabano M, Dobrev D, Wehrens XH. Calmodulin kinase II-mediated sarcoplasmic reticulum $\mathrm{Ca}^{2+}$ leak promotes atrial fibrillation in mice. J Clin Invest. 2009; 119:1940-1951. [PubMed: 19603549]

104. Chen L, Marquardt ML, Tester DJ, Sampson KJ, Ackerman MJ, Kass RS. Mutation of an Akinase-anchoring protein causes long-QT syndrome. Proceedings of the National Academy of Sciences of the United States of America. 2007; 104:20990-20995. [PubMed: 18093912]

105. Chen PS, Chen LS, Cao JM, Sharifi B, Karagueuzian HS, Fishbein MC. Sympathetic nerve sprouting, electrical remodeling and the mechanisms of sudden cardiac death. Cardiovasc Res. 2001; 50:409-416. [PubMed: 11334845]

106. Chen PS, Chen LS, Fishbein MC, Lin SF, Nattel S. Role of the autonomic nervous system in atrial fibrillation: pathophysiology and therapy. Circ Res. 2014; 114:1500-1515. [PubMed: 24763467]

107. Chen Q, Kirsch GE, Zhang D, Brugada R, Brugada J, Brugada P, Potenza D, Moya A, Borggrefe M, Breithardt G, Ortiz-Lopez R, Wang Z, Antzelevitch C, O'Brien RE, Schulze-Bahr E, Keating MT, Towbin JA, Wang Q. Genetic basis and molecular mechanism for idiopathic ventricular fibrillation. Nature. 1998; 392:293-296. [PubMed: 9521325]

108. Chen X, Piacentino V 3rd, Furukawa S, Goldman B, Margulies KB, Houser SR. L-type Ca2+ channel density and regulation are altered in failing human ventricular myocytes and recover after support with mechanical assist devices. Circ Res. 2002; 91:517-524. [PubMed: 12242270]

109. Chen YH, Xu SJ, Bendahhou S, Wang XL, Wang Y, Xu WY, Jin HW, Sun H, Su XY, Zhuang QN, Yang YQ, Li YB, Liu Y, Xu HJ, Li XF, Ma N, Mou CP, Chen Z, Barhanin J, Huang W. KCNQ1 gain-of-function mutation in familial atrial fibrillation. Science. 2003; 299:251-254. [PubMed: 12522251]

110. Cheng EP, Yuan C, Navedo MF, Dixon RE, Nieves-Cintron M, Scott JD, Santana LF. Restoration of normal L-type Ca2 + channel function during Timothy syndrome by ablation of an anchoring protein. Circ Res. 2011; 109:255-261. [PubMed: 21700933]

111. Cheng J, Kamiya K, Liu W, Tsuji Y, Toyama J, Kodama I. Heterogeneous distribution of the two components of delayed rectifier K+ current: a potential mechanism of the proarrhythmic effects of methanesulfonanilideclass III agents. Cardiovasc Res. 1999; 43:135-147. [PubMed: 10536698]

112. Christ T, Boknik P, Wohrl S, Wettwer E, Graf EM, Bosch RF, Knaut M, Schmitz W, Ravens U, Dobrev D. L-Type $\mathrm{Ca}^{2+}$ Current Downregulation in Chronic Human Atrial Fibrillation Is Associated With Increased Activity of Protein Phosphatases. Circulation. 2004; 110:2651-2657. [PubMed: 15492323]

113. Christ T, Wettwer E, Voigt N, Hala O, Radicke S, Matschke K, Varro A, Dobrev D, Ravens U. Pathology-specific effects of the $\mathrm{I}_{\mathrm{Kur}} / \mathrm{I}_{\mathrm{to}} / \mathrm{I}_{\mathrm{K}, \mathrm{ACh}}$ blocker AVE0118 on ion channels in human chronic atrial fibrillation. Br J Pharmacol. 2008; 154:1619-1630. [PubMed: 18536759]

114. Christophersen IE, Olesen MS, Liang B, Andersen MN, Larsen AP, Nielsen JB, Haunso S, Olesen SP, Tveit A, Svendsen JH, Schmitt N. Genetic variation in KCNA5: impact on the atrialspecific potassium current IKur in patients with lone atrial fibrillation. European heart journal. 2013; 34:1517-1525. [PubMed: 23264583]

115. Chua SK, Chang PC, Maruyama M, Turker I, Shinohara T, Shen MJ, Chen Z, Shen C, Rubartvon der Lohe M, Lopshire JC, Ogawa M, Weiss JN, Lin SF, Ai T, Chen PS. Small-conductance calcium-activated potassium channel and recurrent ventricular fibrillation in failing rabbit ventricles. Circulation research. 2011; 108:971-979. [PubMed: 21350217]

116. Clark RB, Bouchard RA, Salinas-Stefanon E, Sanchez-Chapula J, Giles WR. Heterogeneity of action potential waveforms and potassium currents in rat ventricle. Cardiovasc Res. 1993; 27:1795-1799. [PubMed: 8275526] 
117. Cohen SA. Immunocytochemical localization of $\mathrm{rH} 1$ sodium channel in adult rat heart atria and ventricle. Presence in terminal intercalated disks. Circulation. 1996; 94:3083-3086. [PubMed: 8989112]

118. Colecraft HM, Alseikhan B, Takahashi SX, Chaudhuri D, Mittman S, Yegnasubramanian V, Alvania RS, Johns DC, Marban E, Yue DT. Novel functional properties of $\mathrm{Ca}(2+)$ channel beta subunits revealed by their expression in adult rat heart cells. J Physiol. 2002; 541:435-452. [PubMed: 12042350]

119. Coppen SR, Kodama I, Boyett MR, Dobrzynski H, Takagishi Y, Honjo H, Yeh HI, Severs NJ. Connexin45, a major connexin of the rabbit sinoatrial node, is co-expressed with connexin43 in a restricted zone at the nodal-crista terminalis border. The journal of histochemistry and cytochemistry : official journal of the Histochemistry Society. 1999; 47:907-918. [PubMed: 10375379]

120. Coppen SR, Severs NJ, Gourdie RG. Connexin45 (alpha 6) expression delineates an extended conduction system in the embryonic and mature rodent heart. Developmental genetics. 1999; 24:82-90. [PubMed: 10079513]

121. Cordeiro JM, Greene L, Heilmann C, Antzelevitch D, Antzelevitch C. Transmural heterogeneity of calcium activity and mechanical function in the canine left ventricle. American journal of physiology Heart and circulatory physiology. 2004; 286:H1471-H1479. [PubMed: 14670817]

122. Cordeiro JM, Spitzer KW, Giles WR. Repolarizing K+ currents in rabbit heart Purkinje cells. The Journal of Physiology. 1998; 508(Pt 3):811-823. [PubMed: 9518735]

123. Crisel RK, Farzaneh-Far R, Na B, Whooley MA. First-degree atrioventricular block is associated with heart failure and death in persons with stable coronary artery disease: data from the Heart and Soul Study. European heart journal. 2011; 32:1875-1880. [PubMed: 21606074]

124. Crotti L, Johnson CN, Graf E, De Ferrari GM, Cuneo BF, Ovadia M, Papagiannis J, Feldkamp MD, Rathi SG, Kunic JD, Pedrazzini M, Wieland T, Lichtner P, Beckmann BM, Clark T, Shaffer C, Benson DW, Kaab S, Meitinger T, Strom TM, Chazin WJ, Schwartz PJ, George AL Jr. Calmodulin mutations associated with recurrent cardiac arrest in infants. Circulation. 2013; 127:1009-1017. [PubMed: 23388215]

125. Cunha SR, Hund TJ, Hashemi S, Voigt N, Li N, Wright P, Koval O, Li J, Gudmundsson H, Gumina RJ, Karck M, Schott JJ, Probst V, Le Marec H, Anderson ME, Dobrev D, Wehrens XH, Mohler PJ. Defects in ankyrin-based membrane protein targeting pathways underlie atrial fibrillation. Circulation. 2011; 124:1212-1222. [PubMed: 21859974]

126. Curran J, Brown KH, Santiago DJ, Pogwizd S, Bers DM, Shannon TR. Spontaneous Ca waves in ventricular myocytes from failing hearts depend on $\mathrm{Ca}(2+)$-calmodulin-dependent protein kinase II. J Mol Cell Cardiol. 2010; 49:25-32. [PubMed: 20353795]

127. Curran J, Hinton MJ, Rios E, Bers DM, Shannon TR. Beta-adrenergic enhancement of sarcoplasmic reticulum calcium leak in cardiac myocytes is mediated by calcium/calmodulindependent protein kinase. Circ Res. 2007; 100:391-398. [PubMed: 17234966]

128. Curran ME, Splawski I, Timothy KW, Vincent GM, Green ED, Keating MT. A molecular basis for cardiac arrhythmia: HERG mutations cause long QT syndrome. Cell. 1995; 80:795-803. [PubMed: 7889573]

129. Currie S, Elliott EB, Smith GL, Loughrey CM. Two candidates at the heart of dysfunction: The ryanodine receptor and calcium/calmodulin protein kinase II as potential targets for therapeutic intervention-An in vivo perspective. Pharmacology \& therapeutics. 2011; 131:204-220. [PubMed: 21414358]

130. Currie S, Loughrey CM, Craig MA, Smith GL. Calcium/calmodulin-dependent protein kinase IIdelta associates with the ryanodine receptor complex and regulates channel function in rabbit heart. The Biochemical journal. 2004; 377:357-366. [PubMed: 14556649]

131. Darbar D, Kannankeril PJ, Donahue BS, Kucera G, Stubblefield T, Haines JL, George AL Jr, Roden DM. Cardiac sodium channel (SCN5A) variants associated with atrial fibrillation. Circulation. 2008; 117:1927-1935. [PubMed: 18378609]

132. Davies MJ, Pomerance A. Quantitative study of ageing changes in the human sinoatrial node and internodal tracts. British heart journal. 1972; 34:150-152. [PubMed: 5007792] 
133. Delpon E, Cordeiro JM, Nunez L, Thomsen PE, Guerchicoff A, Pollevick GD, Wu Y, Kanters JK, Larsen CT, Hofman-Bang J, Burashnikov E, Christiansen M, Antzelevitch C. Functional effects of KCNE3 mutation and its role in the development of Brugada syndrome. Circ Arrhythm Electrophysiol. 2008; 1:209-218. [PubMed: 19122847]

134. Deo M, Ruan Y, Pandit SV, Shah K, Berenfeld O, Blaufox A, Cerrone M, Noujaim SF, Denegri M, Jalife J, Priori SG. KCNJ2 mutation in short QT syndrome 3 results in atrial fibrillation and ventricular proarrhythmia. Proceedings of the National Academy of Sciences of the United States of America. 2013; 110:4291-4296. [PubMed: 23440193]

135. DePaoli AM, Bell GI, Stoffel M. G protein-activated inwardly rectifying potassium channel (GIRK1/KGA) mRNA in adult rat heart and brain by in situ hybridization histochemistry. Molecular and cellular neurosciences. 1994; 5:515-522. [PubMed: 7704424]

136. Dhamoon AS, Pandit SV, Sarmast F, Parisian KR, Guha P, Li Y, Bagwe S, Taffet SM, Anumonwo JM. Unique Kir2.x properties determine regional and species differences in the cardiac inward rectifier K+ current. Circ Res. 2004; 94:1332-1339. [PubMed: 15087421]

137. Dhar Malhotra J, Chen C, Rivolta I, Abriel H, Malhotra R, Mattei LN, Brosius FC, Kass RS, Isom LL. Characterization of sodium channel alpha- and beta-subunits in rat and mouse cardiac myocytes. Circulation. 2001; 103:1303-1310. [PubMed: 11238277]

138. Di Diego JM, Sun ZQ, Antzelevitch C. I(to) and action potential notch are smaller in left vs. right canine ventricular epicardium. Am J Physiol. 1996; 271:H548-H561. [PubMed: 8770096]

139. Difrancesco D. A new interpretation of the pace-maker current in calf Purkinje fibres. The Journal of Physiology. 1981; 314:359-376. [PubMed: 6273533]

140. Difrancesco D. A study of the ionic nature of the pace-maker current in calf Purkinje fibres. The Journal of Physiology. 1981; 314:377-393. [PubMed: 6273534]

141. DiFrancesco D, Noble D. The funny current has a major pacemaking role in the sinus node. Heart rhythm : the official journal of the Heart Rhythm Society. 2012; 9:299-301. [PubMed: 21925134]

142. Dimmer C, Tavernier R, Gjorgov N, Van Nooten G, Clement DL, Jordaens L. Variations of autonomic tone preceding onset of atrial fibrillation after coronary artery bypass grafting. Am $\mathrm{J}$ Cardiol. 1998; 82:22-25. [PubMed: 9671003]

143. Dixon AK, Gubitz AK, Ashford ML, Richardson PJ, Freeman TC. Distribution of mRNA encoding the inwardly rectifying K+ channel, BIR1 in rat tissues. FEBS letters. 1995; 374:135140. [PubMed: 7589501]

144. Dixon JE, Shi W, Wang HS, McDonald C, Yu H, Wymore RS, Cohen IS, McKinnon D. Role of the Kv4.3 K+ channel in ventricular muscle. A molecular correlate for the transient outward current. Circ Res. 1996; 79:659-668. [PubMed: 8831489]

145. Dobrev D, Friedrich A, Voigt N, Jost N, Wettwer E, Christ T, Knaut M, Ravens U. The G protein-gated potassium current $\mathrm{I}_{\mathrm{K}, \mathrm{ACh}}$ is constitutively active in patients with chronic atrial fibrillation. Circulation. 2005; 112:3697-3706. [PubMed: 16330682]

146. Dobrev D, Graf E, Wettwer E, Himmel HM, Hala O, Doerfel C, Christ T, Schuler S, Ravens U. Molecular Basis of Downregulation of G-Protein-Coupled Inward Rectifying $\mathrm{K}^{+}$Current $\left(\mathrm{I}_{\mathrm{K}, \mathrm{ACh}}\right)$ in Chronic Human Atrial Fibrillation: Decrease in GIRK4 mRNA Correlates With Reduced $\mathrm{I}_{\mathrm{K}, \mathrm{ACh}}$ and Muscarinic Receptor-Mediated Shortening of Action Potentials. Circulation. 2001; 104:2551-2557. [PubMed: 11714649]

147. Dobrev D, Nattel S. Calcium Handling Abnormalities in Atrial Fibrillation as a Target for Innovative Therapeutics. Journal of Cardiovascular Pharmacology. 2008; 52:293-299. [PubMed: 18791467]

148. Dobrev D, Ravens U. Remodeling of cardiomyocyte ion channels in human atrial fibrillation. Basic Res Cardiol. 2003; 98:137-148. [PubMed: 12883831]

149. Dobrev D, Voigt N, Wehrens XHT. The ryanodine receptor channel as a molecular motif in atrial fibrillation: pathophysiological and therapeutic implications. Cardiovascular Research. 2011; 89:734-743. [PubMed: 20943673]

150. Dobrzynski H, Anderson RH, Atkinson A, Borbas Z, D\&apos;Souza A, Fraser JF, Inada S, Logantha SJRJ, Monfredi O, Morris GM, Moorman AFM, Nikolaidou T, Schneider H, Szuts V, Temple IP, Yanni J, Boyett MR. Structure, function and clinical relevance of the cardiac 
conduction system, including the atrioventricular ring and outflow tract tissues. Pharmacology \&amp; therapeutics. 2013; 139:260-288. [PubMed: 23612425]

151. Dobrzynski H, Marples DD, Musa H, Yamanushi TT, Henderson Z, Takagishi Y, Honjo H, Kodama I, Boyett MR. Distribution of the muscarinic K+ channel proteins Kir3.1 and Kir3.4 in the ventricle, atrium, and sinoatrial node of heart. The journal of histochemistry and cytochemistry : official journal of the Histochemistry Society. 2001; 49:1221-1234. [PubMed: 11561006]

152. Dobrzynski H, Nikolski VP, Sambelashvili AT, Greener ID, Yamamoto M, Boyett MR, Efimov IR. Site of origin and molecular substrate of atrioventricular junctional rhythm in the rabbit heart. Circulation Research. 2003; 93:1102-1110. [PubMed: 14563715]

153. Doupnik CA, Davidson N, Lester HA. The inward rectifier potassium channel family. Current opinion in neurobiology. 1995; 5:268-277. [PubMed: 7580148]

154. Dun W, Boyden PA. The Purkinje cell; 2008 style. Journal of Molecular and Cellular Cardiology. 2008; 45:617-624. [PubMed: 18778712]

155. Dzhura I, Wu Y, Colbran RJ, Balser JR, Anderson ME. Calmodulin kinase determines calciumdependent facilitation of L-type calcium channels. Nat Cell Biol. 2000; 2:173-177. [PubMed: 10707089]

156. Edwards AG, Grandi E, Hake JE, Patel S, Li P, Miyamoto S, Omens JH, Brown JH, Bers DM, $\mathrm{McCulloch}$ AD. Non-equilibrium reactivation of the Na+ current drives early afterdepolarizations in mouse ventricle. In revision for Circ: Arrhyth\&EP. 2014

157. Ehrlich JR, Cha TJ, Zhang L, Chartier D, Melnyk P, Hohnloser SH, Nattel S. Cellular electrophysiology of canine pulmonary vein cardiomyocytes: action potential and ionic current properties. J Physiol. 2003; 551:801-813. [PubMed: 12847206]

158. Ehrlich JR, Nattel S, Hohnloser SH. Atrial fibrillation and congestive heart failure: specific considerations at the intersection of two common and important cardiac disease sets. Journal of cardiovascular electrophysiology. 2002; 13:399-405. [PubMed: 12033360]

159. Eiras S, Narolska NA, van Loon RB, Boontje NM, Zaremba R, Jimenez CR, Visser FC, Stooker W, van der Velden J, Stienen GJ. Alterations in contractile protein composition and function in human atrial dilatation and atrial fibrillation. J Mol Cell Cardiol. 2006; 41:467-477. [PubMed: 16901501]

160. El-Armouche A, Boknik P, Eschenhagen T, Carrier L, Knaut M, Ravens U, Dobrev D. Molecular determinants of altered $\mathrm{Ca}^{2+}$ handling in human chronic atrial fibrillation. Circulation. 2006; 114:670-680. [PubMed: 16894034]

161. Ellinghaus P, Scheubel RJ, Dobrev D, Ravens U, Holtz J, Huetter J, Nielsch U, Morawietz H. Comparing the global mRNA expression profile of human atrial and ventricular myocardium with high-density oligonucleotide arrays. The Journal of thoracic and cardiovascular surgery. 2005; 129:1383-1390. [PubMed: 15942582]

162. Erickson JR, Joiner ML, Guan X, Kutschke W, Yang J, Oddis CV, Bartlett RK, Lowe JS, O'Donnell SE, Aykin-Burns N, Zimmerman MC, Zimmerman K, Ham AJ, Weiss RM, Spitz DR, Shea MA, Colbran RJ, Mohler PJ, Anderson ME. A dynamic pathway for calcium-independent activation of CaMKII by methionine oxidation. Cell. 2008; 133:462-474. [PubMed: 18455987]

163. Eschenhagen T. Is ryanodine receptor phosphorylation key to the fight or flight response and heart failure? J Clin Invest. 2010; 120:4197-4203. [PubMed: 21099119]

164. Faggiano P, d\&apos;Aloia A, Gualeni A, Gardini A, Giordano A. Mechanisms and immediate outcome of in-hospital cardiac arrest in patients with advanced heart failure secondary to ischemic or idiopathic dilated cardiomyopathy. Am J Cardiol. 2001; 87:655-657. A610-A651. [PubMed: 11230859]

165. Fallavollita JA, Heavey BM, Luisi AJ Jr, Michalek SM, Baldwa S, Mashtare TL Jr, Hutson AD, Dekemp RA, Haka MS, Sajjad M, Cimato TR, Curtis AB, Cain ME, Canty JM Jr. Regional myocardial sympathetic denervation predicts the risk of sudden cardiac arrest in ischemic cardiomyopathy. J Am Coll Cardiol. 2014; 63:141-149. [PubMed: 24076296]

166. Fedida D, Giles WR. Regional variations in action potentials and transient outward current in myocytes isolated from rabbit left ventricle. J Physiol. 1991; 442:191-209. [PubMed: 1665856] 
167. Fedorov VV, Glukhov AV, Chang R, Kostecki G, Aferol H, Hucker WJ, Wuskell JP, Loew LM, Schuessler RB, Moazami N, Efimov IR. Optical mapping of the isolated coronary-perfused human sinus node. Journal of the American College of Cardiology. 2010; 56:1386-1394. [PubMed: 20946995]

168. Fedorov VV, Schuessler RB, Hemphill M, Ambrosi CM, Chang R, Voloshina AS, Brown K, Hucker WJ, Efimov IR. Structural and functional evidence for discrete exit pathways that connect the canine sinoatrial node and atria. Circulation Research. 2009; 104:915-923. [PubMed: 19246679]

169. Feng J, Yue L, Wang Z, Nattel S. Ionic mechanisms of regional action potential heterogeneity in the canine right atrium. Circ Res. 1998; 83:541-551. [PubMed: 9734477]

170. Fermini B, Wang Z, Duan D, Nattel S. Differences in rate dependence of transient outward current in rabbit and human atrium. Am J Physiol. 1992; 263:H1747-H1754. [PubMed: 1481900]

171. Firek L, Giles WR. Outward currents underlying repolarization in human atrial myocytes. Cardiovasc Res. 1995; 30:31-38. [PubMed: 7553721]

172. Fiset C, Clark RB, Shimoni Y, Giles WR. Shal-type channels contribute to the Ca2+-independent transient outward K+ current in rat ventricle. J Physiol. 1997; 500(Pt 1):51-64. [PubMed: 9097932]

173. Flagg TP, Kurata HT, Masia R, Caputa G, Magnuson MA, Lefer DJ, Coetzee WA, Nichols CG. Differential structure of atrial and ventricular KATP: atrial KATP channels require SUR1. Circ Res. 2008; 103:1458-1465. [PubMed: 18974387]

174. Frank K, Kranias EG. Phospholamban and cardiac contractility. Annals of medicine. 2000; 32:572-578. [PubMed: 11127935]

175. Fulop L, Banyasz T, Magyar J, Szentandrassy N, Varro A, Nanasi PP. Reopening of L-type calcium channels in human ventricular myocytes during applied epicardial action potentials. Acta physiologica Scandinavica. 2004; 180:39-47. [PubMed: 14706111]

176. Furukawa T, Myerburg RJ, Furukawa N, Bassett AL, Kimura S. Differences in transient outward currents of feline endocardial and epicardial myocytes. Circ Res. 1990; 67:1287-1291. [PubMed: 2225360]

177. Furushima H, Chinushi M, Okamura K, Iijima K, Komura S, Tanabe Y, Okada S, Izumi D, Aizawa Y. Comparison of conduction delay in the right ventricular outflow tract between Brugada syndrome and right ventricular cardiomyopathy: investigation of signal average ECG in the precordial leads. Europace : European pacing, arrhythmias, and cardiac electrophysiology : journal of the working groups on cardiac pacing, arrhythmias, and cardiac cellular electrophysiology of the European Society of Cardiology. 2007; 9:951-956.

178. Gaborit N, Le Bouter S, Szuts V, Varro A, Escande D, Nattel S, Demolombe S. Regional and tissue specific transcript signatures of ion channel genes in the non-diseased human heart. J Physiol. 2007; 582:675-693. [PubMed: 17478540]

179. Gao B, Sekido Y, Maximov A, Saad M, Forgacs E, Latif F, Wei MH, Lerman M, Lee JH, PerezReyes E, Bezprozvanny I, Minna JD. Functional properties of a new voltage-dependent calcium channel alpha(2)delta auxiliary subunit gene (CACNA2D2). J Biol Chem. 2000; 275:1223712242. [PubMed: 10766861]

180. Gao G, Xie A, Huang SC, Zhou A, Zhang J, Herman AM, Ghassemzadeh S, Jeong EM, Kasturirangan S, Raicu M, Sobieski MA 2nd, Bhat G, Tatooles A, Benz EJ Jr, Kamp TJ, Dudley SC Jr. Role of RBM25/LUC7L3 in abnormal cardiac sodium channel splicing regulation in human heart failure. Circulation. 2011; 124:1124-1131. [PubMed: 21859973]

181. Gellens ME, George AL Jr, Chen LQ, Chahine M, Horn R, Barchi RL, Kallen RG. Primary structure and functional expression of the human cardiac tetrodotoxin-insensitive voltagedependent sodium channel. Proceedings of the National Academy of Sciences of the United States of America. 1992; 89:554-558. [PubMed: 1309946]

182. George $\mathrm{CH}$. Sarcoplasmic reticulum $\mathrm{Ca} 2+$ leak in heart failure: mere observation or functional relevance? Cardiovasc Res. 2008; 77:302-314. [PubMed: 18006486]

183. Giles WR, Imaizumi Y. Comparison of potassium currents in rabbit atrial and ventricular cells. J Physiol. 1988; 405:123-145. [PubMed: 2855639] 
184. Ginsburg KS, Bers DM. Modulation of excitation-contraction coupling by isoproterenol in cardiomyocytes with controlled SR Ca2+ load and Ca2+ current trigger. J Physiol. 2004; 556:463-480. [PubMed: 14724205]

185. Giudicessi JR, Ye D, Tester DJ, Crotti L, Mugione A, Nesterenko VV, Albertson RM, Antzelevitch C, Schwartz PJ, Ackerman MJ. Transient outward current (I(to)) gain-of-function mutations in the KCND3-encoded Kv4.3 potassium channel and Brugada syndrome. Heart Rhythm. 2011; 8:1024-1032. [PubMed: 21349352]

186. Go AS, Mozaffarian D, Roger VL, Benjamin EJ, Berry JD, Blaha MJ, Dai S, Ford ES, Fox CS, Franco S, Fullerton HJ, Gillespie C, Hailpern SM, Heit JA, Howard VJ, Huffman MD, Judd SE, Kissela BM, Kittner SJ, Lackland DT, Lichtman JH, Lisabeth LD, Mackey RH, Magid DJ, Marcus GM, Marelli A, Matchar DB, McGuire DK, Mohler ER 3rd, Moy CS, Mussolino ME, Neumar RW, Nichol G, Pandey DK, Paynter NP, Reeves MJ, Sorlie PD, Stein J, Towfighi A, Turan TN, Virani SS, Wong ND, Woo D, Turner MB. American Heart Association Statistics C, Stroke Statistics S. Heart disease and stroke statistics--2014 update: a report from the American Heart Association. Circulation. 2014; 129:e28-e292. [PubMed: 24352519]

187. Gollob MH, Jones DL, Krahn AD, Danis L, Gong XQ, Shao Q, Liu X, Veinot JP, Tang AS, Stewart AF, Tesson F, Klein GJ, Yee R, Skanes AC, Guiraudon GM, Ebihara L, Bai D. Somatic mutations in the connexin 40 gene (GJA5) in atrial fibrillation. The New England journal of medicine. 2006; 354:2677-2688. [PubMed: 16790700]

188. Gonzalez de la Fuente M, Barana A, Gomez R, Amoros I, Dolz-Gaiton P, Sacristan S, Atienza F, Pita A, Pinto A, Fernandez-Aviles F, Caballero R, Tamargo J, Delpon E. Chronic atrial fibrillation up-regulates beta1-Adrenoceptors affecting repolarizing currents and action potential duration. Cardiovasc Res. 2013; 97:379-388. [PubMed: 23060133]

189. Gorza L, Schiaffino S, Volpe P. Inositol 1,4,5-trisphosphate receptor in heart: evidence for its concentration in Purkinje myocytes of the conduction system. The Journal of cell biology. 1993; 121:345-353. [PubMed: 8385671]

190. Gourdie RG, Severs NJ, Green CR, Rothery S, Germroth P, Thompson RP. The spatial distribution and relative abundance of gap-junctional connexin 40 and connexin 43 correlate to functional properties of components of the cardiac atrioventricular conduction system. Journal of cell science. 1993; 105(Pt 4):985-991. [PubMed: 8227219]

191. Grammer JB, Bosch RF, Kuhlkamp V, Seipel L. Molecular remodeling of Kv4.3 potassium channels in human atrial fibrillation. J Cardiovasc Electrophysiol. 2000; 11:626-633. [PubMed: 10868735]

192. Grandi, E.; Bers, DM. Models of the Ventricular Action Potential in Health and Disease. In: Zipes, DP.; Jalife, J., editors. Cardiac Electrophysiology: from Cell to Bedside. 6th ed.. Saunders; 2013.

193. Grandi E, Pandit SV, Voigt N, Workman AJ, Dobrev D, Jalife J, Bers DM. Human atrial action potential and $\mathrm{Ca}^{2+}$ model: sinus rhythm and chronic atrial fibrillation. Circ Res. 2011; 109:10551066. [PubMed: 21921263]

194. Grandi E, Pasqualini FS, Bers DM. A novel computational model of the human ventricular action potential and Ca transient. J Mol Cell Cardiol. 2010; 48:112-121. [PubMed: 19835882]

195. Grandi E, Puglisi JL, Wagner S, Maier LS, Severi S, Bers DM. Simulation of Ca-calmodulindependent protein kinase II on rabbit ventricular myocyte ion currents and action potentials. Biophys J. 2007; 93:3835-3847. [PubMed: 17704163]

196. Grandi E, Workman AJ, Pandit SV. Altered Excitation-Contraction Coupling in Human Chronic Atrial Fibrillation. J Atr Fibrillation. 2012; 4:37-53.

197. Greener ID, Monfredi O, Inada S, Chandler NJ, Tellez JO, Atkinson A, Taube M-A, Billeter R, Anderson RH, Efimov IR, Molenaar P, Sigg DC, Sharma V, Boyett MR, Dobrzynski H. Molecular architecture of the human specialised atrioventricular conduction axis. Journal of Molecular and Cellular Cardiology. 2011; 50:642-651. [PubMed: 21256850]

198. Greener ID, Tellez JO, Dobrzynski H, Yamamoto M, Graham GM, Billeter R, Boyett MR. Ion channel transcript expression at the rabbit atrioventricular conduction axis. Circulation: Arrhythmia and Electrophysiology. 2009; 2:305-315. [PubMed: 19808481]

199. Greiser M, Neuberger HR, Harks E, El-Armouche A, Boknik P, de Haan S, Verheyen F, Verheule S, Schmitz W, Ravens U, Nattel S, Allessie MA, Dobrev D, Schotten U. Distinct contractile and 
molecular differences between two goat models of atrial dysfunction: AV block-induced atrial dilatation and atrial fibrillation. J Mol Cell Cardiol. 2009; 46:385-394. [PubMed: 19100271]

200. Guerra JM, Everett THt, Lee KW, Wilson E, Olgin JE. Effects of the gap junction modifier rotigaptide (ZP123) on atrial conduction and vulnerability to atrial fibrillation. Circulation. 2006; 114:110-118. [PubMed: 16818812]

201. Guerrero PA, Schuessler RB, Davis LM, Beyer EC, Johnson CM, Yamada KA, Saffitz JE. Slow ventricular conduction in mice heterozygous for a connexin43 null mutation. J Clin Invest. 1997; 99:1991-1998. [PubMed: 9109444]

202. Gui L, Bao Z, Jia Y, Qin X, Cheng ZJ, Zhu J, Chen QH. Ventricular tachyarrhythmias in rats with acute myocardial infarction involves activation of small-conductance $\mathrm{Ca} 2+$-activated $\mathrm{K}+$ channels. American journal of physiology Heart and circulatory physiology. 2013; 304:H118H130. [PubMed: 23086994]

203. Guo W, Li H, Aimond F, Johns DC, Rhodes KJ, Trimmer JS, Nerbonne JM. Role of heteromultimers in the generation of myocardial transient outward K+ currents. Circ Res. 2002; 90:586-593. [PubMed: 11909823]

204. Guo W, Li H, London B, Nerbonne JM. Functional consequences of elimination of i(to,f) and i(to,s): early afterdepolarizations, atrioventricular block, and ventricular arrhythmias in mice lacking Kv1.4 and expressing a dominant-negative Kv4 alpha subunit. Circ Res. 2000; 87:73-79. [PubMed: 10884375]

205. Gurney A, Manoury B. Two-pore potassium channels in the cardiovascular system. European biophysics journal : EBJ. 2009; 38:305-318. [PubMed: 18449536]

206. Gussak I, Chaitman BR, Kopecky SL, Nerbonne JM. Rapid ventricular repolarization in rodents: electrocardiographic manifestations, molecular mechanisms, and clinical insights. Journal of electrocardiology. 2000; 33:159-170. [PubMed: 10819409]

207. Hagendorff A, Schumacher B, Kirchhoff S, Luderitz B, Willecke K. Conduction disturbances and increased atrial vulnerability in Connexin40-deficient mice analyzed by transesophageal stimulation. Circulation. 1999; 99:1508-1515. [PubMed: 10086977]

208. Hagiwara N, Irisawa H, Kameyama M. Contribution of two types of calcium currents to the pacemaker potentials of rabbit sino-atrial node cells. The Journal of Physiology. 1988; 395:233253. [PubMed: 2457676]

209. Handrock R, Schroder F, Hirt S, Haverich A, Mittmann C, Herzig S. Single-channel properties of L-type calcium channels from failing human ventricle. Cardiovasc Res. 1998; 37:445-455. [PubMed: 9614499]

210. Hao X, Zhang Y, Zhang X, Nirmalan M, Davies L, Konstantinou D, Yin F, Dobrzynski H, Wang X, Grace A, Zhang H, Boyett M, Huang CLH, Lei M. TGF- $\beta 1$-mediated fibrosis and ion channel remodeling are key mechanisms in producing the sinus node dysfunction associated with SCN5A deficiency and aging. Circulation: Arrhythmia and Electrophysiology. 2011; 4:397-406. [PubMed: 21493874]

211. He K, Shi X, Zhang X, Dang S, Ma X, Liu F, Xu M, Lv Z, Han D, Fang X, Zhang Y. Longdistance intercellular connectivity between cardiomyocytes and cardiofibroblasts mediated by membrane nanotubes. Cardiovasc Res. 2011; 92:39-47. [PubMed: 21719573]

212. Heath BM, Terrar DA. The deactivation kinetics of the delayed rectifier components IKr and IKs in guinea-pig isolated ventricular myocytes. Experimental physiology. 1996; 81:605-621. [PubMed: 8853269]

213. Heath BM, Terrar DA. Separation of the components of the delayed rectifier potassium current using selective blockers of IKr and IKs in guinea-pig isolated ventricular myocytes. Experimental physiology. 1996; 81:587-603. [PubMed: 8853268]

214. Heijman J, Spatjens RL, Seyen SR, Lentink V, Kuijpers HJ, Boulet IR, de Windt LJ, David M, Volders PG. Dominant-negative control of cAMP-dependent IKs upregulation in human long-QT syndrome type 1. Circulation research. 2012; 110:211-219. [PubMed: 22095730]

215. Herren AW, Bers DM, Grandi E. Post-translational modifications of the cardiac Na channel: contribution of CaMKII-dependent phosphorylation to acquired arrhythmias. Am J Physiol Heart Circ Physiol. 2013; 305:H431-H445. [PubMed: 23771687] 
216. Himmel HM, Wettwer E, Li Q, Ravens U. Four different components contribute to outward current in rat ventricular myocytes. The American journal of physiology. 1999; 277:H107-H118. [PubMed: 10409188]

217. Hirano Y, Moscucci A, January CT. Direct measurement of L-type Ca2+ window current in heart cells. Circulation Research. 1992; 70:445-455. [PubMed: 1371428]

218. Hiraoka M, Kawano S. Calcium-sensitive and insensitive transient outward current in rabbit ventricular myocytes. J Physiol. 1989; 410:187-212. [PubMed: 2552080]

219. Hobai IA, O'Rourke B. Decreased sarcoplasmic reticulum calcium content is responsible for defective excitation-contraction coupling in canine heart failure. Circulation. 2001; 103:15771584. [PubMed: 11257088]

220. Hobai IA, O'Rourke B. Enhanced $\mathrm{Ca}(2+)$-activated $\mathrm{Na}(+)-\mathrm{Ca}(2+)$ exchange activity in canine pacing-induced heart failure. Circ Res. 2000; 87:690-698. [PubMed: 11029405]

221. Hoch B, Meyer R, Hetzer R, Krause EG, Karczewski P. Identification and expression of deltaisoforms of the multifunctional $\mathrm{Ca} 2+/$ calmodulin-dependent protein kinase in failing and nonfailing human myocardium. Circ Res. 1999; 84:713-721. [PubMed: 10189359]

222. Hodgson-Zingman DM, Karst ML, Zingman LV, Heublein DM, Darbar D, Herron KJ, Ballew JD, de Andrade M, Burnett JC Jr, Olson TM. Atrial natriuretic peptide frameshift mutation in familial atrial fibrillation. The New England journal of medicine. 2008; 359:158-165. [PubMed: 18614783]

223. Holzem KM, Efimov IR. Arrhythmogenic remodelling of activation and repolarization in the failing human heart. Europace : European pacing, arrhythmias, and cardiac electrophysiology : journal of the working groups on cardiac pacing, arrhythmias, and cardiac cellular electrophysiology of the European Society of Cardiology. 2012; 14(Suppl 5):v50-v57.

224. Hong K, Piper DR, Diaz-Valdecantos A, Brugada J, Oliva A, Burashnikov E, Santos-de-Soto J, Grueso-Montero J, Diaz-Enfante E, Brugada P, Sachse F, Sanguinetti MC, Brugada R. De novo KCNQ1 mutation responsible for atrial fibrillation and short QT syndrome in utero. Cardiovasc Res. 2005; 68:433-440. [PubMed: 16109388]

225. Honjo H, Boyett MR, Coppen SR, Takagishi Y, Opthof T, Severs NJ, Kodama I. Heterogeneous expression of connexins in rabbit sinoatrial node cells: correlation between connexin isotype and cell size. Cardiovascular Research. 2002; 53:89-96. [PubMed: 11744016]

226. Honjo H, Boyett MR, Kodama I, Toyama J. Correlation between electrical activity and the size of rabbit sino-atrial node cells. The Journal of Physiology. 1996; 496(Pt 3):795-808. [PubMed: 8930845]

227. Horie M, Hayashi S, Kawai C. Two types of delayed rectifying K+ channels in atrial cells of guinea pig heart. The Japanese journal of physiology. 1990; 40:479-490. [PubMed: 2077173]

228. Hove-Madsen L, Llach A, Bayes-Genis A, Roura S, Rodriguez Font E, Aris A, Cinca J. Atrial fibrillation is associated with increased spontaneous calcium release from the sarcoplasmic reticulum in human atrial myocytes. Circulation. 2004; 110:1358-1363. [PubMed: 15313939]

229. Hsieh YC, Chang PC, Hsueh CH, Lee YS, Shen C, Weiss JN, Chen Z, Ai T, Lin SF, Chen PS. Apamin-sensitive potassium current modulates action potential duration restitution and arrhythmogenesis of failing rabbit ventricles. Circulation Arrhythmia and electrophysiology. 2013; 6:410-418. [PubMed: 23420832]

230. Hu D, Barajas-Martinez H, Burashnikov E, Springer M, Wu Y, Varro A, Pfeiffer R, Koopmann TT, Cordeiro JM, Guerchicoff A, Pollevick GD, Antzelevitch C. A mutation in the beta 3 subunit of the cardiac sodium channel associated with Brugada ECG phenotype. Circulation Cardiovascular genetics. 2009; 2:270-278. [PubMed: 20031595]

231. Huang B, Wang S, Qin D, Boutjdir M, El-Sherif N. Diminished basal phosphorylation level of phospholamban in the postinfarction remodeled rat ventricle: role of beta-adrenergic pathway, G(i) protein, phosphodiesterase, and phosphatases. Circ Res. 1999; 85:848-855. [PubMed: 10532953]

232. Hucker WJ, Sharma V, Nikolski VP, Efimov IR. Atrioventricular conduction with and without AV nodal delay: two pathways to the bundle of His in the rabbit heart. American journal of physiology Heart and circulatory physiology. 2007; 293:H1122-H1130. [PubMed: 17496219] 
233. Hullin R, Khan IF, Wirtz S, Mohacsi P, Varadi G, Schwartz A, Herzig S. Cardiac L-type calcium channel beta-subunits expressed in human heart have differential effects on single channel characteristics. The Journal of biological chemistry. 2003; 278:21623-21630. [PubMed: 12606548]

234. Hullin R, Singer-Lahat D, Freichel M, Biel M, Dascal N, Hofmann F, Flockerzi V. Calcium channel beta subunit heterogeneity: functional expression of cloned cDNA from heart, aorta and brain. Embo J. 1992; 11:885-890. [PubMed: 1312465]

235. Inada S, Hancox JC, Zhang H, Boyett MR. One-dimensional mathematical model of the atrioventricular node including atrio-nodal, nodal, and nodal-his cells. Biophysical journal. 2009; 97:2117-2127. [PubMed: 19843444]

236. Inoue M, Imanaga I. Masking of A-type $\mathrm{K}+$ channel in guinea pig cardiac cells by extracellular Ca2+ Am J Physiol. 1993; 264:C1434-C1438. [PubMed: 8333498]

237. Isomoto S, Kurachi Y. Function, regulation, pharmacology, and molecular structure of ATPsensitive K+ channels in the cardiovascular system. J Cardiovasc Electrophysiol. 1997; 8:14311446. [PubMed: 9436781]

238. Jalife J. Deja vu in the theories of atrial fibrillation dynamics. Cardiovasc Res. 2011; 89:766-775. [PubMed: 21097807]

239. Janse MJ, Sosunov EA, Coronel R, Opthof T, Anyukhovsky EP, de Bakker JM, Plotnikov AN, Shlapakova IN, Danilo P Jr, Tijssen JG, Rosen MR. Repolarization gradients in the canine left ventricle before and after induction of short-term cardiac memory. Circulation. 2005; 112:17111718. [PubMed: 16157774]

240. Janse MJ, Wit AL. Electrophysiological mechanisms of ventricular arrhythmias resulting from myocardial ischemia and infarction. Physiological reviews. 1989; 69:1049-1169. [PubMed: 2678165]

241. January CT, Riddle JM. Early afterdepolarizations: mechanism of induction and block. A role for L-type Ca2+ current. Circulation Research. 1989; 64:977-990. [PubMed: 2468430]

242. Jones SA, Boyett MR, Lancaster MK. Declining into failure: the age-dependent loss of the L-type calcium channel within the sinoatrial node. Circulation. 2007; 115:1183-1190. [PubMed: 17339548]

243. Jones SA, Lancaster MK, Boyett MR. Ageing-related changes of connexins and conduction within the sinoatrial node. The Journal of Physiology. 2004; 560:429-437. [PubMed: 15308686]

244. Josephson IR, Sanchez-Chapula J, Brown AM. Early outward current in rat single ventricular cells. Circ Res. 1984; 54:157-162. [PubMed: 6319044]

245. Jost N, Papp JG, Varro A. Slow delayed rectifier potassium current (IKs) and the repolarization reserve. Ann Noninvasive Electrocardiol. 2007; 12:64-78. [PubMed: 17286653]

246. Jost N, Papp JG, Varro A. Slow delayed rectifier potassium current (IKs) and the repolarization reserve. Annals of noninvasive electrocardiology : the official journal of the International Society for Holter and Noninvasive Electrocardiology, Inc. 2007; 12:64-78.

247. Jost N, Virag L, Bitay M, Takacs J, Lengyel C, Biliczki P, Nagy Z, Bogats G, Lathrop DA, Papp JG, Varro A. Restricting excessive cardiac action potential and QT prolongation: a vital role for IKs in human ventricular muscle. Circulation. 2005; 112:1392-1399. [PubMed: 16129791]

248. Jost N, Virag L, Comtois P, Ordog B, Szuts V, Seprenyi G, Bitay M, Kohajda Z, Koncz I, Nagy N, Szel T, Magyar J, Kovacs M, Puskas LG, Lengyel C, Wettwer E, Ravens U, Nanasi PP, Papp JG, Varro A, Nattel S. Ionic mechanisms limiting cardiac repolarization reserve in humans compared to dogs. J Physiol. 2013; 591:4189-4206. [PubMed: 23878377]

249. Kaab S, Dixon J, Duc J, Ashen D, Nabauer M, Beuckelmann DJ, Steinbeck G, McKinnon D, Tomaselli GF. Molecular basis of transient outward potassium current downregulation in human heart failure: a decrease in Kv4.3 mRNA correlates with a reduction in current density. Circulation. 1998; 98:1383-1393. [PubMed: 9760292]

250. Kaab S, Nuss HB, Chiamvimonvat N, O'Rourke B, Pak PH, Kass DA, Marban E, Tomaselli GF. Ionic mechanism of action potential prolongation in ventricular myocytes from dogs with pacinginduced heart failure. Circ Res. 1996; 78:262-273. [PubMed: 8575070]

251. Kaese S, Verheule S. Cardiac electrophysiology in mice: a matter of size. Frontiers in physiology. 2012; 3:345. [PubMed: 22973235] 
252. Kanazawa H, Ieda M, Kimura K, Arai T, Kawaguchi-Manabe H, Matsuhashi T, Endo J, Sano M, Kawakami T, Kimura T, Monkawa T, Hayashi M, Iwanami A, Okano H, Okada Y, IshibashiUeda H, Ogawa S, Fukuda K. Heart failure causes cholinergic transdifferentiation of cardiac sympathetic nerves via gp130-signaling cytokines in rodents. J Clin Invest. 2010; 120:408-421. [PubMed: 20051627]

253. Kane GC, Behfar A, Dyer RB, O'Cochlain DF, Liu XK, Hodgson DM, Reyes S, Miki T, Seino S, Terzic A. KCNJ11 gene knockout of the Kir6.2 KATP channel causes maladaptive remodeling and heart failure in hypertension. Human molecular genetics. 2006; 15:2285-2297. [PubMed: 16782803]

254. Kanter HL, Laing JG, Beau SL, Beyer EC, Saffitz JE. Distinct patterns of connexin expression in canine Purkinje fibers and ventricular muscle. Circ Res. 1993; 72:1124-1131. [PubMed: 8386597]

255. Kass RS, Sanguinetti MC. Inactivation of calcium channel current in the calf cardiac Purkinje fiber. Evidence for voltage- and calcium-mediated mechanisms. J Gen Physiol. 1984; 84:705726. [PubMed: 6096480]

256. Kato T, Iwasaki YK, Nattel S. Connexins and atrial fibrillation: filling in the gaps. Circulation. 2012; 125:203-206. [PubMed: 22158757]

257. Kattygnarath D, Maugenre S, Neyroud N, Balse E, Ichai C, Denjoy I, Dilanian G, Martins RP, Fressart V, Berthet M, Schott JJ, Leenhardt A, Probst V, Le Marec H, Hainque B, Coulombe A, Hatem SN, Guicheney P. MOG1: a new susceptibility gene for Brugada syndrome. Circulation Cardiovascular genetics. 2011; 4:261-268. [PubMed: 21447824]

258. Keith A, Flack M. The Form and Nature of the Muscular Connections between the Primary Divisions of the Vertebrate Heart. Journal of anatomy and physiology. 1907; 41:172-189. [PubMed: 17232727]

259. Kirchhefer U, Schmitz W, Scholz H, Neumann J. Activity of cAMP-dependent protein kinase and $\mathrm{Ca} 2+/$ calmodulin-dependent protein kinase in failing and nonfailing human hearts. Cardiovasc Res. 1999; 42:254-261. [PubMed: 10435018]

260. Kirchhof CJ, Bonke FI, Allessie MA. Evidence for the presence of electrotonic depression of pacemakers in the rabbit atrioventricular node. The effects of uncoupling from the surrounding myocardium. Basic research in cardiology. 1988; 83:190-201. [PubMed: 3395316]

261. Kiss E, Ball NA, Kranias EG, Walsh RA. Differential changes in cardiac phospholamban and sarcoplasmic reticular $\mathrm{Ca}(2+)$-ATPase protein levels. Effects on $\mathrm{Ca} 2+$ transport and mechanics in compensated pressure-overload hypertrophy and congestive heart failure. Circ Res. 1995; 77:759-764. [PubMed: 7554123]

262. Kjekshus J. Arrhythmias and mortality in congestive heart failure. Am J Cardiol. 1990; 65:42I48I.

263. Kline RP, Kupersmith J. Effects of extracellular potassium accumulation and sodium pump activation on automatic canine Purkinje fibres. The Journal of Physiology. 1982; 324:507-533. [PubMed: 7097608]

264. Kneller J, Kalifa J, Zou R, Zaitsev AV, Warren M, Berenfeld O, Vigmond EJ, Leon LJ, Nattel S, Jalife J. Mechanisms of atrial fibrillation termination by pure sodium channel blockade in an ionically-realistic mathematical model. Circ Res. 2005; 96:e35-e47. [PubMed: 15731458]

265. Kodama I, Nikmaram MR, Boyett MR, Suzuki R, Honjo H, Owen JM. Regional differences in the role of the $\mathrm{Ca} 2+$ and $\mathrm{Na}+$ currents in pacemaker activity in the sinoatrial node. The American journal of physiology. 1997; 272:H2793-H2806. [PubMed: 9227559]

266. Kong W, Po S, Yamagishi T, Ashen MD, Stetten G, Tomaselli GF. Isolation and characterization of the human gene encoding Ito: further diversity by alternative mRNA splicing. Am J Physiol. 1998; 275:H1963-H1970. [PubMed: 9843794]

267. Kucera JP, Rohr S, Rudy Y. Localization of sodium channels in intercalated disks modulates cardiac conduction. Circ Res. 2002; 91:1176-1182. [PubMed: 12480819]

268. Kuo HC, Cheng CF, Clark RB, Lin JJ, Lin JL, Hoshijima M, Nguyen-Tran VT, Gu Y, Ikeda Y, Chu PH, Ross J, Giles WR, Chien KR. A defect in the Kv channel-interacting protein 2 (KChIP2) gene leads to a complete loss of I(to) and confers susceptibility to ventricular tachycardia. Cell. 2001; 107:801-813. [PubMed: 11747815] 
269. Kurita T, Shimizu W, Inagaki M, Suyama K, Taguchi A, Satomi K, Aihara N, Kamakura S, Kobayashi J, Kosakai Y. The electrophysiologic mechanism of ST-segment elevation in Brugada syndrome. J Am Coll Cardiol. 2002; 40:330-334. [PubMed: 12106940]

270. Kuryshev YA, Brittenham GM, Fujioka H, Kannan P, Shieh CC, Cohen SA, Brown AM. Decreased sodium and increased transient outward potassium currents in iron-loaded cardiac myocytes. Implications for the arrhythmogenesis of human siderotic heart disease. Circulation. 1999; 100:675-683. [PubMed: 10441107]

271. Kusumoto FM, Phillips R, Goldschlager N. Pacing therapy in the elderly. The American journal of geriatric cardiology. 2002; 11:305-316. [PubMed: 12214169]

272. Kyndt F, Probst V, Potet F, Demolombe S, Chevallier JC, Baro I, Moisan JP, Boisseau P, Schott JJ, Escande D, Le Marec H. Novel SCN5A mutation leading either to isolated cardiac conduction defect or Brugada syndrome in a large French family. Circulation. 2001; 104:3081-3086. [PubMed: 11748104]

273. Lahat H, Pras E, Olender T, Avidan N, Ben-Asher E, Man O, Levy-Nissenbaum E, Khoury A, Lorber A, Goldman B, Lancet D, Eldar M. A missense mutation in a highly conserved region of CASQ2 is associated with autosomal recessive catecholamine-induced polymorphic ventricular tachycardia in Bedouin families from Israel. American journal of human genetics. 2001; 69:1378-1384. [PubMed: 11704930]

274. Lai LP, Su MJ, Lin JL, Tsai CH, Lin FY, Chen YS, Hwang JJ, Huang SK, Tseng YZ, Lien WP. Measurement of funny current $\left(\mathrm{I}_{\mathrm{f}}\right)$ channel mRNA in human atrial tissue: correlation with left atrial filling pressure and atrial fibrillation. J Cardiovasc Electrophysiol. 1999; 10:947-953. [PubMed: 10413374]

275. Lakatta EG, DiFrancesco D. What keeps us ticking: a funny current, a calcium clock, or both? Journal of Molecular and Cellular Cardiology. 2009; 47:157-170. [PubMed: 19361514]

276. Lakatta EG, Maltsev VA, Vinogradova TM. A coupled SYSTEM of intracellular Ca2+ clocks and surface membrane voltage clocks controls the timekeeping mechanism of the heart\&apos;s pacemaker. Circulation Research. 2010; 106:659-673. [PubMed: 20203315]

277. Larsen AP, Olesen SP, Grunnet M, Jespersen T. Characterization of hERG1a and hERG1b potassium channels-a possible role for hERG1b in the I (Kr) current. Pflugers Archiv : European journal of physiology. 2008; 456:1137-1148. [PubMed: 18504605]

278. Laurent G, Leong-Poi H, Mangat I, Moe GW, Hu X, So PP, Tarulli E, Ramadeen A, Rossman EI, Hennan JK, Dorian P. Effects of chronic gap junction conduction-enhancing antiarrhythmic peptide GAP-134 administration on experimental atrial fibrillation in dogs. Circ Arrhythm Electrophysiol. 2009; 2:171-178. [PubMed: 19808462]

279. Le Scouarnec S, Bhasin N, Vieyres C, Hund TJ, Cunha SR, Koval O, Marionneau C, Chen B, Wu Y, Demolombe S, Song L-S, Le Marec H, Probst V, Schott J-J, Anderson ME, Mohler PJ. Dysfunction in ankyrin-B-dependent ion channel and transporter targeting causes human sinus node disease. Proceedings of the National Academy of Sciences of the United States of America. 2008; 105:15617-15622. [PubMed: 18832177]

280. Lee HC, Rudy Y, Po-Yuan P, Sheu SH, Chang JG, Cui J. Modulation of KCNQ1 alternative splicing regulates cardiac IKs and action potential repolarization. Heart Rhythm. 2013; 10:1220 1228. [PubMed: 23608591]

281. Lei M, Jones SA, Liu J, Lancaster MK, Fung SS, Dobrzynski H, Camelliti P, Maier SK, Noble D, Boyett MR. Requirement of neuronal- and cardiac-type sodium channels for murine sinoatrial node pacemaking. J Physiol. 2004; 559:835-848. [PubMed: 15254155]

282. Lengyel C, Iost N, Virag L, Varro A, Lathrop DA, Papp JG. Pharmacological block of the slow component of the outward delayed rectifier current $(\mathrm{I}(\mathrm{Ks})$ ) fails to lengthen rabbit ventricular muscle QT(c) and action potential duration. Br J Pharmacol. 2001; 132:101-110. [PubMed: 11156566]

283. Lev M. Aging changes in the human sinoatrial node. Journal of gerontology. 1954; 9:1-9. [PubMed: 13130870]

284. Li D, Zhang L, Kneller J, Nattel S. Potential ionic mechanism for repolarization differences between canine right and left atrium. Circ Res. 2001; 88:1168-1175. [PubMed: 11397783] 
285. Li GR, Feng J, Yue L, Carrier M. Transmural heterogeneity of action potentials and Ito1 in myocytes isolated from the human right ventricle. Am J Physiol. 1998; 275:H369-H377. [PubMed: 9683422]

286. Li GR, Feng J, Yue L, Carrier M, Nattel S. Evidence for two components of delayed rectifier K+ current in human ventricular myocytes. Circ Res. 1996; 78:689-696. [PubMed: 8635226]

287. Li GR, Lau CP, Ducharme A, Tardif JC, Nattel S. Transmural action potential and ionic current remodeling in ventricles of failing canine hearts. Am J Physiol Heart Circ Physiol. 2002; 283:H1031-H1041. [PubMed: 12181133]

288. Li GR, Lau CP, Leung TK, Nattel S. Ionic current abnormalities associated with prolonged action potentials in cardiomyocytes from diseased human right ventricles. Heart Rhythm. 2004; 1:460468. [PubMed: 15851200]

289. Li GR, Nattel S. Properties of human atrial $\mathrm{I}_{\mathrm{Ca}}$ at physiological temperatures and relevance to action potential. Am J Physiol Heart Circ Physiol. 1997; 272:H227-H235.

290. Li GR, Nattel S. Properties of human atrial ICa at physiological temperatures and relevance to action potential. Am J Physiol. 1997; 272:H227-H235. [PubMed: 9038942]

291. Li J, Greener ID, Inada S, Nikolski VP, Yamamoto M, Hancox JC, Zhang H, Billeter R, Efimov IR, Dobrzynski H, Boyett MR. Computer three-dimensional reconstruction of the atrioventricular node. Circulation Research. 2008; 102:975-985. [PubMed: 18309098]

292. Li N, Timofeyev V, Tuteja D, Xu D, Lu L, Zhang Q, Zhang Z, Singapuri A, Albert TR, Rajagopal AV, Bond CT, Periasamy M, Adelman J, Chiamvimonvat N. Ablation of a Ca2+activated $\mathrm{K}+$ channel (SK2 channel) results in action potential prolongation in atrial myocytes and atrial fibrillation. J Physiol. 2009; 587:1087-1100. [PubMed: 19139040]

293. Li X, Zima AV, Sheikh F, Blatter LA, Chen J. Endothelin-1-induced arrhythmogenic Ca2+ signaling is abolished in atrial myocytes of inositol-1,4,5-trisphosphate(IP3)-receptor type 2deficient mice. Circ Res. 2005; 96:1274-1281. [PubMed: 15933266]

294. Li Y, Kranias EG, Mignery GA, Bers DM. Protein kinase A phosphorylation of the ryanodine receptor does not affect calcium sparks in mouse ventricular myocytes. Circ Res. 2002; 90:309316. [PubMed: 11861420]

295. Liang X, Xie H, Zhu PH, Hu J, Zhao Q, Wang CS, Yang C. Ryanodine receptor-mediated Ca ${ }^{2+}$ events in atrial myocytes of patients with atrial fibrillation. Cardiology. 2008; 111:102-110. [PubMed: 18376121]

296. Limberg SH, Netter MF, Rolfes C, Rinne S, Schlichthorl G, Zuzarte M, Vassiliou T, Moosdorf R, Wulf H, Daut J, Sachse FB, Decher N. TASK-1 channels may modulate action potential duration of human atrial cardiomyocytes. Cellular physiology and biochemistry : international journal of experimental cellular physiology, biochemistry, and pharmacology. 2011; 28:613-624.

297. Lin J, Keener JP. Modeling electrical activity of myocardial cells incorporating the effects of ephaptic coupling. Proceedings of the National Academy of Sciences of the United States of America. 2010; 107:20935-20940. [PubMed: 21078961]

298. Litovsky SH, Antzelevitch C. Transient outward current prominent in canine ventricular epicardium but not endocardium. Circulation research. 1988; 62:116-126. [PubMed: 2826039]

299. Litovsky SH, Antzelevitch C. Transient outward current prominent in canine ventricular epicardium but not endocardium. Circ Res. 1988; 62:116-126. [PubMed: 2826039]

300. Liu DW, Antzelevitch C. Characteristics of the delayed rectifier current (IKr and IKs) in canine ventricular epicardial, midmyocardial, and endocardial myocytes. A weaker IKs contributes to the longer action potential of the M cell. Circ Res. 1995; 76:351-365. [PubMed: 7859382]

301. Liu DW, Gintant GA, Antzelevitch C. Ionic bases for electrophysiological distinctions among epicardial, midmyocardial, and endocardial myocytes from the free wall of the canine left ventricle. Circ Res. 1993; 72:671-687. [PubMed: 8431990]

302. Liu GX, Derst C, Schlichthorl G, Heinen S, Seebohm G, Bruggemann A, Kummer W, Veh RW, Daut J, Preisig-Muller R. Comparison of cloned Kir2 channels with native inward rectifier K+ channels from guinea-pig cardiomyocytes. J Physiol. 2001; 532:115-126. [PubMed: 11283229]

303. Liu XK, Yamada S, Kane GC, Alekseev AE, Hodgson DM, O'Cochlain F, Jahangir A, Miki T, Seino S, Terzic A. Genetic disruption of Kir6.2, the pore-forming subunit of ATP-sensitive K+ 
channel, predisposes to catecholamine-induced ventricular dysrhythmia. Diabetes. 2004; 53(Suppl 3):S165-S168. [PubMed: 15561906]

304. London B, Michalec M, Mehdi H, Zhu X, Kerchner L, Sanyal S, Viswanathan PC, Pfahnl AE, Shang LL, Madhusudanan M, Baty CJ, Lagana S, Aleong R, Gutmann R, Ackerman MJ, McNamara DM, Weiss R, Dudley SC Jr. Mutation in glycerol-3-phosphate dehydrogenase 1 like gene (GPD1-L) decreases cardiac Na+ current and causes inherited arrhythmias. Circulation. 2007; 116:2260-2268. [PubMed: 17967977]

305. London B, Trudeau MC, Newton KP, Beyer AK, Copeland NG, Gilbert DJ, Jenkins NA, Satler CA, Robertson GA. Two isoforms of the mouse ether-a-go-go-related gene coassemble to form channels with properties similar to the rapidly activating component of the cardiac delayed rectifier K+ current. Circulation research. 1997; 81:870-878. [PubMed: 9351462]

306. Lopatin AN, Nichols CG. Inward rectifiers in the heart: an update on I(K1). J Mol Cell Cardiol. 2001; 33:625-638. [PubMed: 11273717]

307. Lundby A, Ravn LS, Svendsen JH, Hauns S, Olesen SP, Schmitt N. KCNE3 mutation V17M identified in a patient with lone atrial fibrillation. Cellular physiology and biochemistry : international journal of experimental cellular physiology, biochemistry, and pharmacology. 2008; 21:47-54.

308. Lundquist AL, Manderfield LJ, Vanoye CG, Rogers CS, Donahue BS, Chang PA, Drinkwater DC, Murray KT, George AL Jr. Expression of multiple KCNE genes in human heart may enable variable modulation of I(Ks). Journal of molecular and cellular cardiology. 2005; 38:277-287. [PubMed: 15698834]

309. Lundquist AL, Turner CL, Ballester LY, George AL Jr. Expression and transcriptional control of human KCNE genes. Genomics. 2006; 87:119-128. [PubMed: 16303284]

310. Machida T, Hashimoto N, Kuwahara I, Ogino Y, Matsuura J, Yamamoto W, Itano Y, Zamma A, Matsumoto R, Kamon J, Kobayashi T, Ishiwata N, Yamashita T, Ogura T, Nakaya H. Effects of a highly selective acetylcholine-activated $\mathrm{K}+$ channel blocker on experimental atrial fibrillation. Circ Arrhythm Electrophysiol. 2011; 4:94-102. [PubMed: 21156770]

311. Mahida S. Expanding role of SK channels in cardiac electrophysiology. Heart Rhythm. 2014; 11:1233-1238. [PubMed: 24681007]

312. Mahida S, Lubitz SA, Rienstra M, Milan DJ, Ellinor PT. Monogenic atrial fibrillation as pathophysiological paradigms. Cardiovasc Res. 2011; 89:692-700. [PubMed: 21123219]

313. Mahida S, Mills RW, Tucker NR, Simonson B, Macri V, Lemoine MD, Das S, Milan DJ, Ellinor PT. Overexpression of KCNN3 results in sudden cardiac death. Cardiovasc Res. 2014; 101:326334. [PubMed: 24296650]

314. Maier LS, Barckhausen P, Weisser J, Aleksic I, Baryalei M, Pieske B. $\mathrm{Ca}^{2+}$ handling in isolated human atrial myocardium. Am J Physiol Heart Circ Physiol. 2000; 279:H952-H958. [PubMed: 10993755]

315. Maier LS, Zhang T, Chen L, DeSantiago J, Brown JH, Bers DM. Transgenic CaMKIIdeltaC overexpression uniquely alters cardiac myocyte $\mathrm{Ca} 2+$ handling: reduced SR Ca2+ load and activated SR Ca2+ release. Circ Res. 2003; 92:904-911. [PubMed: 12676813]

316. Maier SK, Westenbroek RE, Yamanushi TT, Dobrzynski H, Boyett MR, Catterall WA, Scheuer T. An unexpected requirement for brain-type sodium channels for control of heart rate in the mouse sinoatrial node. Proceedings of the National Academy of Sciences of the United States of America. 2003; 100:3507-3512. [PubMed: 12631690]

317. Maltsev VA, Lakatta EG. The funny current in the context of the coupled-clock pacemaker cell system. Heart rhythm : the official journal of the Heart Rhythm Society. 2012; 9:302-307. [PubMed: 21925132]

318. Mangoni ME, Couette B, Bourinet E, Platzer J, Reimer D, Striessnig J, Nargeot J. Functional role of L-type Cav1.3 Ca2+ channels in cardiac pacemaker activity. Proceedings of the National Academy of Sciences of the United States of America. 2003; 100:5543-5548. [PubMed: 12700358]

319. Marionneau C, Couette B, Liu J, Li H, Mangoni ME, Nargeot J, Lei M, Escande D, Demolombe S. Specific pattern of ionic channel gene expression associated with pacemaker activity in the mouse heart. J Physiol. 2005; 562:223-234. [PubMed: 15498808] 
320. Martinez ML, Heredia MP, Delgado C. Expression of T-type Ca(2+) channels in ventricular cells from hypertrophied rat hearts. J Mol Cell Cardiol. 1999; 31:1617-1625. [PubMed: 10471346]

321. Marx SO, Kurokawa J, Reiken S, Motoike H, D'Armiento J, Marks AR, Kass RS. Requirement of a macromolecular signaling complex for beta adrenergic receptor modulation of the KCNQ1KCNE1 potassium channel. Science. 2002; 295:496-499. [PubMed: 11799244]

322. Marx SO, Reiken S, Hisamatsu Y, Jayaraman T, Burkhoff D, Rosemblit N, Marks AR. PKA phosphorylation dissociates FKBP12.6 from the calcium release channel (ryanodine receptor): defective regulation in failing hearts. Cell. 2000; 101:365-376. [PubMed: 10830164]

323. Matsuyama, T-a; Inoue, S.; Kobayashi, Y.; Sakai, T.; Saito, T.; Katagiri, T.; Ota, H. Anatomical diversity and age-related histological changes in the human right atrial posterolateral wall. Europace : European pacing, arrhythmias, and cardiac electrophysiology : journal of the working groups on cardiac pacing, arrhythmias, and cardiac cellular electrophysiology of the European Society of Cardiology. 2004; 6:307-315.

324. McDonald TV, Yu Z, Ming Z, Palma E, Meyers MB, Wang KW, Goldstein SA, Fishman GI. A minK-HERG complex regulates the cardiac potassium current $\mathrm{I}(\mathrm{Kr})$. Nature. 1997; 388:289-292. [PubMed: 9230439]

325. Medeiros-Domingo A, Kaku T, Tester DJ, Iturralde-Torres P, Itty A, Ye B, Valdivia C, Ueda K, Canizales-Quinteros S, Tusie-Luna MT, Makielski JC, Ackerman MJ. SCN4B-encoded sodium channel beta4 subunit in congenital long-QT syndrome. Circulation. 2007; 116:134-142. [PubMed: 17592081]

326. Medeiros-Domingo A, Tan BH, Crotti L, Tester DJ, Eckhardt L, Cuoretti A, Kroboth SL, Song C, Zhou Q, Kopp D, Schwartz PJ, Makielski JC, Ackerman MJ. Gain-of-function mutation S422L in the KCNJ8-encoded cardiac K(ATP) channel Kir6.1 as a pathogenic substrate for J-wave syndromes. Heart Rhythm. 2010; 7:1466-1471. [PubMed: 20558321]

327. Melnyk P, Ehrlich JR, Pourrier M, Villeneuve L, Cha TJ, Nattel S. Comparison of ion channel distribution and expression in cardiomyocytes of canine pulmonary veins versus left atrium. Cardiovasc Res. 2005; 65:104-116. [PubMed: 15621038]

328. Miake J, Marbán E, Nuss HB. Biological pacemaker created by gene transfer. Nature. 2002; 419:132-133. [PubMed: 12226654]

329. Mihm MJ, Yu F, Carnes CA, Reiser PJ, McCarthy PM, Van Wagoner DR, Bauer JA. Impaired myofibrillar energetics and oxidative injury during human atrial fibrillation. Circulation. 2001; 104:174-180. [PubMed: 11447082]

330. Milanesi R, Baruscotti M, Gnecchi-Ruscone T, DiFrancesco D. Familial sinus bradycardia associated with a mutation in the cardiac pacemaker channel. The New England journal of medicine. 2006; 354:151-157. [PubMed: 16407510]

331. Mitcheson JS, Sanguinetti MC. Biophysical properties and molecular basis of cardiac rapid and slow delayed rectifier potassium channels. Cellular physiology and biochemistry : international journal of experimental cellular physiology, biochemistry, and pharmacology. 1999; 9:201-216.

332. Moe GK, Preston JB, Burlington H. Physiologic evidence for a dual A-V transmission system. Circulation Research. 1956; 4:357-375. [PubMed: 13330177]

333. Mohler PJ, Gramolini AO, Bennett V. Ankyrins. Journal of cell science. 2002; 115:1565-1566. [PubMed: 11950874]

334. Mohler PJ, Schott JJ, Gramolini AO, Dilly KW, Guatimosim S, duBell WH, Song LS, Haurogne K, Kyndt F, Ali ME, Rogers TB, Lederer WJ, Escande D, Le Marec H, Bennett V. Ankyrin-B mutation causes type 4 long-QT cardiac arrhythmia and sudden cardiac death. Nature. 2003; 421:634-639. [PubMed: 12571597]

335. Mond HG, Proclemer A. The 11th world survey of cardiac pacing and implantable cardioverterdefibrillators: calendar year 2009--a World Society of Arrhythmia\&apos;s project. Pacing and clinical electrophysiology : PACE. 2011; 34:1013-1027. [PubMed: 21707667]

336. Mori Y, Fishman GI, Peskin CS. Ephaptic conduction in a cardiac strand model with 3D electrodiffusion. Proceedings of the National Academy of Sciences of the United States of America. 2008; 105:6463-6468. [PubMed: 18434544] 
337. Morita H, Fukushima-Kusano K, Nagase S, Takenaka-Morita S, Nishii N, Kakishita M, Nakamura K, Emori T, Matsubara H, Ohe T. Site-specific arrhythmogenesis in patients with Brugada syndrome. J Cardiovasc Electrophysiol. 2003; 14:373-379. [PubMed: 12741708]

338. Morita H, Kusano-Fukushima K, Nagase S, Fujimoto Y, Hisamatsu K, Fujio H, Haraoka K, Kobayashi M, Morita ST, Nakamura K, Emori T, Matsubara H, Hina K, Kita T, Fukatani M, Ohe T. Atrial fibrillation and atrial vulnerability in patients with Brugada syndrome. J Am Coll Cardiol. 2002; 40:1437-1444. [PubMed: 12392834]

339. Morotti S, Edwards AG, McCulloch AD, Bers DM, Grandi E. A novel computational model of mouse myocyte electrophysiology to assess the synergy between $\mathrm{Na}+$ loading and CaMKII. The Journal of physiology. 2014; 592:1181-1197. [PubMed: 24421356]

340. Morotti S, Grandi E, Summa A, Ginsburg KS, Bers DM. Theoretical study of L-type Ca(2+) current inactivation kinetics during action potential repolarization and early afterdepolarizations. J Physiol. 2012; 590:4465-4481. [PubMed: 22586219]

341. Mukherjee R and Spinale FG. L-type calcium channel abundance and function with cardiac hypertrophy and failure: a review. J Mol Cell Cardiol. 1998; 30:1899-1916. [PubMed: 9799645]

342. Munk AA, Adjemian RA, Zhao J, Ogbaghebriel A, Shrier A. Electrophysiological properties of morphologically distinct cells isolated from the rabbit atrioventricular node. The Journal of Physiology. 1996; 493(Pt 3):801-818. [PubMed: 8799901]

343. Myles RC, Wang L, Bers DM, Ripplinger CM. Decreased IK1 and increased ryanodine receptor sensitivity synergistically contribute to sustained focal arrhythmia in the intact rabbit heart. $\mathrm{J}$ Physiol. 2014

344. Myles RC, Wang L, Kang C, Bers DM, Ripplinger CM. Local beta-adrenergic stimulation overcomes source-sink mismatch to generate focal arrhythmia. Circ Res. 2012; 110:1454-1464. [PubMed: 22539768]

345. Nabauer M, Beuckelmann DJ, Erdmann E. Characteristics of transient outward current in human ventricular myocytes from patients with terminal heart failure. Circ Res. 1993; 73:386-394. [PubMed: 8330381]

346. Nabauer M, Beuckelmann DJ, Uberfuhr P, Steinbeck G. Regional differences in current density and rate-dependent properties of the transient outward current in subepicardial and subendocardial myocytes of human left ventricle. Circulation. 1996; 93:168-177. [PubMed: 8616924]

347. Nagy N, Szuts V, Horvath Z, Seprenyi G, Farkas AS, Acsai K, Prorok J, Bitay M, Kun A, Pataricza J, Papp JG, Nanasi PP, Varro A, Toth A. Does small-conductance calcium-activated potassium channel contribute to cardiac repolarization? J Mol Cell Cardiol. 2009; 47:656-663. [PubMed: 19632238]

348. Nattel S, Burstein B, Dobrev D. Atrial Remodeling and Atrial Fibrillation. Circulation: Arrhythmia and Electrophysiology. 2008; 1:62-73. [PubMed: 19808395]

349. Nattel S, Maguy A, Le Bouter S, Yeh YH. Arrhythmogenic ion-channel remodeling in the heart: heart failure, myocardial infarction, and atrial fibrillation. Physiological reviews. 2007; 87:425456. [PubMed: 17429037]

350. Neef S, Dybkova N, Sossalla S, Ort KR, Fluschnik N, Neumann K, Seipelt R, Schondube FA, Hasenfuss G, Maier LS. CaMKII-Dependent Diastolic SR Ca ${ }^{2+}$ Leak and Elevated Diastolic $\mathrm{Ca}^{2+}$ Levels in Right Atrial Myocardium of Patients With Atrial Fibrillation. Circ Res. 2010; 106:1134-1144. [PubMed: 20056922]

351. Nerbonne JM, Kass RS. Molecular physiology of cardiac repolarization. Physiological reviews. 2005; 85:1205-1253. [PubMed: 16183911]

352. Neyroud N, Tesson F, Denjoy I, Leibovici M, Donger C, Barhanin J, Faure S, Gary F, Coumel P, Petit C, Schwartz K, Guicheney P. A novel mutation in the potassium channel gene KVLQT1 causes the Jervell and Lange-Nielsen cardioauditory syndrome. Nat Genet. 1997; 15:186-189. [PubMed: 9020846]

353. Nguyen BL, Fishbein MC, Chen LS, Chen PS, Masroor S. Histopathological substrate for chronic atrial fibrillation in humans. Heart Rhythm. 2009; 6:454-460. [PubMed: 19324302]

354. Nichols CG and Lopatin AN. Inward rectifier potassium channels. Annual review of physiology. 1997; 59:171-191. 
355. Nichols CG, Makhina EN, Pearson WL, Sha Q, Lopatin AN. Inward rectification and implications for cardiac excitability. Circ Res. 1996; 78:1-7. [PubMed: 8603491]

356. Nielsen JB, Bentzen BH, Olesen MS, David JP, Olesen SP, Haunso S, Svendsen JH, Schmitt N. Gain-of-function mutations in potassium channel subunit KCNE2 associated with early-onset lone atrial fibrillation. Biomarkers in medicine. 2014; 8:557-570. [PubMed: 24796621]

357. Nikmaram MR, Boyett MR, Kodama I, Suzuki R, Honjo H. Variation in effects of Cs+, ULFS-49, and ZD-7288 within sinoatrial node. The American journal of physiology. 1997; 272:H2782-H2792. [PubMed: 9227558]

358. Nishisato K, Hashimoto A, Nakata T, Doi T, Yamamoto H, Nagahara D, Shimoshige S, Yuda S, Tsuchihashi K, Shimamoto K. Impaired cardiac sympathetic innervation and myocardial perfusion are related to lethal arrhythmia: quantification of cardiac tracers in patients with ICDs. Journal of nuclear medicine : official publication, Society of Nuclear Medicine. 2010; 51:12411249.

359. Niwa $\mathrm{N}$ and Nerbonne JM. Molecular determinants of cardiac transient outward potassium current (I(to)) expression and regulation. J Mol Cell Cardiol. 2010; 48:12-25. [PubMed: 19619557]

360. Nof E, Glikson M, Antzelevitch C. Genetics and Sinus Node Dysfunction. Journal of atrial fibrillation. 2009; 1:328-336. [PubMed: 20686678]

361. Nof E, Luria D, Brass D, Marek D, Lahat H, Reznik-Wolf H, Pras E, Dascal N, Eldar M, Glikson M. Point mutation in the HCN4 cardiac ion channel pore affecting synthesis, trafficking, and functional expression is associated with familial asymptomatic sinus bradycardia. Circulation. 2007; 116:463-470. [PubMed: 17646576]

362. Nuss HB and Houser SR. T-type Ca2+ current is expressed in hypertrophied adult feline left ventricular myocytes. Circ Res. 1993; 73:777-782. [PubMed: 8396509]

363. Nuss HB, Kaab S, Kass DA, Tomaselli GF, Marban E. Cellular basis of ventricular arrhythmias and abnormal automaticity in heart failure. Am J Physiol. 1999; 277:H80-H91. [PubMed: 10409185]

364. Nyegaard M, Overgaard MT, Sondergaard MT, Vranas M, Behr ER, Hildebrandt LL, Lund J, Hedley PL, Camm AJ, Wettrell G, Fosdal I, Christiansen M, Borglum AD. Mutations in calmodulin cause ventricular tachycardia and sudden cardiac death. American journal of human genetics. 2012; 91:703-712. [PubMed: 23040497]

365. O'Rourke B, Kass DA, Tomaselli GF, Kaab S, Tunin R, Marban E. Mechanisms of altered excitation-contraction coupling in canine tachycardia-induced heart failure, I: experimental studies. Circ Res. 1999; 84:562-570. [PubMed: 10082478]

366. Ohno S, Zankov DP, Ding WG, Itoh H, Makiyama T, Doi T, Shizuta S, Hattori T, Miyamoto A, Naiki N, Hancox JC, Matsuura H, Horie M. KCNE5 (KCNE1L) variants are novel modulators of Brugada syndrome and idiopathic ventricular fibrillation. Circ Arrhythm Electrophysiol. 2011; 4:352-361. [PubMed: 21493962]

367. Okada R and Kawai S. Histopathology of the conduction system in sudden cardiac death. Japanese circulation journal. 1983; 47:573-580. [PubMed: 6854914]

368. Olesen MS, Jespersen T, Nielsen JB, Liang B, Moller DV, Hedley P, Christiansen M, Varro A, Olesen SP, Haunso S, Schmitt N, Svendsen JH. Mutations in sodium channel beta-subunit SCN3B are associated with early-onset lone atrial fibrillation. Cardiovasc Res. 2011; 89:786793. [PubMed: 21051419]

369. Olson TM, Alekseev AE, Liu XK, Park S, Zingman LV, Bienengraeber M, Sattiraju S, Ballew JD, Jahangir A, Terzic A. Kv1.5 channelopathy due to KCNA5 loss-of-function mutation causes human atrial fibrillation. Human molecular genetics. 2006; 15:2185-2191. [PubMed: 16772329]

370. Olson TM, Alekseev AE, Moreau C, Liu XK, Zingman LV, Miki T, Seino S, Asirvatham SJ, Jahangir A, Terzic A. KATP channel mutation confers risk for vein of Marshall adrenergic atrial fibrillation. Nat Clin Pract Cardiovasc Med. 2007; 4:110-116. [PubMed: 17245405]

371. Olson TM and Terzic A. Human K(ATP) channelopathies: diseases of metabolic homeostasis. Pflugers Arch. 2010; 460:295-306. [PubMed: 20033705]

372. Otway R, Vandenberg JI, Guo G, Varghese A, Castro ML, Liu J, Zhao J, Bursill JA, Wyse KR, Crotty H, Baddeley O, Walker B, Kuchar D, Thorburn C, Fatkin D. Stretch-sensitive KCNQ1 
mutation A link between genetic and environmental factors in the pathogenesis of atrial fibrillation? J Am Coll Cardiol. 2007; 49:578-586. [PubMed: 17276182]

373. Ozgen N, Dun W, Sosunov EA, Anyukhovsky EP, Hirose M, Duffy HS, Boyden PA, Rosen MR. Early electrical remodeling in rabbit pulmonary vein results from trafficking of intracellular SK2 channels to membrane sites. Cardiovasc Res. 2007; 75:758-769. [PubMed: 17588552]

374. Pandit SV, Berenfeld O, Anumonwo JM, Zaritski RM, Kneller J, Nattel S, Jalife J. Ionic determinants of functional reentry in a 2-D model of human atrial cells during simulated chronic atrial fibrillation. Biophys J. 2005; 88:3806-3821. [PubMed: 15792974]

375. Park DS and Fishman GI. The cardiac conduction system. Circulation. 2011; 123:904-915. [PubMed: 21357845]

376. Patterson E, Lazzara R, Szabo B, Liu H, Tang D, Li YH, Scherlag BJ, Po SS. Sodium-calcium exchange initiated by the $\mathrm{Ca} 2+$ transient: an arrhythmia trigger within pulmonary veins. J Am Coll Cardiol. 2006; 47:1196-1206. [PubMed: 16545652]

377. Pereon Y, Demolombe S, Baro I, Drouin E, Charpentier F, Escande D. Differential expression of KvLQT1 isoforms across the human ventricular wall. Am J Physiol Heart Circ Physiol. 2000; 278:H1908-H1915. [PubMed: 10843888]

378. Perez-Garcia MT, Kamp TJ, Marban E. Functional properties of cardiac L-type calcium channels transiently expressed in HEK293 cells. Roles of alpha 1 and beta subunits. J Gen Physiol. 1995; 105:289-305. [PubMed: 7539049]

379. Perez-Reyes E. Molecular physiology of low-voltage-activated t-type calcium channels. Physiological reviews. 2003; 83:117-161. [PubMed: 12506128]

380. Perez-Reyes E, Castellano A, Kim HS, Bertrand P, Baggstrom E, Lacerda AE, Wei XY, Birnbaumer L. Cloning and expression of a cardiac/brain beta subunit of the L-type calcium channel. J Biol Chem. 1992; 267:1792-1797. [PubMed: 1370480]

381. Persson F, Andersson B, Duker G, Jacobson I, Carlsson L. Functional effects of the late sodium current inhibition by AZD7009 and lidocaine in rabbit isolated atrial and ventricular tissue and Purkinje fibre. European journal of pharmacology. 2007; 558:133-143. [PubMed: 17198698]

382. Petrecca K, Amellal F, Laird DW, Cohen SA, Shrier A. Sodium channel distribution within the rabbit atrioventricular node as analysed by confocal microscopy. J Physiol. 1997; 501(Pt 2):263274. [PubMed: 9192299]

383. Piacentino V 3rd, Weber CR, Chen X, Weisser-Thomas J, Margulies KB, Bers DM, Houser SR. Cellular basis of abnormal calcium transients of failing human ventricular myocytes. Circ Res. 2003; 92:651-658. [PubMed: 12600875]

384. Pitt GS, Dun W, Boyden PA. Remodeled cardiac calcium channels. J Mol Cell Cardiol. 2006; 41:373-388. [PubMed: 16901502]

385. Poelzing S, Akar FG, Baron E, Rosenbaum DS. Heterogeneous connexin43 expression produces electrophysiological heterogeneities across ventricular wall. Am J Physiol Heart Circ Physiol. 2004; 286:H2001-H2009. [PubMed: 14704225]

386. Pogwizd SM and Bers DM. Na/Ca exchange in heart failure: contractile dysfunction and arrhythmogenesis. Annals of the New York Academy of Sciences. 2002; 976:454-465. [PubMed: 12502595]

387. Pogwizd SM, Qi M, Yuan W, Samarel AM, Bers DM. Upregulation of $\mathrm{Na}(+) / \mathrm{Ca}(2+)$ exchanger expression and function in an arrhythmogenic rabbit model of heart failure. Circ Res. 1999; 85:1009-1019. [PubMed: 10571531]

388. Pogwizd SM, Schlotthauer K, Li L, Yuan W, Bers DM. Arrhythmogenesis and contractile dysfunction in heart failure: Roles of sodium-calcium exchange, inward rectifier potassium current, and residual beta-adrenergic responsiveness. Circ Res. 2001; 88:1159-1167. [PubMed: 11397782]

389. Pollack GH. Intercellular coupling in the atrioventricular node and other tissues of the rabbit heart. The Journal of Physiology. 1976; 255:275-298. [PubMed: 1255518]

390. Postma AV, Denjoy I, Hoorntje TM, Lupoglazoff J-M, Da Costa A, Sebillon P, Mannens MMAM, Wilde AAM, Guicheney P. Absence of calsequestrin 2 causes severe forms of catecholaminergic polymorphic ventricular tachycardia. Circulation Research. 2002; 91:e21-e26. [PubMed: 12386154] 
391. Postma AV, Denjoy I, Kamblock J, Alders M, Lupoglazoff J-M, Vaksmann G, Dubosq-Bidot L, Sebillon P, Mannens MMAM, Guicheney P, Wilde AAM. Catecholaminergic polymorphic ventricular tachycardia: RYR2 mutations, bradycardia, and follow up of the patients. Journal of medical genetics. 2005; 42:863-870. [PubMed: 16272262]

392. Prestle J, Dieterich S, Preuss M, Bieligk U, Hasenfuss G. Heterogeneous transmural gene expression of calcium-handling proteins and natriuretic peptides in the failing human heart. Cardiovasc Res. 1999; 43:323-331. [PubMed: 10536662]

393. Priori SG and Corr PB. Mechanisms underlying early and delayed afterdepolarizations induced by catecholamines. Am J Physiol. 1990; 258:H1796-H1805. [PubMed: 2163219]

394. Priori SG, Napolitano C, Tiso N, Memmi M, Vignati G, Bloise R, Sorrentino V, Danieli GA. Mutations in the cardiac ryanodine receptor gene (hRyR2) underlie catecholaminergic polymorphic ventricular tachycardia. Circulation. 2001; 103:196-200. [PubMed: 11208676]

395. Priori SG, Pandit SV, Rivolta I, Berenfeld O, Ronchetti E, Dhamoon A, Napolitano C, Anumonwo J, di Barletta MR, Gudapakkam S, Bosi G, Stramba-Badiale M, Jalife J. A novel form of short QT syndrome (SQT3) is caused by a mutation in the KCNJ2 gene. Circ Res. 2005; 96:800-807. [PubMed: 15761194]

396. Probst V, Kyndt F, Potet F, Trochu J-N, Mialet G, Demolombe S, Schott J-J, Baró I, Escande D, Le Marec H. Haploinsufficiency in combination with aging causes SCN5A-linked hereditary Lenègre disease. JAC. 2003; 41:643-652.

397. Prosser BL, Ward CW, Lederer WJ. X-ROS signaling: rapid mechano-chemo transduction in heart. Science. 2011; 333:1440-1445. [PubMed: 21903813]

398. Qi XY, Diness JG, Brundel BJ, Zhou XB, Naud P, Wu CT, Huang H, Harada M, Aflaki M, Dobrev D, Grunnet M, Nattel S. Role of small-conductance calcium-activated potassium channels in atrial electrophysiology and fibrillation in the dog. Circulation. 2014; 129:430-440. [PubMed: 24190961]

399. Qu Y, Baroudi G, Yue Y, El-Sherif N, Boutjdir M. Localization and modulation of \{alpha\}1D (Cav1.3) L-type Ca channel by protein kinase A. Am J Physiol Heart Circ Physiol. 2005; 288:H2123-H2130. [PubMed: 15615842]

400. Ramakers C, Stengl M, Spatjens RL, Moorman AF, Vos MA. Molecular and electrical characterization of the canine cardiac ventricular septum. J Mol Cell Cardiol. 2005; 38:153-161. [PubMed: 15623432]

401. Ramakers C, Vos MA, Doevendans PA, Schoenmakers M, Wu YS, Scicchitano S, Iodice A, Thomas GP, Antzelevitch C, Dumaine R. Coordinated down-regulation of KCNQ1 and KCNE1 expression contributes to reduction of $\mathrm{I}(\mathrm{Ks})$ in canine hypertrophied hearts. Cardiovasc Res. 2003; 57:486-496. [PubMed: 12566121]

402. Ravens U, Poulet C, Wettwer E, Knaut M. Atrial selectivity of antiarrhythmic drugs. J Physiol. 2013; 591:4087-4097. [PubMed: 23732646]

403. Ravn LS, Aizawa Y, Pollevick GD, Hofman-Bang J, Cordeiro JM, Dixen U, Jensen G, Wu Y, Burashnikov E, Haunso S, Guerchicoff A, Hu D, Svendsen JH, Christiansen M, Antzelevitch C. Gain of function in IKs secondary to a mutation in KCNE5 associated with atrial fibrillation. Heart Rhythm. 2008; 5:427-435. [PubMed: 18313602]

404. Reinecke H, Studer R, Vetter R, Holtz J, Drexler H. Cardiac Na+/Ca2+ exchange activity in patients with end-stage heart failure. Cardiovasc Res. 1996; 31:48-54. [PubMed: 8849588]

405. Ritchie MD, Denny JC, Zuvich RL, Crawford DC, Schildcrout JS, Bastarache L, Ramirez AH, Mosley JD, Pulley JM, Basford MA, Bradford Y, Rasmussen LV, Pathak J, Chute CG, Kullo IJ, McCarty CA, Chisholm RL, Kho AN, Carlson CS, Larson EB, Jarvik GP, Sotoodehnia N, Cohorts for H, Aging Research in Genomic Epidemiology QRSG. Manolio TA, Li R, Masys DR, Haines JL, Roden DM. Genome- and phenome-wide analyses of cardiac conduction identifies markers of arrhythmia risk. Circulation. 2013; 127:1377-1385. [PubMed: 23463857]

406. Robinson RB, Boyden PA, Hoffman BF, Hewett KW. Electrical restitution process in dispersed canine cardiac Purkinje and ventricular cells. Am J Physiol. 1987; 253:H1018-H1025. [PubMed: 3688246]

407. Rook MB, Evers MM, Vos MA, Bierhuizen MF. Biology of cardiac sodium channel Nav1.5 expression. Cardiovasc Res. 2012; 93:12-23. [PubMed: 21937582] 
408. Rosati B, Grau F, McKinnon D. Regional variation in mRNA transcript abundance within the ventricular wall. J Mol Cell Cardiol. 2006; 40:295-302. [PubMed: 16412459]

409. Rosati B, Pan Z, Lypen S, Wang HS, Cohen I, Dixon JE, McKinnon D. Regulation of KChIP2 potassium channel beta subunit gene expression underlies the gradient of transient outward current in canine and human ventricle. J Physiol. 2001; 533:119-125. [PubMed: 11351020]

410. Rose J, Armoundas AA, Tian Y, DiSilvestre D, Burysek M, Halperin V, O'Rourke B, Kass DA, Marban E, Tomaselli GF. Molecular correlates of altered expression of potassium currents in failing rabbit myocardium. Am J Physiol Heart Circ Physiol. 2005; 288:H2077-H2087. [PubMed: 15637125]

411. Rosen MR, Nargeot J, Salama G. The case for the funny current and the calcium clock. Heart rhythm : the official journal of the Heart Rhythm Society. 2012; 9:616-618. [PubMed: 21996036]

412. Roux-Buisson N, Cacheux M, Fourest-Lieuvin A, Fauconnier J, Brocard J, Denjoy I, Durand P, Guicheney P, Kyndt F, Leenhardt A, Le Marec H, Lucet V, Mabo P, Probst V, Monnier N, Ray PF, Santoni E, Tremeaux P, Lacampagne A, Faure J, Lunardi J, Marty I. Absence of triadin, a protein of the calcium release complex, is responsible for cardiac arrhythmia with sudden death in human. Human molecular genetics. 2012; 21:2759-2767. [PubMed: 22422768]

413. Rozanski GJ, Xu Z, Whitney RT, Murakami H, Zucker IH. Electrophysiology of rabbit ventricular myocytes following sustained rapid ventricular pacing. J Mol Cell Cardiol. 1997; 29:721-732. [PubMed: 9140829]

414. Ruan Y, Liu N, Priori SG. Sodium channel mutations and arrhythmias. Nature reviews Cardiology. 2009; 6:337-348. [PubMed: 19377496]

415. Rubart M, Zipes DP. Mechanisms of sudden cardiac death. J Clin Invest. 2005; 115:2305-2315. [PubMed: 16138184]

416. Rudy Y, Ackerman MJ, Bers DM, Clancy CE, Houser SR, London B, McCulloch AD, Przywara DA, Rasmusson RL, Solaro RJ, Trayanova NA, Van Wagoner DR, Varro A, Weiss JN, Lathrop DA. Systems approach to understanding electromechanical activity in the human heart: a national heart, lung, and blood institute workshop summary. Circulation. 2008; 118:1202-1211. [PubMed: 18779456]

417. Saenen JB, Vrints CJ. Molecular aspects of the congenital and acquired Long QT Syndrome: clinical implications. J Mol Cell Cardiol. 2008; 44:633-646. [PubMed: 18336833]

418. Salata JJ, Jurkiewicz NK, Jow B, Folander K, Guinosso PJ Jr, Raynor B, Swanson R, Fermini B. IK of rabbit ventricle is composed of two currents: evidence for IKs. Am J Physiol. 1996; 271:H2477-H2489. [PubMed: 8997308]

419. Sánchez-Quintana D, Cabrera JA, Farré J, Climent V, Anderson RH, Ho SY. Sinus node revisited in the era of electroanatomical mapping and catheter ablation. Heart (British Cardiac Society). 2005; 91:189-194. [PubMed: 15657230]

420. Sanguinetti MC, Curran ME, Zou A, Shen J, Spector PS, Atkinson DL, Keating MT. Coassembly of K(V)LQT1 and minK (IsK) proteins to form cardiac I(Ks) potassium channel. Nature. 1996; 384:80-83. [PubMed: 8900283]

421. Sanguinetti MC, Jiang C, Curran ME, Keating MT. A mechanistic link between an inherited and an acquired cardiac arrhythmia: HERG encodes the IKr potassium channel. Cell. 1995; 81:299307. [PubMed: 7736582]

422. Sanguinetti MC, Jurkiewicz NK. Two components of cardiac delayed rectifier K+ current. Differential sensitivity to block by class III antiarrhythmic agents. J Gen Physiol. 1990; 96:195215. [PubMed: 2170562]

423. Sanguinetti MC, Zou A. Molecular physiology of cardiac delayed rectifier K+ channels. Heart Vessels. 1997; (Suppl 12):170-172. [PubMed: 9476573]

424. Satin J, Kyle JW, Chen M, Bell P, Cribbs LL, Fozzard HA, Rogart RB. A mutant of TTXresistant cardiac sodium channels with TTX-sensitive properties. Science. 1992; 256:1202-1205. [PubMed: 1375397]

425. Schmitt N, Grunnet M, Olesen SP. Cardiac potassium channel subtypes: new roles in repolarization and arrhythmia. Physiological reviews. 2014; 94:609-653. [PubMed: 24692356] 
426. Schott JJ, Alshinawi C, Kyndt F, Probst V, Hoorntje TM, Hulsbeek M, Wilde AA, Escande D, Mannens MM, Le Marec H. Cardiac conduction defects associate with mutations in SCN5A. Nat Genet. 1999; 23:20-21. [PubMed: 10471492]

427. Schott JJ, Charpentier F, Peltier S, Foley P, Drouin E, Bouhour JB, Donnelly P, Vergnaud G, Bachner L, Moisan JP, et al. Mapping of a gene for long QT syndrome to chromosome 4q25-27. American journal of human genetics. 1995; 57:1114-1122. [PubMed: 7485162]

428. Schotten U, de Haan S, Verheule S, Harks EG, Frechen D, Bodewig E, Greiser M, Ram R, Maessen J, Kelm M, Allessie M, Van Wagoner DR. Blockade of atrial-specific $\mathrm{K}^{+}$-currents increases atrial but not ventricular contractility by enhancing reverse mode $\mathrm{Na}^{+} / \mathrm{Ca}^{2+}$-exchange. Cardiovasc Res. 2007; 73:37-47. [PubMed: 17157284]

429. Schotten U, Greiser M, Benke D, Buerkel K, Ehrenteidt B, Stellbrink C, Vazquez-Jimenez JF, Schoendube F, Hanrath P, Allessie M. Atrial fibrillation-induced atrial contractile dysfunction: a tachycardiomyopathy of a different sort. Cardiovasc Res. 2002; 53:192-201. [PubMed: 11744028]

430. Schram G, Pourrier M, Melnyk P, Nattel S. Differential distribution of cardiac ion channel expression as a basis for regional specialization in electrical function. Circ Res. 2002; 90:939950. [PubMed: 12016259]

431. Schram G, Pourrier M, Melnyk P, Nattel S. Differential Distribution of Cardiac Ion Channel Expression as a Basis for Regional Specialization in Electrical Function. Circ Res. 2002; 90:939950. [PubMed: 12016259]

432. Schram G, Pourrier M, Wang Z, White M, Nattel S. Barium block of Kir2 and human cardiac inward rectifier currents: evidence for subunit-heteromeric contribution to native currents. Cardiovasc Res. 2003; 59:328-338. [PubMed: 12909316]

433. Schroder F, Handrock R, Beuckelmann DJ, Hirt S, Hullin R, Priebe L, Schwinger RH, Weil J, Herzig S. Increased availability and open probability of single L-type calcium channels from failing compared with nonfailing human ventricle. Circulation. 1998; 98:969-976. [PubMed: 9737516]

434. Schroeder BC, Waldegger S, Fehr S, Bleich M, Warth R, Greger R, Jentsch TJ. A constitutively open potassium channel formed by KCNQ1 and KCNE3. Nature. 2000; 403:196-199. [PubMed: 10646604]

435. Schuessler RB. Abnormal sinus node function in clinical arrhythmias. Journal of cardiovascular electrophysiology. 2003; 14:215-217. [PubMed: 12693509]

436. Schulze-Bahr E, Haverkamp W, Wedekind H, Rubie C, Hordt M, Borggrefe M, Assmann G, Breithardt G, Funke H. Autosomal recessive long-QT syndrome (Jervell Lange-Nielsen syndrome) is genetically heterogeneous. Hum Genet. 1997; 100:573-576. [PubMed: 9341873]

437. Schulze-Bahr E, Neu A, Friederich P, Kaupp UB, Breithardt G, Pongs O, Isbrandt D. Pacemaker channel dysfunction in a patient with sinus node disease. The Journal of clinical investigation. 2003; 111:1537-1545. [PubMed: 12750403]

438. Schwartz PJ, Crotti L, Insolia R. Long-QT syndrome: from genetics to management. Circ Arrhythm Electrophysiol. 2012; 5:868-877. [PubMed: 22895603]

439. Schwinger RH, Bohm M, Schmidt U, Karczewski P, Bavendiek U, Flesch M, Krause EG, Erdmann E. Unchanged protein levels of SERCA II and phospholamban but reduced Ca2+ uptake and $\mathrm{Ca}(2+)$-ATPase activity of cardiac sarcoplasmic reticulum from dilated cardiomyopathy patients compared with patients with nonfailing hearts. Circulation. 1995; 92:3220-3228. [PubMed: 7586307]

440. Schwinger RH, Hoischen S, Reuter H, Hullin R. Regional expression and functional characterization of the L-type $\mathrm{Ca} 2+$-channel in myocardium from patients with end-stage heart failure and in non-failing human hearts. Journal of molecular and cellular cardiology. 1999; 31:283-296. [PubMed: 10072735]

441. Schwinger RH, Munch G, Bolck B, Karczewski P, Krause EG, Erdmann E. Reduced Ca(2+)sensitivity of SERCA 2a in failing human myocardium due to reduced serin-16 phospholamban phosphorylation. J Mol Cell Cardiol. 1999; 31:479-491. [PubMed: 10198180]

442. Seino S, Miki T. Gene targeting approach to clarification of ion channel function: studies of Kir6.x null mice. J Physiol. 2004; 554:295-300. [PubMed: 12826653] 
443. Selnick HG, Liverton NJ, Baldwin JJ, Butcher JW, Claremon DA, Elliott JM, Freidinger RM, King SA, Libby BE, McIntyre CJ, Pribush DA, Remy DC, Smith GR, Tebben AJ, Jurkiewicz NK, Lynch JJ, Salata JJ, Sanguinetti MC, Siegl PK, Slaughter DE, Vyas K. Class III antiarrhythmic activity in vivo by selective blockade of the slowly activating cardiac delayed rectifier potassium current IKs by (R)-2-(2,4-trifluoromethyl)-N-[2-oxo-5-phenyl-1-(2,2,2trifluoroethyl)- 2, 3-dihydro-1H-benzo[e][1,4]diazepin-3-yl]acetamide. J Med Chem. 1997; 40:3865-3868. [PubMed: 9397166]

444. Shah M, Akar FG, Tomaselli GF. Molecular basis of arrhythmias. Circulation. 2005; 112:25172529. [PubMed: 16230503]

445. Shan J, Xie W, Betzenhauser M, Reiken S, Chen BX, Wronska A, Marks AR. Calcium leak through ryanodine receptors leads to atrial fibrillation in 3 mouse models of catecholaminergic polymorphic ventricular tachycardia. Circ Res. 2012; 111:708-717. [PubMed: 22828895]

446. Shang LL, Pfahnl AE, Sanyal S, Jiao Z, Allen J, Banach K, Fahrenbach J, Weiss D, Taylor WR, Zafari AM, Dudley SC Jr. Human heart failure is associated with abnormal C-terminal splicing variants in the cardiac sodium channel. Circ Res. 2007; 101:1146-1154. [PubMed: 17901361]

447. Shannon TR, Pogwizd SM, Bers DM. Elevated sarcoplasmic reticulum Ca2+ leak in intact ventricular myocytes from rabbits in heart failure. Circ Res. 2003; 93:592-594. [PubMed: 12946948]

448. Shi W, Wymore R, Yu H, Wu J, Wymore RT, Pan Z, Robinson RB, Dixon JE, McKinnon D, Cohen IS. Distribution and prevalence of hyperpolarization-activated cation channel (HCN) mRNA expression in cardiac tissues. Circulation Research. 1999; 85:e1-e6. [PubMed: 10400919]

449. Shibata EF, Drury T, Refsum H, Aldrete V, Giles W. Contributions of a transient outward current to repolarization in human atrium. Am J Physiol. 1989; 257:H1773-H1781. [PubMed: 2557769]

450. Shimoni Y, Clark RB, Giles WR. Role of an inwardly rectifying potassium current in rabbit ventricular action potential. J Physiol. 1992; 448:709-727. [PubMed: 1593485]

451. Shiroshita-Takeshita A, Sakabe M, Haugan K, Hennan JK, Nattel S. Model-dependent effects of the gap junction conduction-enhancing antiarrhythmic peptide rotigaptide (ZP123) on experimental atrial fibrillation in dogs. Circulation. 2007; 115:310-318. [PubMed: 17224477]

452. Sicouri S, Antzelevitch C. A subpopulation of cells with unique electrophysiological properties in the deep subepicardium of the canine ventricle. The M cell. Circ Res. 1991; 68:1729-1741. [PubMed: 2036721]

453. Sigg, DC. Cardiac electrophysiology methods and models. New York: Springer; 2010.

454. Silva J, Rudy Y. Subunit interaction determines IKs participation in cardiac repolarization and repolarization reserve. Circulation. 2005; 112:1384-1391. [PubMed: 16129795]

455. Skasa M, Jungling E, Picht E, Schondube F, Luckhoff A. L-type calcium currents in atrial myocytes from patients with persistent and non-persistent atrial fibrillation. Basic Res Cardiol. 2001; 96:151-159. [PubMed: 11327333]

456. Smits JPP, Koopmann TT, Wilders R, Veldkamp MW, Opthof T, Bhuiyan ZA, Mannens MMAM, Balser JR, Tan HL, Bezzina CR, Wilde AAM. A mutation in the human cardiac sodium channel $(\mathrm{E} 161 \mathrm{~K})$ contributes to sick sinus syndrome, conduction disease and Brugada syndrome in two families. Journal of Molecular and Cellular Cardiology. 2005; 38:969-981. [PubMed: 15910881]

457. Soldatov NM. Genomic structure of human L-type Ca2+ channel. Genomics. 1994; 22:77-87. [PubMed: 7959794]

458. Soltysinska E, Olesen SP, Christ T, Wettwer E, Varro A, Grunnet M, Jespersen T. Transmural expression of ion channels and transporters in human nondiseased and end-stage failing hearts. Pflugers Arch. 2009; 459:11-23. [PubMed: 19768467]

459. Sossalla S, Kallmeyer B, Wagner S, Mazur M, Maurer U, Toischer K, Schmitto JD, Seipelt R, Schondube FA, Hasenfuss G, Belardinelli L, Maier LS. Altered $\mathrm{Na}^{+}$currents in atrial fibrillation effects of ranolazine on arrhythmias and contractility in human atrial myocardium. J Am Coll Cardiol. 2010; 55:2330-2342. [PubMed: 20488304] 
460. Spach MS, Lieberman M, Scott JG, Barr RC, Johnson EA, Kootsey JM. Excitation sequences of the atrial septum and the AV node in isolated hearts of the dog and rabbit. Circulation Research. 1971; 29:156-172. [PubMed: 5566672]

461. Splawski I, Timothy KW, Sharpe LM, Decher N, Kumar P, Bloise R, Napolitano C, Schwartz PJ, Joseph RM, Condouris K, Tager-Flusberg H, Priori SG, Sanguinetti MC, Keating MT. Ca(V)1.2 calcium channel dysfunction causes a multisystem disorder including arrhythmia and autism. Cell. 2004; 119:19-31. [PubMed: 15454078]

462. Splawski I, Tristani-Firouzi M, Lehmann MH, Sanguinetti MC, Keating MT. Mutations in the hminK gene cause long QT syndrome and suppress IKs function. Nat Genet. 1997; 17:338-340. [PubMed: 9354802]

463. Stange M, Xu L, Balshaw D, Yamaguchi N, Meissner G. Characterization of recombinant skeletal muscle (Ser-2843) and cardiac muscle (Ser-2809) ryanodine receptor phosphorylation mutants. J Biol Chem. 2003; 278:51693-51702. [PubMed: 14532276]

464. Stevenson WG, Stevenson LW, Middlekauff HR, Saxon LA. Sudden death prevention in patients with advanced ventricular dysfunction. Circulation. 1993; 88:2953-2961. [PubMed: 8252708]

465. Studer R, Reinecke H, Bilger J, Eschenhagen T, Bohm M, Hasenfuss G, Just H, Holtz J, Drexler $\mathrm{H}$. Gene expression of the cardiac $\mathrm{Na}(+)-\mathrm{Ca} 2+$ exchanger in end-stage human heart failure. Circ Res. 1994; 75:443-453. [PubMed: 8062418]

466. Sugai M, Kono R, Kunita Y. A morphologic study on human conduction system of heart considering influences of some disorders of individuals. Acta pathologica japonica. 1981; 31:1325. [PubMed: 6453498]

467. Sun Y, Yang YQ, Gong XQ, Wang XH, Li RG, Tan HW, Liu X, Fang WY, Bai D. Novel germline GJA5/connexin40 mutations associated with lone atrial fibrillation impair gap junctional intercellular communication. Hum Mutat. 2013; 34:603-609. [PubMed: 23348765]

468. Suzuki M, Li RA, Miki T, Uemura H, Sakamoto N, Ohmoto-Sekine Y, Tamagawa M, Ogura T, Seino S, Marban E, Nakaya H. Functional roles of cardiac and vascular ATP-sensitive potassium channels clarified by Kir6.2-knockout mice. Circ Res. 2001; 88:570-577. [PubMed: 11282890]

469. Suzuki M, Sasaki N, Miki T, Sakamoto N, Ohmoto-Sekine Y, Tamagawa M, Seino S, Marban E, Nakaya H. Role of sarcolemmal K(ATP) channels in cardioprotection against ischemia/ reperfusion injury in mice. J Clin Invest. 2002; 109:509-516. [PubMed: 11854323]

470. Swaminathan PD, Purohit A, Soni S, Voigt N, Singh MV, Glukhov AV, Gao Z, He BJ, Luczak ED, Joiner M-1A, Kutschke W, Yang J, Donahue JK, Weiss RM, Grumbach IM, Ogawa M, Chen P-S, Efimov I, Dobrev D, Mohler PJ, Hund TJ, Anderson ME. Oxidized CaMKII causes cardiac sinus node dysfunction in mice. The Journal of clinical investigation. 2011; 121:3277-3288. [PubMed: 21785215]

471. Szabo G, Szentandrassy N, Biro T, Toth BI, Czifra G, Magyar J, Banyasz T, Varro A, Kovacs L, Nanasi PP. Asymmetrical distribution of ion channels in canine and human left-ventricular wall: epicardium versus midmyocardium. Pflugers Arch. 2005; 450:307-316. [PubMed: 15952036]

472. Szentadrassy N, Banyasz T, Biro T, Szabo G, Toth BI, Magyar J, Lazar J, Varro A, Kovacs L, Nanasi PP. Apico-basal inhomogeneity in distribution of ion channels in canine and human ventricular myocardium. Cardiovasc Res. 2005; 65:851-860. [PubMed: 15721865]

473. Szumowski L, Sanders P, Walczak F, Hocini M, Jaïs P, Kepski R, Szufladowicz E, Urbanek P, Derejko P, Bodalski R, Haïssaguerre M. Mapping and ablation of polymorphic ventricular tachycardia after myocardial infarction. JAC. 2004; 44:1700-1706.

474. Takahashi N, Morishige K, Jahangir A, Yamada M, Findlay I, Koyama H, Kurachi Y. Molecular cloning and functional expression of cDNA encoding a second class of inward rectifier potassium channels in the mouse brain. J Biol Chem. 1994; 269:23274-23279. [PubMed: 8083233]

475. Tan AY, Li H, Wachsmann-Hogiu S, Chen LS, Chen PS, Fishbein MC. Autonomic innervation and segmental muscular disconnections at the human pulmonary vein-atrial junction: implications for catheter ablation of atrial-pulmonary vein junction. J Am Coll Cardiol. 2006; 48:132-143. [PubMed: 16814659] 
476. Tawil R, Ptacek LJ, Pavlakis SG, DeVivo DC, Penn AS, Ozdemir C, Griggs RC. Andersen's syndrome: potassium-sensitive periodic paralysis, ventricular ectopy, and dysmorphic features. Annals of neurology. 1994; 35:326-330. [PubMed: 8080508]

477. Tellez JO, Dobrzynski H, Greener ID, Graham GM, Laing E, Honjo H, Hubbard SJ, Boyett MR, Billeter R. Differential expression of ion channel transcripts in atrial muscle and sinoatrial node in rabbit. Circulation Research. 2006; 99:1384-1393. [PubMed: 17082478]

478. Tellez JO, Mczewski M, Yanni J, Sutyagin P, Mackiewicz U, Atkinson A, Inada S, Beresewicz A, Billeter R, Dobrzynski H, Boyett MR. Ageing-dependent remodelling of ion channel and $\mathrm{Ca} 2+$ clock genes underlying sino-atrial node pacemaking. Experimental physiology. 2011; 96:1163-1178. [PubMed: 21724736]

479. Templin C, Ghadri JR, Rougier JS, Baumer A, Kaplan V, Albesa M, Sticht H, Rauch A, Puleo C, Hu D, Barajas-Martinez H, Antzelevitch C, Luscher TF, Abriel H, Duru F. Identification of a novel loss-of-function calcium channel gene mutation in short QT syndrome (SQTS6). European heart journal. 2011; 32:1077-1088. [PubMed: 21383000]

480. Terentyev D, Gyorke I, Belevych AE, Terentyeva R, Sridhar A, Nishijima Y, de Blanco EC, Khanna S, Sen CK, Cardounel AJ, Carnes CA, Gyorke S. Redox modification of ryanodine receptors contributes to sarcoplasmic reticulum $\mathrm{Ca} 2+$ leak in chronic heart failure. Circ Res. 2008; 103:1466-1472. [PubMed: 19008475]

481. Tessier S, Karczewski P, Krause EG, Pansard Y, Acar C, Lang-Lazdunski M, Mercadier JJ, Hatem SN. Regulation of the transient outward $\mathrm{K}^{+}$current by $\mathrm{Ca}^{2+} /$ calmodulin-dependent protein kinases II in human atrial myocytes. Circ Res. 1999; 85:810-819. [PubMed: 10532949]

482. Tester DJ, Arya P, Will M, Haglund CM, Farley AL, Makielski JC, Ackerman MJ. Genotypic heterogeneity and phenotypic mimicry among unrelated patients referred for catecholaminergic polymorphic ventricular tachycardia genetic testing. Heart Rhythm. 2006; 3:800-805. [PubMed: 16818210]

483. Thomas SA, Schuessler RB, Berul CI, Beardslee MA, Beyer EC, Mendelsohn ME, Saffitz JE. Disparate effects of deficient expression of connexin43 on atrial and ventricular conduction: evidence for chamber-specific molecular determinants of conduction. Circulation. 1998; 97:686691. [PubMed: 9495305]

484. Tinel N, Diochot S, Borsotto M, Lazdunski M, Barhanin J. KCNE2 confers background current characteristics to the cardiac KCNQ1 potassium channel. Embo J. 2000; 19:6326-6330. [PubMed: 11101505]

485. Tomaselli GF, Beuckelmann DJ, Calkins HG, Berger RD, Kessler PD, Lawrence JH, Kass D, Feldman AM, Marban E. Sudden cardiac death in heart failure. The role of abnormal repolarization. Circulation. 1994; 90:2534-2539. [PubMed: 7955213]

486. Tranum-Jensen J, Wilde AA, Vermeulen JT, Janse MJ. Morphology of electrophysiologically identified junctions between Purkinje fibers and ventricular muscle in rabbit and pig hearts. Circulation Research. 1991; 69:429-437. [PubMed: 1860183]

487. Trautwein W, Kassebaum DG. On the mechanism of spontaneous impulse generation in the pacemaker of the heart. J Gen Physiol. 1961; 45:317-330. [PubMed: 13922329]

488. Tristani-Firouzi M, Jensen JL, Donaldson MR, Sansone V, Meola G, Hahn A, Bendahhou S, Kwiecinski H, Fidzianska A, Plaster N, Fu YH, Ptacek LJ, Tawil R. Functional and clinical characterization of KCNJ2 mutations associated with LQT7 (Andersen syndrome). J Clin Invest. 2002; 110:381-388. [PubMed: 12163457]

489. Tristani-Firouzi M, Jensen JL, Donaldson MR, Sansone V, Meola G, Hahn A, Bendahhou S, Kwiecinski H, Fidzianska A, Plaster N, Fu YH, Ptacek LJ, Tawil R. Functional and clinical characterization of KCNJ2 mutations associated with LQT7 (Andersen syndrome). J Clin Invest. 2002; 110:381-388. [PubMed: 12163457]

490. Tristani-Firouzi M, Sanguinetti MC. Structural determinants and biophysical properties of HERG and KCNQ1 channel gating. J Mol Cell Cardiol. 2003; 35:27-35. [PubMed: 12623297]

491. Tseng GN, Hoffman BF. Two components of transient outward current in canine ventricular myocytes. Circ Res. 1989; 64:633-647. [PubMed: 2539269]

492. Tsuji Y, Opthof T, Kamiya K, Yasui K, Liu W, Lu Z, Kodama I. Pacing-induced heart failure causes a reduction of delayed rectifier potassium currents along with decreases in calcium and 
transient outward currents in rabbit ventricle. Cardiovasc Res. 2000; 48:300-309. [PubMed: 11054476]

493. Tsuji Y, Zicha S, Qi XY, Kodama I, Nattel S. Potassium channel subunit remodeling in rabbits exposed to long-term bradycardia or tachycardia: discrete arrhythmogenic consequences related to differential delayed-rectifier changes. Circulation. 2006; 113:345-355. [PubMed: 16432066]

494. Tuomi JM, Tyml K, Jones DL. Atrial tachycardia/fibrillation in the connexin 43 G60S mutant (Oculodentodigital dysplasia) mouse. Am J Physiol Heart Circ Physiol. 2011; 300:H1402H1411. [PubMed: 21239638]

495. Tuteja D, Xu D, Timofeyev V, Lu L, Sharma D, Zhang Z, Xu Y, Nie L, Vazquez AE, Young JN, Glatter KA, Chiamvimonvat N. Differential expression of small-conductance Ca2+-activated K+ channels SK1, SK2, and SK3 in mouse atrial and ventricular myocytes. Am J Physiol Heart Circ Physiol. 2005; 289:H2714-H2723. [PubMed: 16055520]

496. Ueda K, Hirano Y, Higashiuesato Y, Aizawa Y, Hayashi T, Inagaki N, Tana T, Ohya Y, Takishita S, Muratani H, Hiraoka M, Kimura A. Role of HCN4 channel in preventing ventricular arrhythmia. Journal of human genetics. 2009; 54:115-121. [PubMed: 19165230]

497. Ueda K, Nakamura K, Hayashi T, Inagaki N, Takahashi M, Arimura T, Morita H, Higashiuesato Y, Hirano Y, Yasunami M, Takishita S, Yamashina A, Ohe T, Sunamori M, Hiraoka M, Kimura A. Functional characterization of a trafficking-defective HCN4 mutation, D553N, associated with cardiac arrhythmia. The Journal of biological chemistry. 2004; 279:27194-27198. [PubMed: 15123648]

498. Ueda K, Valdivia C, Medeiros-Domingo A, Tester DJ, Vatta M, Farrugia G, Ackerman MJ, Makielski JC. Syntrophin mutation associated with long QT syndrome through activation of the nNOS-SCN5A macromolecular complex. Proceedings of the National Academy of Sciences of the United States of America. 2008; 105:9355-9360. [PubMed: 18591664]

499. Ufret-Vincenty CA, Baro DJ, Lederer WJ, Rockman HA, Quinones LE, Santana LF. Role of sodium channel deglycosylation in the genesis of cardiac arrhythmias in heart failure. J Biol Chem. 2001; 276:28197-28203. [PubMed: 11369778]

500. Undrovinas AI, Maltsev VA, Kyle JW, Silverman N, Sabbah HN. Gating of the late Na+ channel in normal and failing human myocardium. J Mol Cell Cardiol. 2002; 34:1477-1489. [PubMed: 12431447]

501. Undrovinas AI, Maltsev VA, Sabbah HN. Repolarization abnormalities in cardiomyocytes of dogs with chronic heart failure: role of sustained inward current. Cellular and molecular life sciences : CMLS. 1999; 55:494-505. [PubMed: 10228563]

502. Vaidya D, Tamaddon HS, Lo CW, Taffet SM, Delmar M, Morley GE, Jalife J. Null mutation of connexin 43 causes slow propagation of ventricular activation in the late stages of mouse embryonic development. Circ Res. 2001; 88:1196-1202. [PubMed: 11397787]

503. Vaitkevicius R, Saburkina I, Rysevaite K, Vaitkeviciene I, Pauziene N, Zaliunas R, Schauerte P, Jalife J, Pauza DH. Nerve supply of the human pulmonary veins: an anatomical study. Heart Rhythm. 2009; 6:221-228. [PubMed: 19187915]

504. Valdivia CR, Chu WW, Pu J, Foell JD, Haworth RA, Wolff MR, Kamp TJ, Makielski JC. Increased late sodium current in myocytes from a canine heart failure model and from failing human heart. J Mol Cell Cardiol. 2005; 38:475-483. [PubMed: 15733907]

505. Valdivia HH, Kaplan JH, Ellis-Davies GC, Lederer WJ. Rapid adaptation of cardiac ryanodine receptors: modulation by Mg2+ and phosphorylation. Science. 1995; 267:1997-2000. [PubMed: 7701323]

506. van Rijen HV, Eckardt D, Degen J, Theis M, Ott T, Willecke K, Jongsma HJ, Opthof T, de Bakker JM. Slow conduction and enhanced anisotropy increase the propensity for ventricular tachyarrhythmias in adult mice with induced deletion of connexin43. Circulation. 2004; 109:1048-1055. [PubMed: 14967725]

507. van Veen TA, Stein M, Royer A, Le Quang K, Charpentier F, Colledge WH, Huang CL, Wilders R, Grace AA, Escande D, de Bakker JM, van Rijen HV. Impaired impulse propagation in Scn5aknockout mice: combined contribution of excitability, connexin expression, and tissue architecture in relation to aging. Circulation. 2005; 112:1927-1935. [PubMed: 16172272] 
508. Van Wagoner DR, Nerbonne JM. Molecular basis of electrical remodeling in atrial fibrillation. J Mol Cell Cardiol. 2000; 32:1101-1117. [PubMed: 10888261]

509. Van Wagoner DR, Pond AL, Lamorgese M, Rossie SS, McCarthy PM, Nerbonne JM. Atrial LType $\mathrm{Ca}^{2+}$ Currents and Human Atrial Fibrillation. Circ Res. 1999; 85:428-436. [PubMed: 10473672]

510. Van Wagoner DR, Pond AL, McCarthy PM, Trimmer JS, Nerbonne JM. Outward $\mathrm{K}^{+}$current densities and Kv1.5 expression are reduced in chronic human atrial fibrillation. Circ Res. 1997; 80:772-781. [PubMed: 9168779]

511. Varro A, Balati B, Iost N, Takacs J, Virag L, Lathrop DA, Csaba L, Talosi L, Papp JG. The role of the delayed rectifier component IKs in dog ventricular muscle and Purkinje fibre repolarization. J Physiol. 2000; 523(Pt 1):67-81. [PubMed: 10675203]

512. Varro A, Nanasi PP, Lathrop DA. Potassium currents in isolated human atrial and ventricular cardiocytes. Acta physiologica Scandinavica. 1993; 149:133-142. [PubMed: 8266802]

513. Vatta M, Ackerman MJ, Ye B, Makielski JC, Ughanze EE, Taylor EW, Tester DJ, Balijepalli RC, Foell JD, Li Z, Kamp TJ, Towbin JA. Mutant caveolin-3 induces persistent late sodium current and is associated with long-QT syndrome. Circulation. 2006; 114:2104-2112. [PubMed: 17060380]

514. Veldkamp MW, van Ginneken AC, Bouman LN. Single delayed rectifier channels in the membrane of rabbit ventricular myocytes. Circ Res. 1993; 72:865-878. [PubMed: 8443873]

515. Verheijck EE, Wessels A, van Ginneken AC, Bourier J, Markman MW, Vermeulen JL, de Bakker JM, Lamers WH, Opthof T, Bouman LN. Distribution of atrial and nodal cells within the rabbit sinoatrial node: models of sinoatrial transition. Circulation. 1998; 97:1623-1631. [PubMed: 9593568]

516. Verheule S, van Kempen MJ, te Welscher PH, Kwak BR, Jongsma HJ. Characterization of gap junction channels in adult rabbit atrial and ventricular myocardium. Circ Res. 1997; 80:673-681. [PubMed: 9130448]

517. Verkerk AO, Wilders R, Coronel R, Ravesloot JH, Verheijck EE. Ionic remodeling of sinoatrial node cells by heart failure. Circulation. 2003; 108:760-766. [PubMed: 12885752]

518. Vest JA, Wehrens XHT, Reiken SR, Lehnart SE, Dobrev D, Chandra P, Danilo P, Ravens U, Rosen MR, Marks AR. Defective Cardiac Ryanodine Receptor Regulation During Atrial Fibrillation. Circulation. 2005; 111:2025-2032. [PubMed: 15851612]

519. Vinogradova TM, Lyashkov AE, Zhu W, Ruknudin AM, Sirenko S, Yang D, Deo S, Barlow M, Johnson S, Caffrey JL, Zhou Y-Y, Xiao R-P, Cheng H, Stern MD, Maltsev VA, Lakatta EG. High basal protein kinase A-dependent phosphorylation drives rhythmic internal $\mathrm{Ca} 2+$ store oscillations and spontaneous beating of cardiac pacemaker cells. Circulation Research. 2006; 98:505-514. [PubMed: 16424365]

520. Virag L, Iost N, Opincariu M, Szolnoky J, Szecsi J, Bogats G, Szenohradszky P, Varro A, Papp JG. The slow component of the delayed rectifier potassium current in undiseased human ventricular myocytes. Cardiovasc Res. 2001; 49:790-797. [PubMed: 11230978]

521. Voigt N, Trafford AW, Ravens U, Dobrev D. Abstract 2630: Cellular and Molecular Determinants of Altered Atrial Ca2+ Signaling in Patients With Chronic Atrial Fibrillation. Circulation. 2009; 120:S667-d-668.

522. Voigt N, Trafford AW, Wang Q, Wehrens XH, Ravens U, Dobrev D. Abstract 16909: Sarcoplasmic Reticulum Calcium Leak and Enhanced NCX Increase Occurrence of Delayed Afterdepolarisations in Atrial Myocytes from Patients with Chronic Atrial Fibrillation. Circulation. 2010; 122:A16909.

523. Voigt N, Trausch A, Knaut M, Matschke K, Varro A, Van Wagoner DR, Nattel S, Ravens U, Dobrev D. Left-to-right atrial inward rectifier potassium current gradients in patients with paroxysmal versus chronic atrial fibrillation. Circ Arrhythm Electrophysiol. 2010; 3:472-480. [PubMed: 20657029]

524. Volders PG, Sipido KR, Carmeliet E, Spatjens RL, Wellens HJ, Vos MA. Repolarizing K+ currents ITO1 and IKs are larger in right than left canine ventricular midmyocardium. Circulation. 1999; 99:206-210. [PubMed: 9892584] 
525. Volders PG, Stengl M, van Opstal JM, Gerlach U, Spatjens RL, Beekman JD, Sipido KR, Vos MA. Probing the contribution of IKs to canine ventricular repolarization: key role for betaadrenergic receptor stimulation. Circulation. 2003; 107:2753-2760. [PubMed: 12756150]

526. Vozzi C, Dupont E, Coppen SR, Yeh HI, Severs NJ. Chamber-related differences in connexin expression in the human heart. J Mol Cell Cardiol. 1999; 31:991-1003. [PubMed: 10336839]

527. Wagner S, Dybkova N, Rasenack EC, Jacobshagen C, Fabritz L, Kirchhof P, Maier SK, Zhang T, Hasenfuss G, Brown JH, Bers DM, Maier LS. $\mathrm{Ca}^{2+} /$ calmodulin-dependent protein kinase II regulates cardiac $\mathrm{Na}^{+}$channels. J Clin Invest. 2006; 116:3127-3138. [PubMed: 17124532]

528. Wagner S, Hacker E, Grandi E, Weber SL, Dybkova N, Sossalla S, Sowa T, Fabritz L, Kirchhof P, Bers DM, Maier LS. Ca/calmodulin kinase II differentially modulates potassium currents. Circ Arrhythm Electrophysiol. 2009; 2:285-294. [PubMed: 19808479]

529. Wagner S, Ruff HM, Weber SL, Bellmann S, Sowa T, Schulte T, Grandi E, Bers DM, Backs J, Belardinelli L, Maier LS. Reactive Oxygen Species-Activated Ca/Calmodulin Kinase II $\{$ delta $\}$ Is Required for Late $\mathrm{I}_{\mathrm{Na}}$ Augmentation Leading to Cellular Na and Ca Overload. Circ Res. 2011

530. Wainger BJ, DeGennaro M, Santoro B, Siegelbaum SA, Tibbs GR. Molecular mechanism of cAMP modulation of HCN pacemaker channels. Nature. 2001; 411:805-810. [PubMed: 11459060]

531. Wakili R, Voigt N, Kaab S, Dobrev D, Nattel S. Recent advances in the molecular pathophysiology of atrial fibrillation. J Clin Invest. 2011; 121:2955-2968. [PubMed: 21804195]

532. Walsh KB, Kass RS. Distinct voltage-dependent regulation of a heart-delayed IK by protein kinases A and C. The American journal of physiology. 1991; 261:C1081-C1090. [PubMed: 1662903]

533. Walsh KB, Kass RS. Regulation of a heart potassium channel by protein kinase A and C. Science. 1988; 242:67-69. [PubMed: 2845575]

534. Wang DW, Viswanathan PC, Balser JR, George AL, Benson DW. Clinical, genetic, and biophysical characterization of SCN5A mutations associated with atrioventricular conduction block. Circulation. 2002; 105:341-346. [PubMed: 11804990]

535. Wang HS, Cohen IS. Calcium channel heterogeneity in canine left ventricular myocytes. The Journal of physiology. 2003; 547:825-833. [PubMed: 12562927]

536. Wang HS, Cohen IS. Calcium channel heterogeneity in canine left ventricular myocytes. J Physiol. 2003; 547:825-833. [PubMed: 12562927]

537. Wang J, Schwinger RH, Frank K, Muller-Ehmsen J, Martin-Vasallo P, Pressley TA, Xiang A, Erdmann E, McDonough AA. Regional expression of sodium pump subunits isoforms and Na+$\mathrm{Ca++}$ exchanger in the human heart. J Clin Invest. 1996; 98:1650-1658. [PubMed: 8833915]

538. Wang Q, Curran ME, Splawski I, Burn TC, Millholland JM, VanRaay TJ, Shen J, Timothy KW, Vincent GM, de Jager T, Schwartz PJ, Toubin JA, Moss AJ, Atkinson DL, Landes GM, Connors TD, Keating MT. Positional cloning of a novel potassium channel gene: KVLQT1 mutations cause cardiac arrhythmias. Nat Genet. 1996; 12:17-23. [PubMed: 8528244]

539. Wang Q, Li Z, Shen J, Keating MT. Genomic organization of the human SCN5A gene encoding the cardiac sodium channel. Genomics. 1996; 34:9-16. [PubMed: 8661019]

540. Wang Q, Shen J, Splawski I, Atkinson D, Li Z, Robinson JL, Moss AJ, Towbin JA, Keating MT. SCN5A mutations associated with an inherited cardiac arrhythmia, long QT syndrome. Cell. 1995; 80:805-811. [PubMed: 7889574]

541. Wang Z, Fermini B, Nattel S. Delayed rectifier outward current and repolarization in human atrial myocytes. Circ Res. 1993; 73:276-285. [PubMed: 8330373]

542. Wang Z, Fermini B, Nattel S. Sustained depolarization-induced outward current in human atrial myocytes. Evidence for a novel delayed rectifier $\mathrm{K}^{+}$current similar to Kv1.5 cloned channel currents. Circ Res. 1993; 73:1061-1076. [PubMed: 8222078]

543. Wang Z, Yue L, White M, Pelletier G, Nattel S. Differential distribution of inward rectifier potassium channel transcripts in human atrium versus ventricle. Circulation. 1998; 98:24222428. [PubMed: 9832487]

544. Wang ZG, Pelletier LC, Talajic M, Nattel S. Effects of flecainide and quinidine on human atrial action potentials. Role of rate-dependence and comparison with guinea pig, rabbit, and dog tissues. Circulation. 1990; 82:274-283. [PubMed: 2114235] 
545. Watanabe E, Yasui K, Kamiya K, Yamaguchi T, Sakuma I, Honjo H, Ozaki Y, Morimoto S, Hishida H, Kodama I. Upregulation of KCNE1 induces QT interval prolongation in patients with chronic heart failure. Circulation journal : official journal of the Japanese Circulation Society. 2007; 71:471-478. [PubMed: 17384445]

546. Watanabe H, Darbar D, Kaiser DW, Jiramongkolchai K, Chopra S, Donahue BS, Kannankeril PJ, Roden DM. Mutations in sodium channel beta1- and beta2-subunits associated with atrial fibrillation. Circ Arrhythm Electrophysiol. 2009; 2:268-275. [PubMed: 19808477]

547. Watanabe H, Koopmann TT, Le Scouarnec S, Yang T, Ingram CR, Schott JJ, Demolombe S, Probst V, Anselme F, Escande D, Wiesfeld AC, Pfeufer A, Kaab S, Wichmann HE, Hasdemir C, Aizawa Y, Wilde AA, Roden DM, Bezzina CR. Sodium channel beta1 subunit mutations associated with Brugada syndrome and cardiac conduction disease in humans. J Clin Invest. 2008; 118:2260-2268. [PubMed: 18464934]

548. Watanabe T, Delbridge LM, Bustamante JO, McDonald TF. Heterogeneity of the action potential in isolated rat ventricular myocytes and tissue. Circ Res. 1983; 52:280-290. [PubMed: 6825220]

549. Weber MA, Gunther M, Lichy MP, Delorme S, Bongers A, Thilmann C, Essig M, Zuna I, Schad LR, Debus J, Schlemmer HP. Comparison of arterial spin-labeling techniques and dynamic susceptibility-weighted contrast-enhanced MRI in perfusion imaging of normal brain tissue. Investigative radiology. 2003; 38:712-718. [PubMed: 14566181]

550. Wettwer E, Amos G, Gath J, Zerkowski HR, Reidemeister JC, Ravens U. Transient outward current in human and rat ventricular myocytes. Cardiovasc Res. 1993; 27:1662-1669. [PubMed: 8287446]

551. Wettwer E, Amos GJ, Posival H, Ravens U. Transient outward current in human ventricular myocytes of subepicardial and subendocardial origin. Circ Res. 1994; 75:473-482. [PubMed: 8062421]

552. Wettwer E, Hala O, Christ T, Heubach JF, Dobrev D, Knaut M, Varro A, Ravens U. Role of I Kur in controlling action potential shape and contractility in the human atrium: influence of chronic atrial fibrillation. Circulation. 2004; 110:2299-2306. [PubMed: 15477405]

553. Wetzel GT, Chen F, Klitzner TS. Ca2+ channel kinetics in acutely isolated fetal, neonatal, and adult rabbit cardiac myocytes. Circ Res. 1993; 72:1065-1074. [PubMed: 8386596]

554. Wetzel GT, Chen F, Klitzner TS. L- and T-type calcium channels in acutely isolated neonatal and adult cardiac myocytes. Pediatric research. 1991; 30:89-94. [PubMed: 1653937]

555. Wickenden AD, Jegla TJ, Kaprielian R, Backx PH. Regional contributions of Kv1.4, Kv4.2, and Kv4.3 to transient outward K+ current in rat ventricle. Am J Physiol. 1999; 276:H1599-H1607. [PubMed: 10330244]

556. Wilders R, Kumar R, Joyner RW, Jongsma HJ, Verheijck EE, Golod D, van Ginneken AC, Goolsby WN. Action potential conduction between a ventricular cell model and an isolated ventricular cell. Biophys J. 1996; 70:281-295. [PubMed: 8770204]

557. Wirka RC, Gore S, Van Wagoner DR, Arking DE, Lubitz SA, Lunetta KL, Benjamin EJ, Alonso A, Ellinor PT, Barnard J, Chung MK, Smith JD. A common connexin-40 gene promoter variant affects connexin-40 expression in human atria and is associated with atrial fibrillation. Circ Arrhythm Electrophysiol. 2011; 4:87-93. [PubMed: 21076161]

558. Workman AJ, Kane KA, Rankin AC. Cellular bases for human atrial fibrillation. Heart Rhythm. 2008; 5:S1-S6. [PubMed: 18456193]

559. Workman AJ, Kane KA, Rankin AC. Characterisation of the Na, K pump current in atrial cells from patients with and without chronic atrial fibrillation. Cardiovasc Res. 2003; 59:593-602. [PubMed: 14499860]

560. Workman AJ, Kane KA, Rankin AC. The contribution of ionic currents to changes in refractoriness of human atrial myocytes associated with chronic atrial fibrillation. Cardiovascular Research. 2001; 52:226-235. [PubMed: 11684070]

561. Wu G, Huang CX, Tang YH, Jiang H, Wan J, Chen H, Xie Q, Huang ZR. Changes of I K,ATP current density and allosteric modulation during chronic atrial fibrillation. Chin Med J (Engl). 2005; 118:1161-1166. [PubMed: 16117860]

562. Wu Y, Gao Z, Chen B, Koval OM, Singh MV, Guan X, Hund TJ, Kutschke W, Sarma S, Grumbach IM, Wehrens XHT, Mohler PJ, Song L-S, Anderson ME. Calmodulin kinase II is 
required for fight or flight sinoatrial node physiology. Proceedings of the National Academy of Sciences of the United States of America. 2009; 106:5972-5977. [PubMed: 19276108]

563. Xia M, Jin Q, Bendahhou S, He Y, Larroque MM, Chen Y, Zhou Q, Yang Y, Liu Y, Liu B, Zhu Q, Zhou Y, Lin J, Liang B, Li L, Dong X, Pan Z, Wang R, Wan H, Qiu W, Xu W, Eurlings P, Barhanin J, Chen Y. A Kir2.1 gain-of-function mutation underlies familial atrial fibrillation. Biochemical and biophysical research communications. 2005; 332:1012-1019. [PubMed: 15922306]

564. Xiao B, Sutherland C, Walsh MP, Chen SR. Protein kinase A phosphorylation at serine-2808 of the cardiac Ca2+-release channel (ryanodine receptor) does not dissociate 12.6-kDa FK506binding protein (FKBP12.6). Circ Res. 2004; 94:487-495. [PubMed: 14715536]

565. Xiao L, Coutu P, Villeneuve LR, Tadevosyan A, Maguy A, Le Bouter S, Allen BG, Nattel S. Mechanisms underlying rate-dependent remodeling of transient outward potassium current in canine ventricular myocytes. Circ Res. 2008; 103:733-742. [PubMed: 18723449]

566. Xiong W, Tian Y, DiSilvestre D, Tomaselli GF. Transmural heterogeneity of Na+-Ca2+ exchange: evidence for differential expression in normal and failing hearts. Circ Res. 2005; 97:207-209. [PubMed: 16002750]

567. Xu H, Dixon JE, Barry DM, Trimmer JS, Merlie JP, McKinnon D, Nerbonne JM. Developmental analysis reveals mismatches in the expression of $\mathrm{K}+$ channel alpha subunits and voltage-gated $\mathrm{K}$ + channel currents in rat ventricular myocytes. J Gen Physiol. 1996; 108:405-419. [PubMed: 8923266]

568. Xu H, Guo W, Nerbonne JM. Four kinetically distinct depolarization-activated K+ currents in adult mouse ventricular myocytes. J Gen Physiol. 1999; 113:661-678. [PubMed: 10228181]

569. Xu Y, Tuteja D, Zhang Z, Xu D, Zhang Y, Rodriguez J, Nie L, Tuxson HR, Young JN, Glatter KA, Vazquez AE, Yamoah EN, Chiamvimonvat N. Molecular identification and functional roles of a $\mathrm{Ca}(2+)$-activated $\mathrm{K}+$ channel in human and mouse hearts. The Journal of biological chemistry. 2003; 278:49085-49094. [PubMed: 13679367]

570. Yamada KA, Kanter EM, Green KG, Saffitz JE. Transmural distribution of connexins in rodent hearts. J Cardiovasc Electrophysiol. 2004; 15:710-715. [PubMed: 15175068]

571. Yamada S, Kane GC, Behfar A, Liu XK, Dyer RB, Faustino RS, Miki T, Seino S, Terzic A. Protection conferred by myocardial ATP-sensitive $\mathrm{K}+$ channels in pressure overload-induced congestive heart failure revealed in KCNJ11 Kir6.2-null mutant. J Physiol. 2006; 577:10531065. [PubMed: 17038430]

572. Yan GX, Antzelevitch C. Cellular basis for the normal T wave and the electrocardiographic manifestations of the long-QT syndrome. Circulation. 1998; 98:1928-1936. [PubMed: 9799215]

573. Yan GX, Shimizu W, Antzelevitch C. Characteristics and distribution of M cells in arterially perfused canine left ventricular wedge preparations. Circulation. 1998; 98:1921-1927. [PubMed: 9799214]

574. Yang Y, Chen X, Margulies K, Jeevanandam V, Pollack P, Bailey BA, Houser SR. L-type Ca2+ channel alpha 1c subunit isoform switching in failing human ventricular myocardium. Journal of molecular and cellular cardiology. 2000; 32:973-984. [PubMed: 10888251]

575. Yang Y, Li J, Lin X, Yang Y, Hong K, Wang L, Liu J, Li L, Yan D, Liang D, Xiao J, Jin H, Wu J, Zhang Y, Chen YH. Novel KCNA5 loss-of-function mutations responsible for atrial fibrillation. Journal of human genetics. 2009; 54:277-283. [PubMed: 19343045]

576. Yang Y, Liang B, Liu J, Li J, Grunnet M, Olesen SP, Rasmussen HB, Ellinor PT, Gao L, Lin X, Li L, Wang L, Xiao J, Liu Y, Zhang S, Liang D, Peng L, Jespersen T, Chen YH. Identification of a Kir3.4 mutation in congenital long QT syndrome. American journal of human genetics. 2010; 86:872-880. [PubMed: 20560207]

577. Yang Y, Xia M, Jin Q, Bendahhou S, Shi J, Chen Y, Liang B, Lin J, Liu Y, Liu B, Zhou Q, Zhang D, Wang R, Ma N, Su X, Niu K, Pei Y, Xu W, Chen Z, Wan H, Cui J, Barhanin J, Chen Y. Identification of a KCNE2 gain-of-function mutation in patients with familial atrial fibrillation. American journal of human genetics. 2004; 75:899-905. [PubMed: 15368194]

578. Yaniv Y, Maltsev VA. Numerical Modeling Calcium and CaMKII Effects in the SA Node. Frontiers in pharmacology. 2014; 5:58. [PubMed: 24744732] 
579. Yanni J, Maczewski M, Mackiewicz U, Siew S, Fedorenko O, Atkinson A, Price M, Beresewicz A, Anderson RH, Boyett MR, Dobrzynski H. Structural and functional alterations in the atrioventricular node and atrioventricular ring tissue in ischaemia-induced heart failure. Histology and histopathology. 2014; 297:891-902. [PubMed: 24368587]

580. Yanni J, Tellez JO, Maczewski M, Mackiewicz U, Beresewicz A, Billeter R, Dobrzynski H, Boyett MR. Changes in ion channel gene expression underlying heart failure-induced sinoatrial node dysfunction. Circulation: Heart Failure. 2011; 4:496-508. [PubMed: 21565973]

581. Yanni J, Tellez JO, Sutyagin PV, Boyett MR, Dobrzynski H. Structural remodelling of the sinoatrial node in obese old rats. Journal of Molecular and Cellular Cardiology. 2010; 48:653662. [PubMed: 19729016]

582. Yao JA, Gutstein DE, Liu F, Fishman GI, Wit AL. Cell coupling between ventricular myocyte pairs from connexin43-deficient murine hearts. Circ Res. 2003; 93:736-743. [PubMed: 14500334]

583. Yoo S, Dobrzynski H, Fedorov VV, Xu S-Z, Yamanushi TT, Jones SA, Yamamoto M, Nikolski VP, Efimov IR, Boyett MR. Localization of $\mathrm{Na}+$ channel isoforms at the atrioventricular junction and atrioventricular node in the rat. Circulation. 2006; 114:1360-1371. [PubMed: 16966585]

584. Yu FH, Catterall WA. Overview of the voltage-gated sodium channel family. Genome biology. 2003; 4:207. [PubMed: 12620097]

585. Yuan W, Bers DM. Ca-dependent facilitation of cardiac Ca current is due to Ca-calmodulindependent protein kinase. The American journal of physiology. 1994; 267:H982-H993. [PubMed: 8092302]

586. Yue L, Wang Z, Rindt H, Nattel S. Molecular evidence for a role of Shaw (Kv3) potassium channel subunits in potassium currents of dog atrium. J Physiol. 2000; 527(Pt 3):467-478. [PubMed: 10990534]

587. Zaritsky JJ, Eckman DM, Wellman GC, Nelson MT, Schwarz TL. Targeted disruption of Kir2.1 and Kir2.2 genes reveals the essential role of the inwardly rectifying $\mathrm{K}(+)$ current in $\mathrm{K}(+)-$ mediated vasodilation. Circ Res. 2000; 87:160-166. [PubMed: 10904001]

588. Zaritsky JJ, Redell JB, Tempel BL, Schwarz TL. The consequences of disrupting cardiac inwardly rectifying $\mathrm{K}(+)$ current $(\mathrm{I}(\mathrm{K} 1))$ as revealed by the targeted deletion of the murine Kir2.1 and Kir2.2 genes. J Physiol. 2001; 533:697-710. [PubMed: 11410627]

589. Zhang H, Flagg TP, Nichols CG. Cardiac sarcolemmal K(ATP) channels: Latest twists in a questing tale! J Mol Cell Cardiol. 2009; 48:71-75. [PubMed: 19607836]

590. Zhang L, Benson DW, Tristani-Firouzi M, Ptacek LJ, Tawil R, Schwartz PJ, George AL, Horie M, Andelfinger G, Snow GL, Fu Y-H, Ackerman MJ, Vincent GM. Electrocardiographic features in Andersen-Tawil syndrome patients with KCNJ2 mutations: characteristic T-U-wave patterns predict the KCNJ2 genotype. Circulation. 2005; 111:2720-2726. [PubMed: 15911703]

591. Zhang T, Maier LS, Dalton ND, Miyamoto S, Ross J Jr, Bers DM, Brown JH. The deltaC isoform of CaMKII is activated in cardiac hypertrophy and induces dilated cardiomyopathy and heart failure. Circ Res. 2003; 92:912-919. [PubMed: 12676814]

592. Zhang X, Chen S, Yoo S, Chakrabarti S, Zhang T, Ke T, Oberti C, Yong SL, Fang F, Li L, de la Fuente R, Wang L, Chen Q, Wang QK. Mutation in nuclear pore component NUP155 leads to atrial fibrillation and early sudden cardiac death. Cell. 2008; 135:1017-1027. [PubMed: 19070573]

593. Zhou Z. T-Type Calcium Current in Latent Pacemaker Cells Isolated from Cat Right Atrium. Journal of Molecular and Cellular Cardiology. 1994; 26:1211-1219. [PubMed: 7815463]

594. Zhu XR, Wulf A, Schwarz M, Isbrandt D, Pongs O. Characterization of human Kv4.2 mediating a rapidly-inactivating transient voltage-sensitive K+ current. Receptors \& channels. 1999; 6:387400. [PubMed: 10551270]

595. Zicha S, Fernández-Velasco M, Lonardo G, L\&apos;Heureux N, Nattel S. Sinus node dysfunction and hyperpolarization-activated $(\mathrm{HCN})$ channel subunit remodeling in a canine heart failure model. Cardiovascular Research. 2005; 66:472-481. [PubMed: 15914112]

596. Zicha S, Maltsev VA, Nattel S, Sabbah HN, Undrovinas AI. Post-transcriptional alterations in the expression of cardiac $\mathrm{Na}+$ channel subunits in chronic heart failure. J Mol Cell Cardiol. 2004; 37:91-100. [PubMed: 15242739] 
597. Zicha S, Xiao L, Stafford S, Cha TJ, Han W, Varro A, Nattel S. Transmural expression of transient outward potassium current subunits in normal and failing canine and human hearts. $\mathrm{J}$ Physiol. 2004; 561:735-748. [PubMed: 15498806]

598. Zimmer T, Bollensdorff C, Haufe V, Birch-Hirschfeld E, Benndorf K. Mouse heart Na+ channels: primary structure and function of two isoforms and alternatively spliced variants. Am J Physiol Heart Circ Physiol. 2002; 282:H1007-H1017. [PubMed: 11834499]

599. Zingman LV, Hodgson DM, Bast PH, Kane GC, Perez-Terzic C, Gumina RJ, Pucar D, Bienengraeber M, Dzeja PP, Miki T, Seino S, Alekseev AE, Terzic A. Kir6.2 is required for adaptation to stress. Proceedings of the National Academy of Sciences of the United States of America. 2002; 99:13278-13283. [PubMed: 12271142]

600. Zygmunt AC, Eddlestone GT, Thomas GP, Nesterenko VV, Antzelevitch C. Larger late sodium conductance in $\mathrm{M}$ cells contributes to electrical heterogeneity in canine ventricle. Am J Physiol Heart Circ Physiol. 2001; 281:H689-H697. [PubMed: 11454573]

601. Zygmunt AC, Goodrow RJ, Antzelevitch C. I(NaCa) contributes to electrical heterogeneity within the canine ventricle. Am J Physiol Heart Circ Physiol. 2000; 278:H1671-H1678. [PubMed: 10775148] 


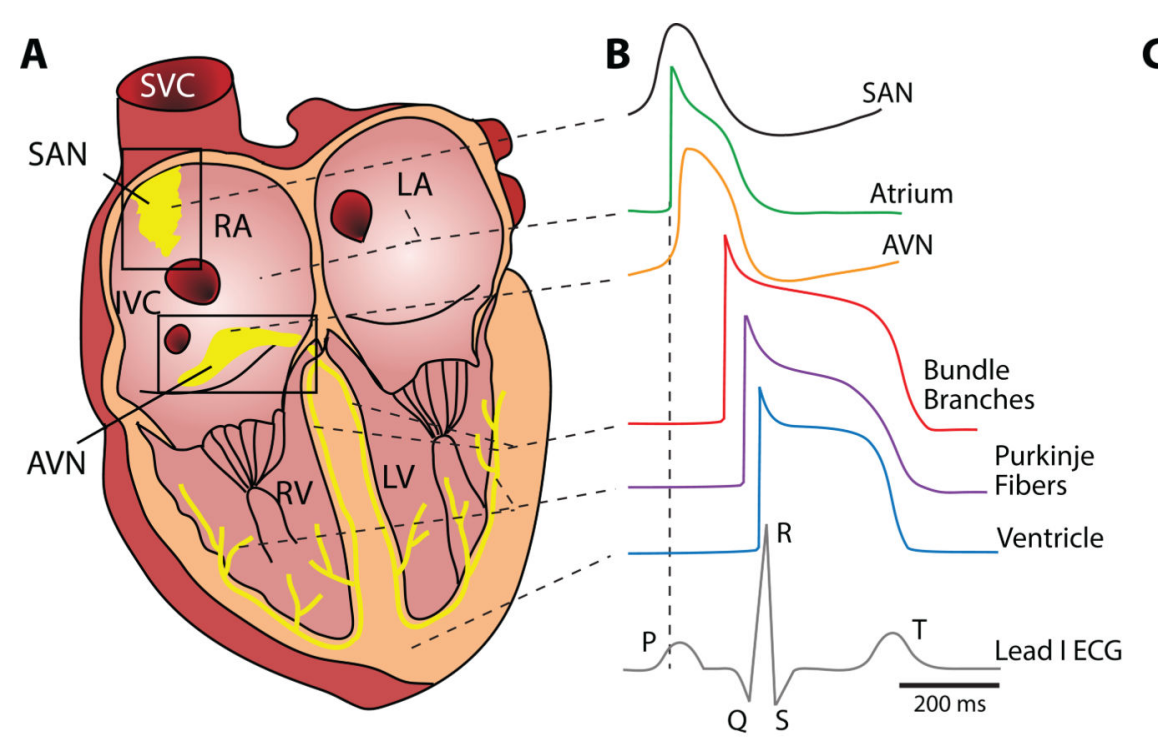

\section{Atrium vs. Ventricle}

A vs. V
Cav1.3, Cav3.1,
Cava282,
Cx40,
Navß1,
Kv1.3, Kv1.5,
Kv1.6, Kv4.2,
Kv4.3, SUR1,
KCNE2, KCNE4,
KCNE5, SK2,
Kir3.1, Kir3.4,
TWIK1, TASK1,
HCN1, HCN4

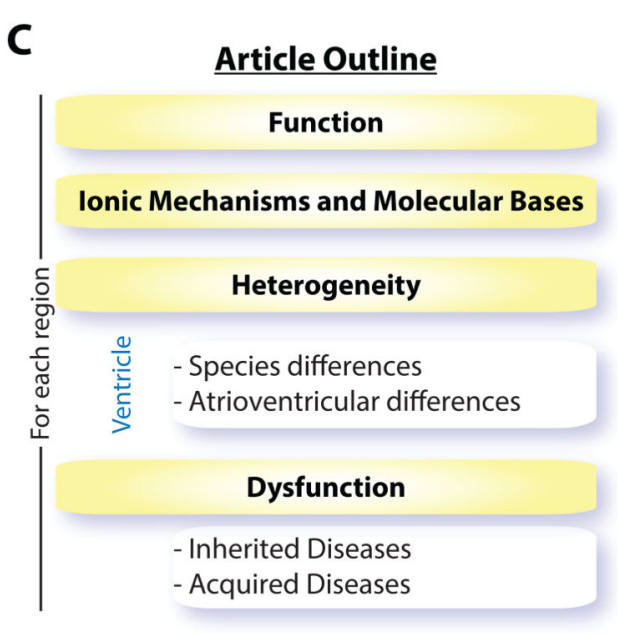

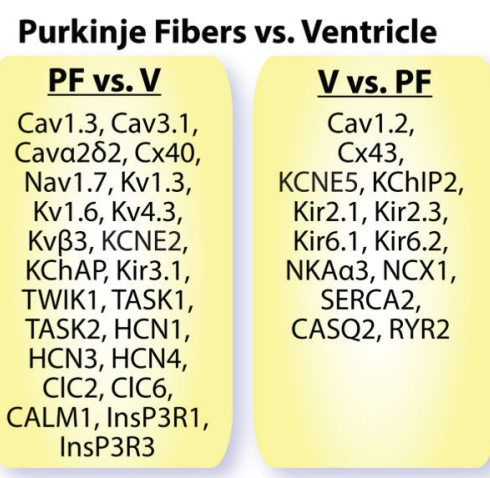
Endocardium vs. Epicardium Endo vs. Epi
Nav1.5, Navß1,
Kv1.4,
Kir3.1

\section{Epi vs.} Endo

\begin{tabular}{c} 
V vs. A \\
\hline Kv1.4, \\
Kir2.1, \\
PLB, RYR2
\end{tabular}

V vs. A
Kv1.4,
Kir2.1,
PLB, RYR2

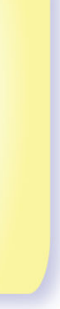

Figure 1. Regional heterogeneity of the electrical properties of the heart

A) Schematic of different regions of the human heart and the corresponding B) AP waveforms (below is a representative lead I ECG). C) Overview of review organization. D) Ion channel and regulatory protein gene expression are compared between corresponding regions of the heart (modified from (178) with permission). SVC: superior vena cava, SAN: sinoatrial node, RA: right atrium, LA: left atrium, IVC: interventricular septum, AVN: atrioventricular node, RV: right ventricle, LV: left ventricle 
A

\section{B}

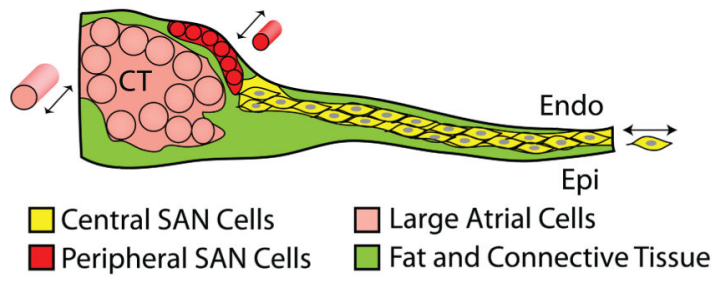

C
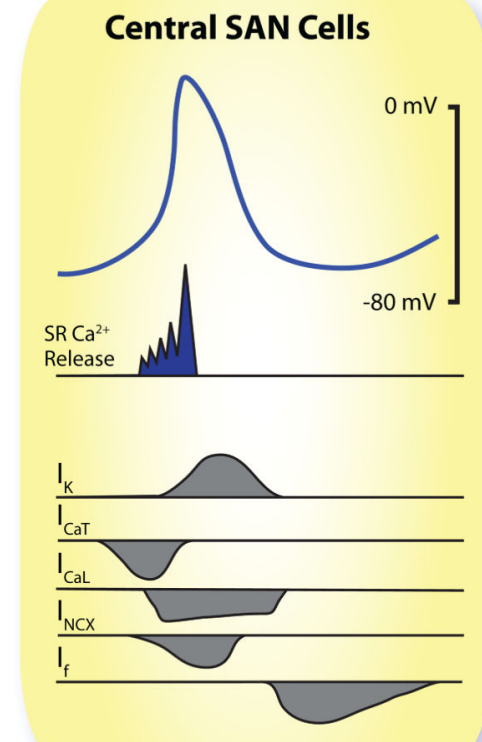

Peripheral SAN Cells

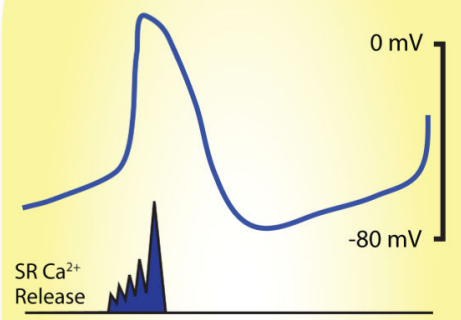

$\mathrm{I}_{\mathrm{Na}}$

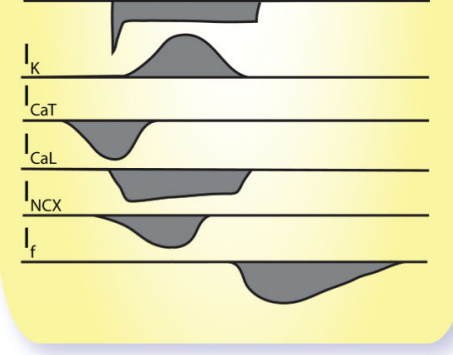

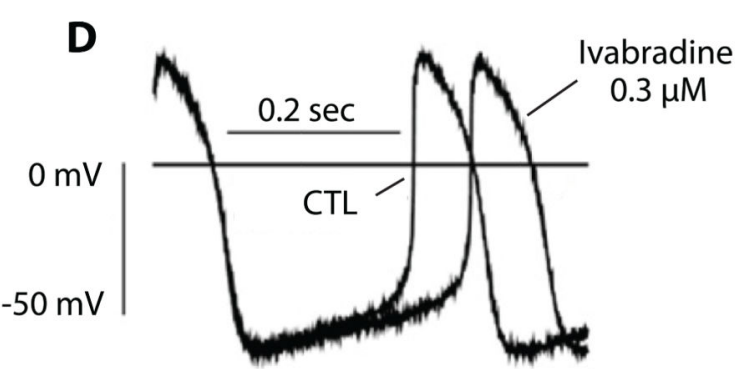

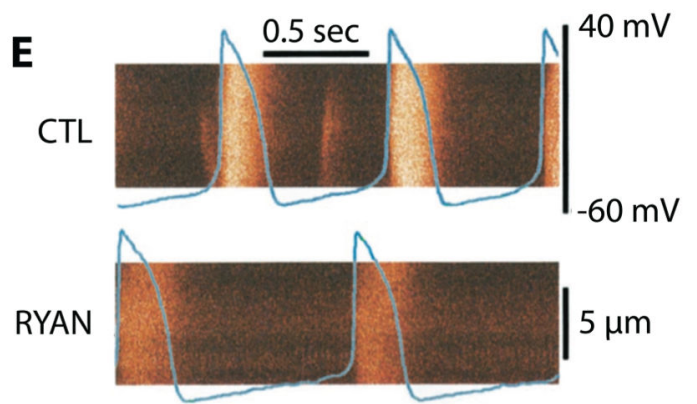

Figure 2. SAN structure and function

A) Schematic showing endocardial view of SAN area (location corresponds to box around SAN in Figure 1A). Approximate area of functional conduction block is shown in gray. B) Transmural view of SAN showing organization of central and peripherial SAN cells.

Redrawn from (74) with permission. C) Example APs and ionic currents from central and peripheral SAN cells. Redrawn from (375) with permission. D) Ivabradine, an $\mathrm{I}_{\mathrm{f}}$ blocker, slows SAN beat rate via slowing the rate of diastolic depolarization (with permission from (85)). E) Slowing of SAN beat rate also occurs with ryanodine, a blocker of RyR $\mathrm{Ca}^{2+}$ release, demonstrating the importance of the $\mathrm{Ca}^{2+}$ clock in contributing to normal SAN pacemaking (with permission from (64)). CT: crista terminalis, CTL: control, Endo: endocardium, Epi: epicardium, IVC: inferior vena cava, RA: right atrium, RYAN: ryanodine, SEP: inter-atrial septum, SVC: superior vena cava 

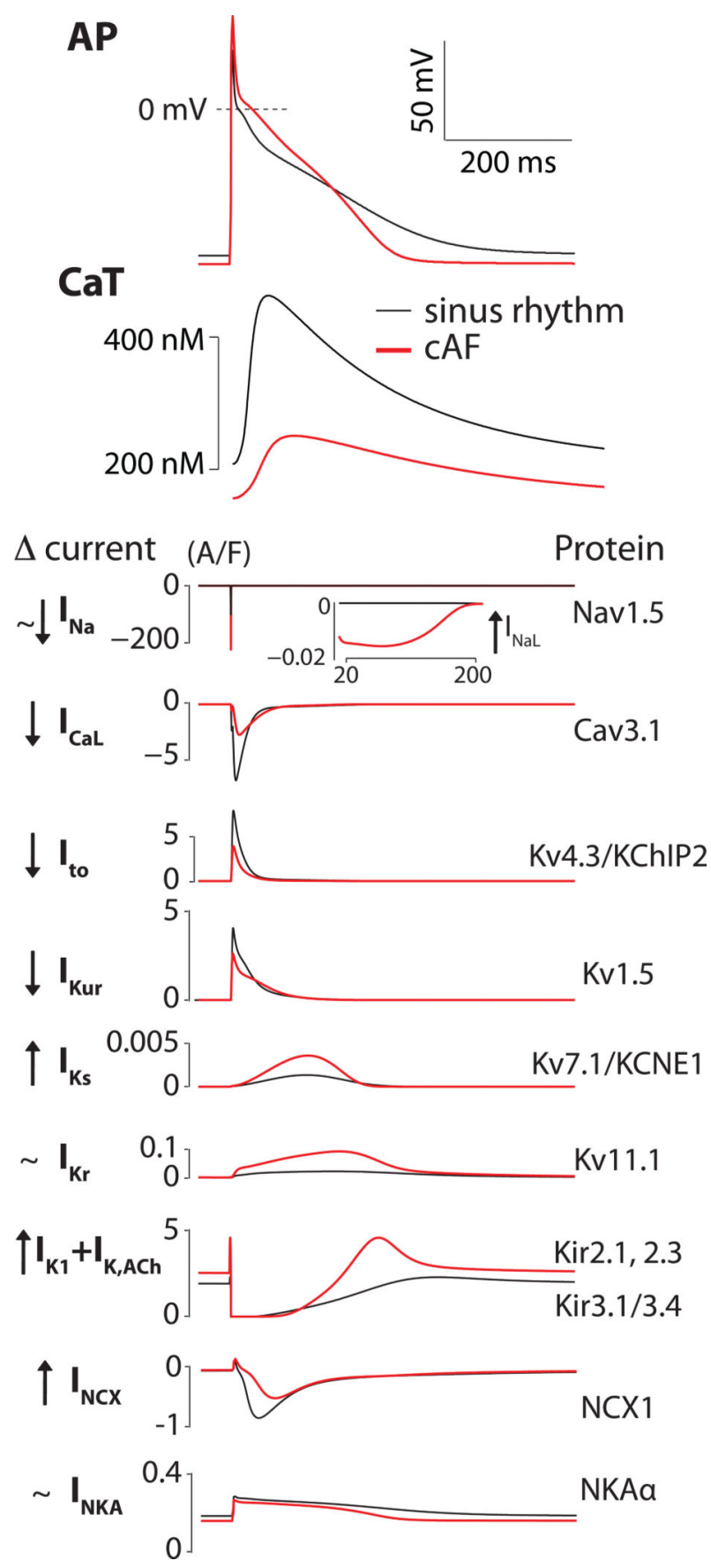

Figure 3. Atrial myocyte function and dysfunction

$\mathrm{AP}, \mathrm{CaT}$, and major underlying ionic currents simulated with computational models of human atrial sinus rhythm (black) and AF (red) myocytes. Modified from (196). 

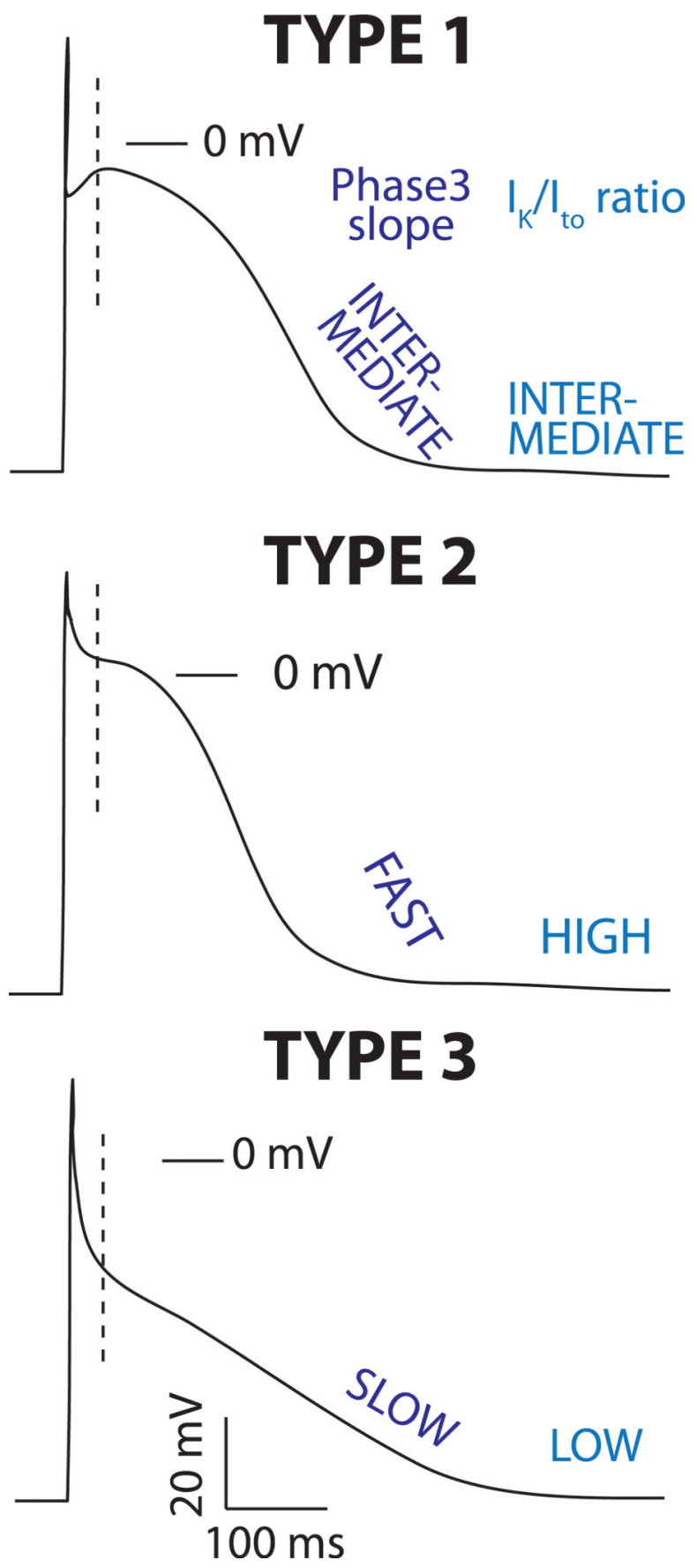

Figure 4. Heterogeneity of atrial electrophysiology

Three different outward current patterns in human atrial myocytes confer distinct AP shape and properties (redrawn from (541) with permission). 
FOCAL ECTOPIC ACTIVITY

\section{REENTRY}

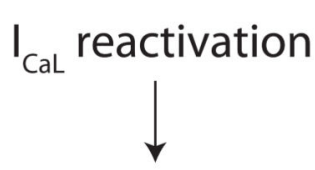

Phase2-EAD

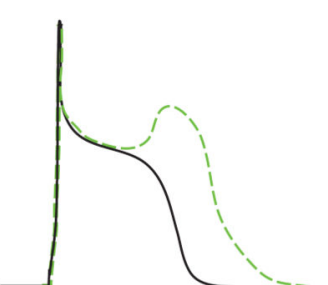

리
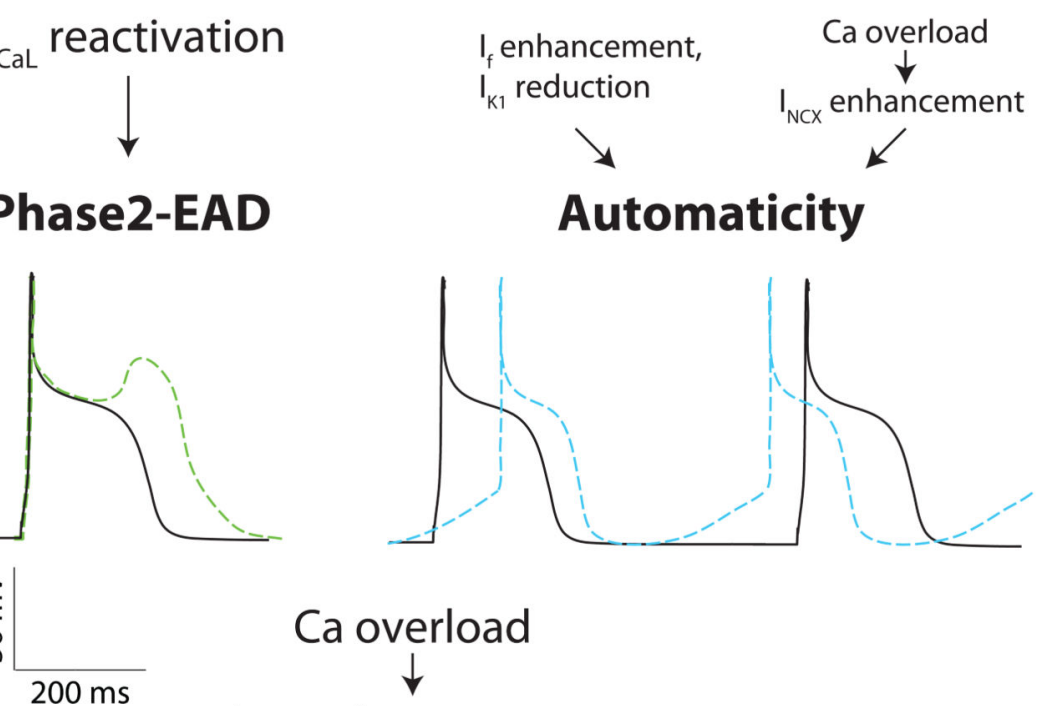

\section{Automaticity}

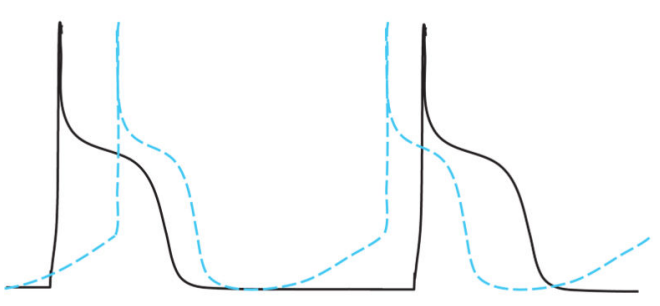

\section{3}

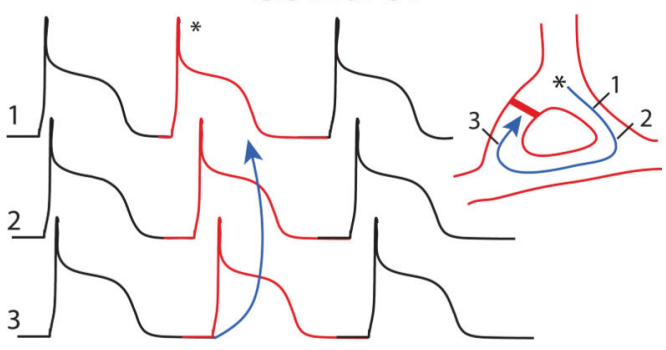

Short Refractory Period
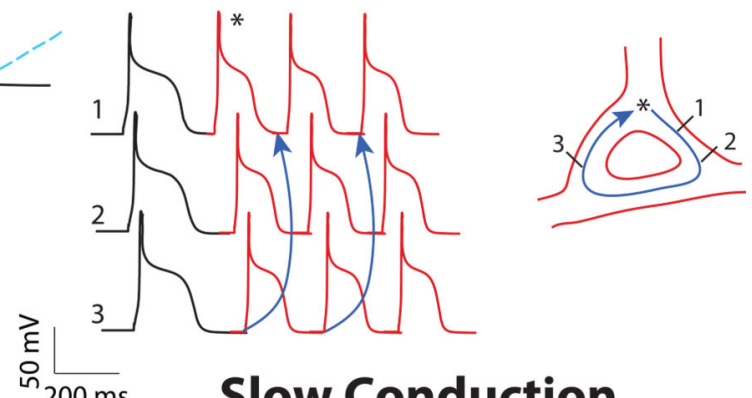

Phase3-EAD

DAD
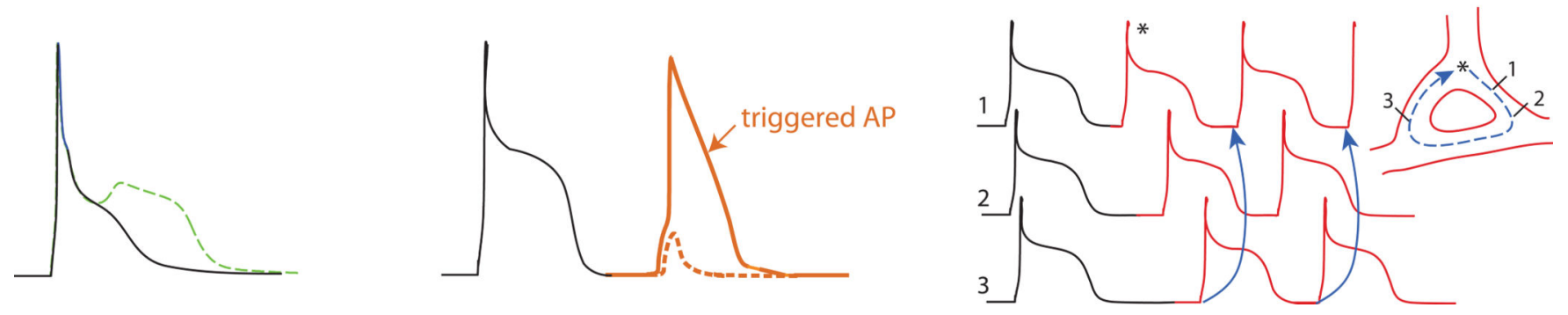

Figure 5. Ionic mechanisms of ectopic activity and reentry Left: cellular mechanisms of early- and delayed afterdepolarizations and cardiac cell automaticity. Right: mechanisms of reentry, redrawn with permission from (531). 

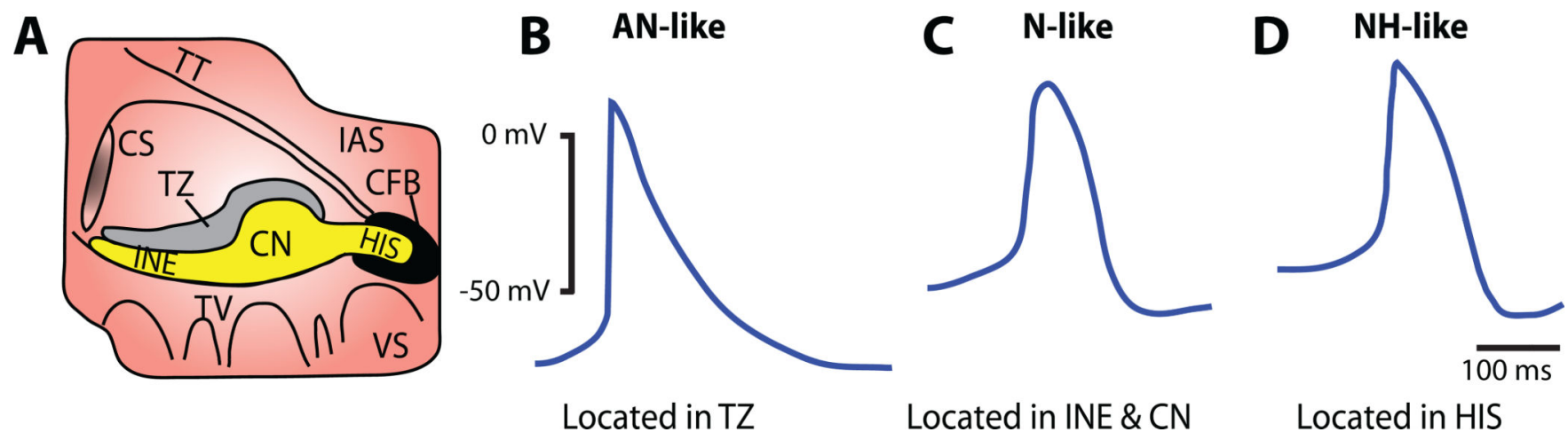

Figure 6. AVN structure and function

A) Schematic showing endocardial view of AVN area (location corresponds to box around AVN in Figure 1A). Redrawn from (232) with permission. B) Example AN-like AP. C) Example N-like AP. D) Example NH-like AP. Panels B-D redrawn with permission from (342). AN: atrio-nodal, CFB: central fibrous body, CN: compact node, CS: coronary sinus, HIS: penetrating His bundle, IAS: inter-atrial septum, INE: inferior nodal extension, N: nodal, NH: nodal-His, TT: tendon of Todaro, TV: tricuspid valve, TZ: transitional zone, VS: ventricular septum 

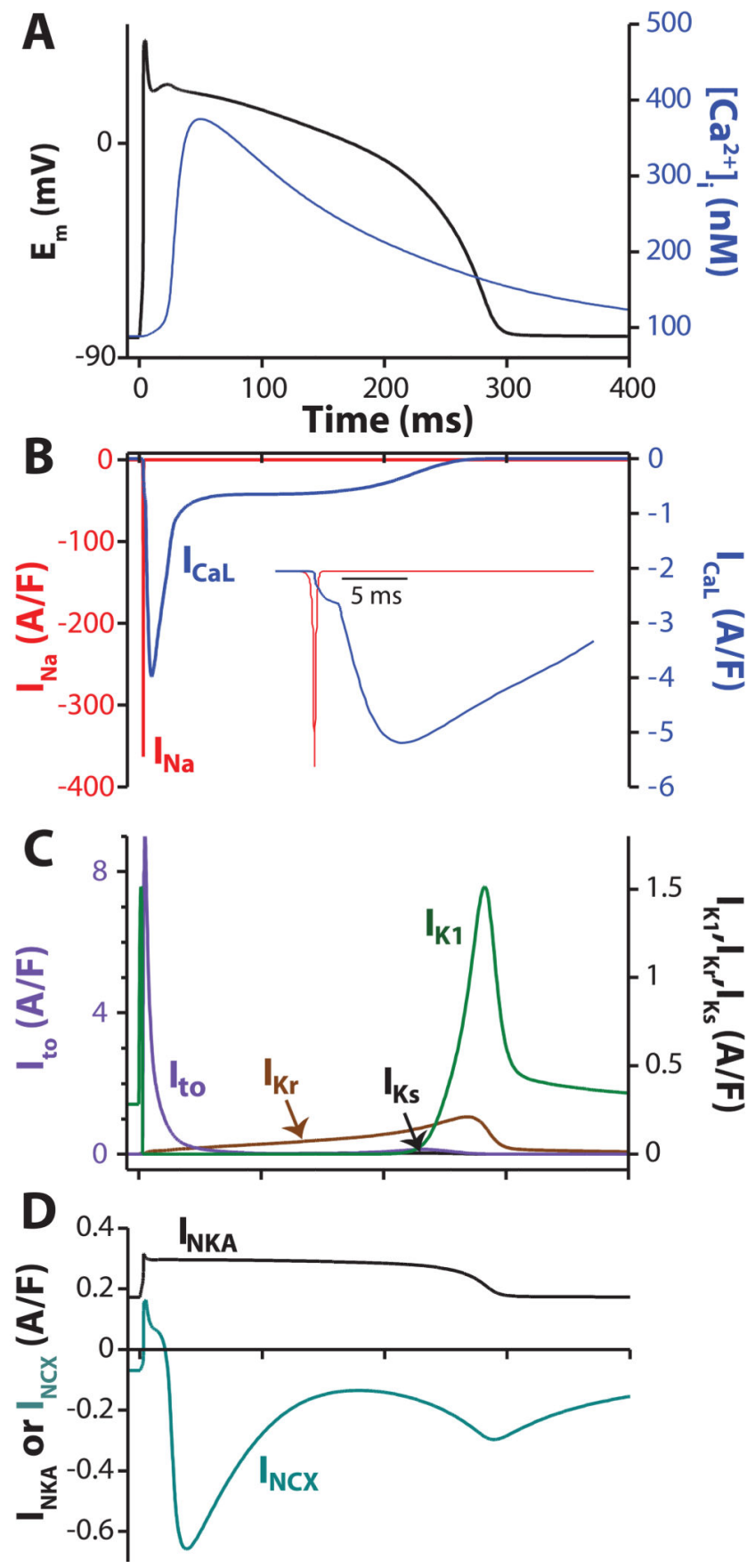

Figure 7. Ventricular AP and ion currents

Depicted in this figure areh A) simulated human ventricular AP (black) and CaT (blue). B) The major depolarizing $\mathrm{Na}^{+}\left(\mathrm{I}_{\mathrm{Na}}\right.$, red) and $\mathrm{Ca}^{2+}\left(\mathrm{I}_{\mathrm{CaL}}\right.$, blue) currents (inset shows the different time-course of activation and current decay), $\mathbf{C}$ ) the major repolarizing $\mathrm{K}^{+}$currents ( $\mathrm{I}_{\text {to }}$, purple; $\mathrm{I}_{\mathrm{Kr}}$, brown; $\mathrm{I}_{\mathrm{Ks}}$, black, and $\mathrm{I}_{\mathrm{K} 1}$, green), and D) $\mathrm{Na}^{+} / \mathrm{Ca}^{2+}$ exchange $\left(\mathrm{I}_{\mathrm{NCX}}\right.$, turquoise) and $\mathrm{Na}^{+} / \mathrm{K}^{+}$pump ( $\mathrm{I}_{\mathrm{NKA}}$, black) currents during a ventricular AP are shown (194). Redrawn with permission from (192). 
A
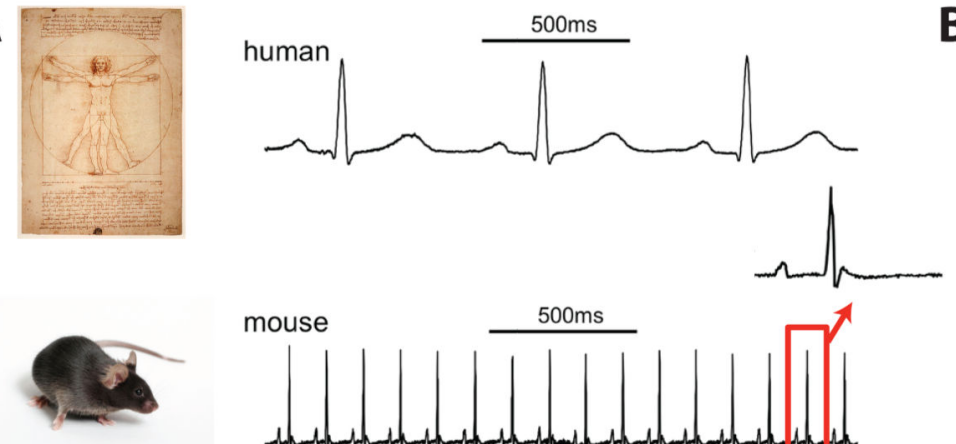

mouse

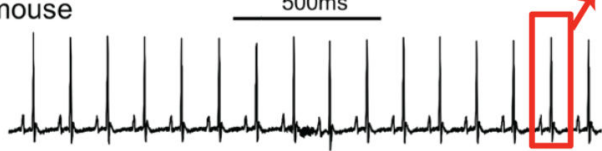

D I $\mathrm{Ir}_{\mathrm{Kr}}$ block
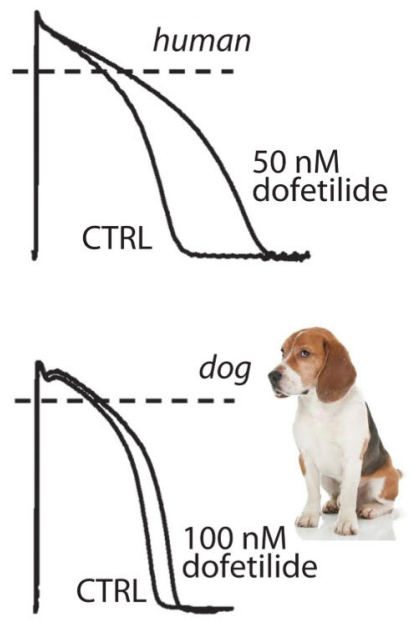

$\mathrm{I}_{\mathrm{Ks}}$ block

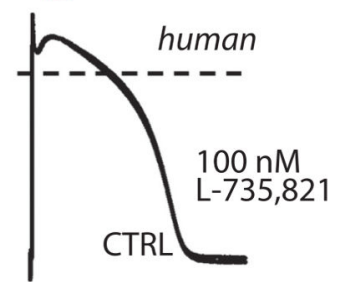

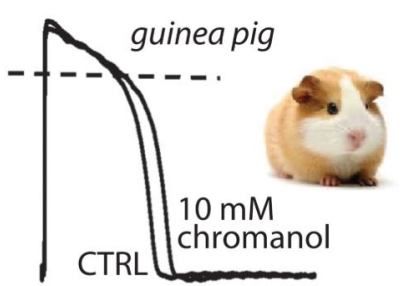

B

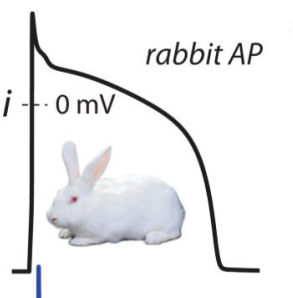

ii-

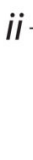

Figure 8. Species Differences in ventricular AP waveforms and drug response

A) Representative traces of ECG recordings from lead I of a human and mouse are depicted (redrawn from (251)). Inset shows a single P-S interval of the mouse ECG. B) A rabbit ventricular AP $(i)$ is shortened and loses its plateau $(i i-v)$ as mouse $\mathrm{K}^{+}$-currents are integrated. C) The simulated I-V relations of mouse $\mathrm{I}_{\mathrm{to}}, \mathrm{I}_{\mathrm{k} \text {,slow }}, \mathrm{I}_{\mathrm{ss}}$, and $\mathrm{I}_{\mathrm{K} 1}$ that are added to the rabbit AP simulation are plotted (reprinted from (339)). D) Shown are ventricular AP recordings of $\mathrm{I}_{\mathrm{Kr}}$ or $\mathrm{I}_{\mathrm{Ks}}$ block in human, dog, or guinea pig. The figure demonstrates the species-specific sensitivity to drug block and changes in AP morphology (reprinted with permission from (416)). 


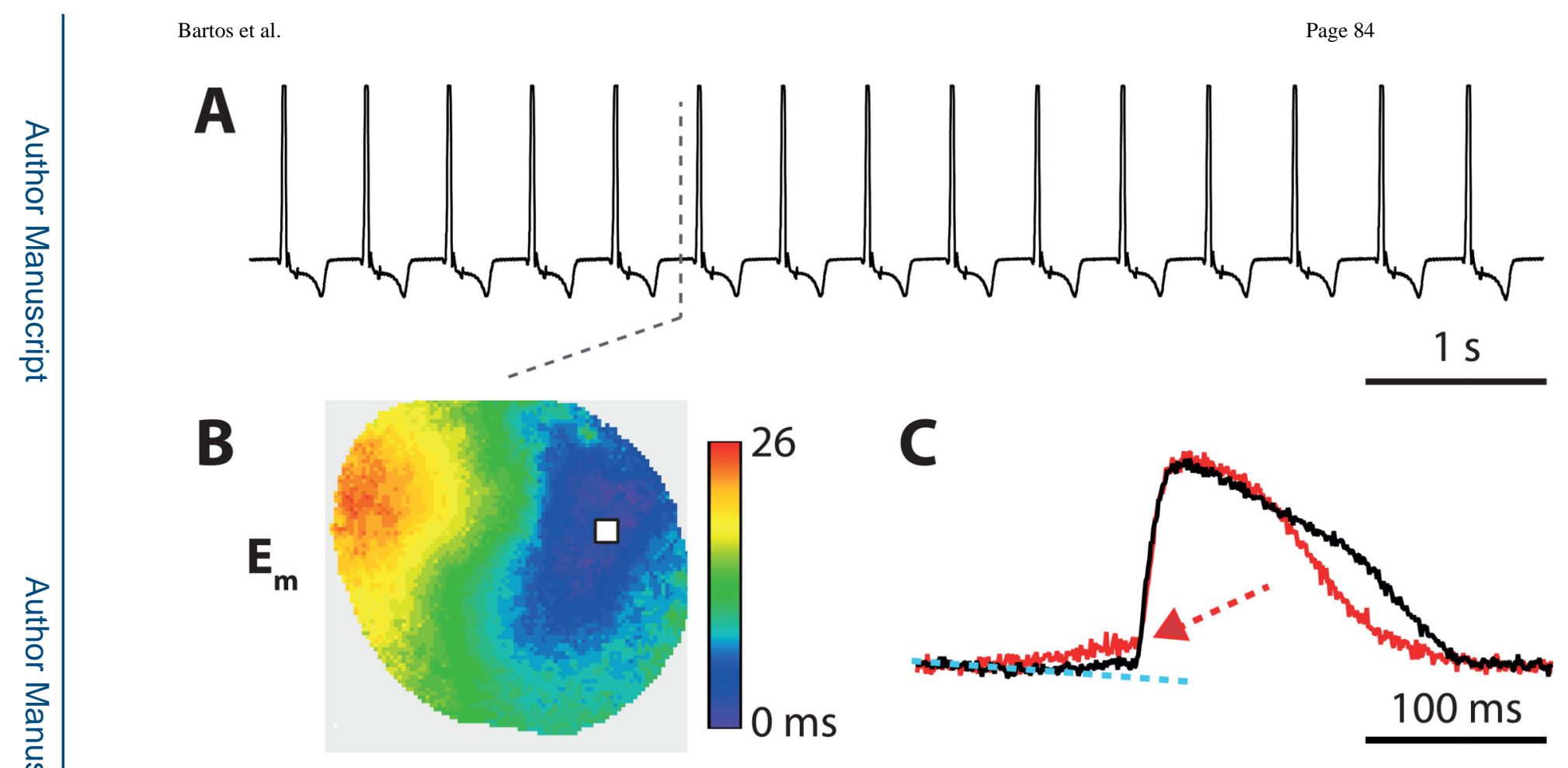

Figure 9. Multiple mechanisms underlie ventricular arrhythmia in $\mathbf{H F}$

A) Sustained focal ventricular tachycardia (VT) induced following local sympathetic stimulation in a normal rabbit heart pretreated with $50 \mu \mathrm{M} \mathrm{BaCl}_{2}$ to reduce $\mathrm{I}_{\mathrm{K} 1}$ and $200 \mu \mathrm{M}$ caffeine to sensitize RyR. When applied simultaneously, a highly arrhythmogenic phenotype was observed, but neither condition alone $\left(\mathrm{BaCl}_{2}\right.$ or caffeine) produced an increase in arrhythmic events (not shown). B) Activation map demonstrating the focal origin and spread of propagation of a single beat of VT. C) Superimposed $E_{m}$ (black) and $\left[\mathrm{Ca}^{2+}\right]_{i}($ red) traces from the origin of focal activity showing diastolic $\mathrm{E}_{\mathrm{m}}$ and $\left[\mathrm{Ca}^{2+}\right]_{\mathrm{i}}$ elevation (reprinted from (343)). 


\section{Table 1}

Molecular bases of altered EC Coupling in human AF (changes vs. sinus rhythm) [Modified from (193)].

\begin{tabular}{|c|c|}
\hline \multicolumn{2}{|c|}{ Cell Size/Structure } \\
\hline Size & Increased length and width (350) \\
\hline $\mathrm{C}_{\mathrm{m}}$ & Increased (94) \\
\hline \multicolumn{2}{|c|}{ Sarcolemmal Ion Currents } \\
\hline$I_{\mathrm{Na}}$ & $\begin{array}{l}\text { No changes }(69,82) \\
\text { Steady-state inactivation shifted right (69) } \\
\text { Slightly reduced current density (459) } \\
\text { Late current increased (459) }\end{array}$ \\
\hline$I_{\mathrm{CaL}}$ & $\begin{array}{l}\text { Reduced current density by } \sim 50 \%(112,148,509,521,560) \\
\text { No changes in voltage dependence of activation and inactivation (509) }\end{array}$ \\
\hline$I_{\mathrm{f}}$ & Increased mRNA levels (274) \\
\hline$I_{\text {to }}$ & Reduced density $-80 \%$ in the RA $-45 \%$ in the LA $(69,79,94,148,191,510,560)$ \\
\hline$I_{\text {Kur }}$ & $\begin{array}{l}\text { Reduced density }-55 \% \text { in the RA }-45 \% \text { in the LA }(79,94,113,148,510) \\
\text { Unchanged }(69,191,560)\end{array}$ \\
\hline$I_{\mathrm{Ks}}$ & Increased 2-fold (94) \\
\hline$I_{\mathrm{K} 1}$ & Upregulated $+100 \%(69,146,148,510,560)$ \\
\hline$I_{\mathrm{K}, \mathrm{ACh}}$ & $\begin{array}{l}\text { Increased basal current by receptor-independent, constitutively active component; increased (69) or reduced carbachol-activated } \\
\text { current }(145,146,523)\end{array}$ \\
\hline$I_{\mathrm{SK}}$ & Increased expression (398) or membrane trafficking (373). \\
\hline$I_{\mathrm{KATP}}$ & $\begin{array}{l}\text { Decreased (28) } \\
\text { Increased (561) }\end{array}$ \\
\hline \multicolumn{2}{|c|}{ Ca and Na handling } \\
\hline$I_{\mathrm{NCX}}$ & Upregulated $(160,350,429,521)$ \\
\hline SERCA & Reduced maximal pump rate (521) and protein expression (160) \\
\hline PLN & $\begin{array}{l}\text { Enhanced PKA and CaMKII phosphorylation (160) } \\
\text { Unaltered CaMKII-dependent phosphorylation (350) }\end{array}$ \\
\hline RyR & $\begin{array}{l}\text { Increased phosphorylation at PKA and CaMKII sites }(350,518,521) \text { resulting in increased channel open probability }(522) \text { and } \\
\mathrm{SR} \mathrm{Ca}^{2+} \text { leak }(228,350)\end{array}$ \\
\hline$I_{\mathrm{NKA}}$ & Unchanged function (559) \\
\hline Ankyrin-B & Downregulated (125) \\
\hline \multicolumn{2}{|c|}{ Protein kinases and phosphatases } \\
\hline CaMKII & Increased expression (481) and phosphorylation (350) \\
\hline PKA & Similar activity in cAF $v s$. sinus rhythm (160) \\
\hline PP1, PP2A & Higher activity (160) \\
\hline \multicolumn{2}{|c|}{ Myofilaments } \\
\hline & $\begin{array}{l}\text { Reduced maximum rate of tension generation and maximum active tension, reduced passive tension, and increase in myofilament } \\
\text { Ca sensitivity (40) } \\
\text { No changes in maximum force and passive force, reduced rate of tension redevelopment (159) } \\
\text { Increased phosphorylation of cMyBP-C }(40) \\
\text { Decreased phosphorylation of cMyBP-C }(160) \\
\text { No changes in cTnI phosphorylation }(40,160)\end{array}$ \\
\hline
\end{tabular}


Table 2

Congenital ventricular arrhythmia syndromes

\begin{tabular}{|c|c|c|c|c|}
\hline Disease & Current Affected & Gene (protein) & Frequency & $\begin{array}{c}\text { Key } \\
\text { Reference }\end{array}$ \\
\hline \multicolumn{5}{|c|}{ Long QT syndrome (LQTS): Romano Ward syndrome (autosomal dominant) } \\
\hline LQT1 & $\mathrm{I}_{\mathrm{Ks}}, \downarrow$ amplitude & $K C N Q 1(\mathrm{Kv} 7.1)$ & $\sim 40 \%$ & $(538)$ \\
\hline LQT2 & $\mathrm{I}_{\mathrm{Kr}}, \downarrow$ amplitude & KCNH2 (Kv11.1, hERG) & $\sim 40 \%$ & (128) \\
\hline LQT3 & $\mathrm{I}_{\mathrm{NaL}}, \uparrow$ late current & SCN5A (Nav1.5) & $\sim 5-10 \%$ & $(540)$ \\
\hline LQT4 (ankryin-B disease) & $\mathrm{I}_{\mathrm{NCX}}, \mathrm{I}_{\mathrm{NaK}}$ & ANK2 (Ankyrin B) & Rare & (427) (334) \\
\hline LQT5 & $\mathrm{I}_{\mathrm{Ks}}, \downarrow$ amplitude & KCNE1 (KCNE1, MiNK1) & $\sim 5 \%$ & $(462)$ \\
\hline LQT6 & $\mathrm{I}_{\mathrm{Kr}}, \downarrow$ amplitude & KCNE2 (KCNE2, MiRP1) & $\sim 3 \%$ & (1) \\
\hline LQT7 (Andersen-Tawil syndrome) & $\mathrm{I}_{\mathrm{K} 1}, \downarrow$ amplitude & KCNJ2 (Kir2.1) & Rare & (489) \\
\hline LQT8 (Timothy syndrome) & $\begin{array}{l}\mathrm{I}_{\mathrm{CaL}}, \uparrow \text { amplitude/ } \\
\text { slows inactivation }\end{array}$ & CACNAIC (Cav1.2) & Rare & $(461)$ \\
\hline LQT9 & $\mathrm{I}_{\mathrm{NaL}}, \uparrow$ late current & CAV3 (caveolin-3) & Rare & (513) \\
\hline LQT10 & $\mathrm{I}_{\mathrm{NaL}}, \uparrow$ late current & $S C N 4 B(\operatorname{Nav} \beta 4)$ & Rare & (325) \\
\hline LQT11 & $\mathrm{I}_{\mathrm{Ks}}, \downarrow$ amplitude & AKAP9 (Yotiao) & Rare & (104) \\
\hline LQT12 & $\mathrm{I}_{\mathrm{NaL}}, \uparrow$ late current & SNTAl (a1-syntrophin) & Rare & $(498)$ \\
\hline LQT13 & $\mathrm{I}_{\mathrm{K}, \mathrm{ACh}}, \downarrow$ amplitude & KCNJ5 (Kir3.4) & Rare & $(576)$ \\
\hline LQTS & $\begin{array}{l}\mathrm{I}_{\mathrm{CaL}}, \uparrow \text { amplitude/ } \\
\text { slows inactivation }\end{array}$ & CALM1, CALM2 (calmodulin) & Rare & (124) \\
\hline \multicolumn{5}{|c|}{ LQTS: Jervelle \& Lange-Nielsen syndrome (associated with deafness, autosomal recessive) } \\
\hline JLN1 & $\mathrm{I}_{\mathrm{Ks}}, \downarrow$ amplitude & $K C N Q 1(\mathrm{Kv} 7.1)$ & Rare & $(352)$ \\
\hline JLN2 & $\mathrm{I}_{\mathrm{Ks}}, \downarrow$ amplitude & KCNE1 (KCNE1, MiNK1) & Rare & $(436)$ \\
\hline \multicolumn{5}{|c|}{ Brugada syndrome $(\mathrm{BrS})$} \\
\hline BrS1 & $\mathrm{I}_{\mathrm{Na}}, \downarrow$ amplitude & SCN5A (Nav1.5) & $\sim 20-30 \%$ & $(107)$ \\
\hline BrS2 & $\mathrm{I}_{\mathrm{Na}}, \downarrow$ amplitude & GDP1-L (glycerol-3-phosphate dehydrogenase) & Rare & (304) \\
\hline BrS3 (SQT4) & $\mathrm{I}_{\mathrm{CaL}}, \downarrow$ amplitude & CACNAIC (Cav1.2) & $\sim 3 \%$ & (19) \\
\hline BrS4 (SQT5) & $\mathrm{I}_{\mathrm{CaL}}, \downarrow$ amplitude & $C A C N B 2 b(\mathrm{Cav} \beta 2 \mathrm{~b})$ & $\sim 3 \%$ & (19) \\
\hline BrS5 & $\mathrm{I}_{\mathrm{Na}}, \downarrow$ amplitude & $S C N 1 B(\operatorname{Nav} \beta 1)$ & Rare & (547) \\
\hline BrS6 & $\mathrm{I}_{\mathrm{to}}, \uparrow$ amplitude & KCNE3 (KCNE3, MiRP2) & Rare & (133) \\
\hline BrS7 & $\mathrm{I}_{\mathrm{Na}}, \downarrow$ amplitude & $S C N 3 B(\operatorname{Nav} \beta 3)$ & Rare & (230) \\
\hline BrS8 & $\mathrm{I}_{\mathrm{f}}$ & HCN4 (HCN4) & Rare & (496) \\
\hline BrS9 & $\mathrm{I}_{\mathrm{KATP}}, \uparrow$ amplitude & KCNJ8 (Kir6.1) & Rare & (326) \\
\hline BrS10 & $\mathrm{I}_{\mathrm{CaL}}, \downarrow$ amplitude & CACNA2D1 (Cava281) & Rare & (90) \\
\hline BrS11 & $\mathrm{I}_{\mathrm{to}}, \uparrow$ amplitude & KCND3 (Kv4.3) & Rare & (185) \\
\hline BrS12 & $\mathrm{I}_{\mathrm{to}}, \uparrow$ amplitude & KCNE5 (KCNE5, MiRP4) & Rare & (366) \\
\hline BrS13 & $\mathrm{I}_{\mathrm{Na}}, \downarrow$ amplitude $?$ & MOG1 (MOG1) & Rare & $(257)$ \\
\hline
\end{tabular}




\begin{tabular}{|c|c|c|c|c|}
\hline Disease & Current Affected & Gene (protein) & Frequency & $\begin{array}{c}\text { Key } \\
\text { Reference }\end{array}$ \\
\hline CPVT1 & $\uparrow \mathrm{SR} \mathrm{Ca}^{2+}$ release & $R y R 2$ (ryanodine receptor) & $\sim 60 \%$ & (394) \\
\hline CPVT2 & $\uparrow \mathrm{SR} \mathrm{Ca}^{2+}$ release & CASQ2 (calsequestrin-2) & $\sim 3-5 \%$ & (273) \\
\hline CPVT3 & $\mathrm{I}_{\mathrm{K} 1}, \downarrow$ amplitude & KCNJ2 (Kir2.1) & Rare & $(482)$ \\
\hline CPVT4 & $\uparrow \mathrm{SR} \mathrm{Ca}^{2+}$ release & $T R D N$ (triadin) & Rare & $(412)$ \\
\hline CPVT & $\uparrow \mathrm{SR} \mathrm{Ca}^{2+}$ release & CALM1 (calmodulin) & Rare & (364) \\
\hline \multicolumn{5}{|c|}{ Short QT syndrome (SQTS) } \\
\hline SQT1 & $\mathrm{I}_{\mathrm{Kr}}, \uparrow$ amplitude & KCNH2 (Kv11.1, hERG) & Rare & (81) \\
\hline SQT2 & $\mathrm{I}_{\mathrm{Ks}}, \uparrow$ amplitude & $K C N Q 1(\mathrm{Kv} 7.1)$ & Rare & (39) \\
\hline SQT3 & $\mathrm{I}_{\mathrm{K} 1}, \uparrow$ amplitude & KCNJ2 (Kir2.1) & Rare & (395) \\
\hline SQT6 & $\mathrm{I}_{\mathrm{CaL}}, \downarrow$ amplitude & CACNA2D1 (Cava281) & Rare & $(479)$ \\
\hline
\end{tabular}

